\title{
STUDY OF REHYDRATION PROPERTIES OF POWDER PRODUCED FROM CHELATED SKIM MILK
}

\author{
A Thesis \\ presented to \\ the Faculty of California Polytechnic State University, \\ San Luis Obispo
}

\author{
In Partial Fulfillment \\ of the Requirements for the Degree \\ Master of Science in Agriculture,
} With Specializations in Dairy Products Technology

by

Kristina Ellice Tan

June 2016 
(C) 2016

Kristina Ellice Tan

ALL RIGHTS RESERVED 
TITLE:

AUTHOR:

DATE SUBMITTED:

COMMITTEE CHAIR:

COMMITTEE MEMBER:

COMMITTEE MEMBER:
Study of Rehydration Properties of Powder

Produced from Chelated Skim Milk

Kristina Ellice Tan

June 2016

Vincent K. Yeung, Ph.D.

Assistant Professor of Dairy Science

Phillip S. Tong, Ph.D.

Professor of Dairy Science

Heather S. Smith, M.S.

Senior Lecturer of Statistics 


\begin{abstract}
Study of Rehydration Properties of Powder Produced from Chelated Skim Milk Kristina Ellice Tan
\end{abstract}

Poor rehydration properties of skim milk powder (SMP) can impact processing efficiency and functionality in finished product applications. Rehydration can be split into four stages: wettability, sinkability, dispersibility, and solubility. Previous work has suggested that chelator addition during SMP manufacture leads to higher solubility compared to SMP without chelators. This study focuses on the addition of ethylene diamine tetraacetic acid (EDTA) or sodium citrate dihydrate (SCD) at concentrations of 5, 10, and $15 \mathrm{mM}$ to skim milk prior to evaporating and spray drying. The objective of this investigation was to determine the effects of the chelator additions on each SMP rehydration property (wettability, sinkability, dispersibility, and solubility) during reconstitution to $10 \%$ total solids. SCD $15 \mathrm{mM}$, SCD $10 \mathrm{mM}$, and SCD $5 \mathrm{mM}$ did not have a significant effect on wettability as measured by IDF method (p-value $0.3234,0.6376$, and 1.0000 , respectively). However, SCD $15 \mathrm{mM}, \mathrm{SCD} 10 \mathrm{mM}$, and SCD $5 \mathrm{mM}$ had higher levels of solubility as measured by particle size analysis of reconstituted 10\%TS samples (p-value $<0.0001$ for all levels) and by solubility index (p-value $<0.0001$ for all levels), compared to the control. EDTA $15 \mathrm{mM}$ and EDTA $10 \mathrm{mM}$ treated SMP's had statistically significantly lower initial wettability compared to the control as measured by both contact angle (p-value $<0.0001$ and 0.0002 respectively) and International Dairy Federation (IDF) method (p-value $<0.0001$ and 0.0031 respectively). This suggests that EDTA 15 
mM and EDTA $10 \mathrm{mM}$ treated SMP's had high surface hydrophobicity. However, both treatments had higher levels of solubility compared to the control, as measured by particle size distribution of a fully solubilized reconstituted 10\% TS sample (p-value $<0.0001$ for both levels) and by solubility index (p-value <0.0001 for both levels).

Changes in the rehydration properties may be due to a shift in the calcium and phosphorus behavior of the treated samples, as measured by Inductively Coupled Plasma Optical Emission Spectrometry (ICP-OES). The changes to the solubility index could be due to a sequence of events. First, the chelators chelate all the ionic calcium in the serum. The decrease in ionic calcium shifts the protein-mineral balance between the minerals in the casein micelle and the minerals in the serum, which leads to a depletion of colloidal calcium phosphate, and a subsequent release of caseins from the initial micelle structure. This behavior influenced by EDTA or SCD dissolves the calcium phosphate bridge so that nanoclusters in the casein micelle do not exist (Dalgleish and Corredig, 2012). Hence, the casein micelle would be disrupted into individual caseins that may create the appearance that the solution as a whole has higher solubility, as seen in the particle size analyses of fully rehydrated reconstituted 10\%TS samples and in the solubility index. Overall, the findings provide insight on how chelators affect the rehydration properties of skim milk powder, when the chelator is added to liquid skim milk, prior to evaporating and spray drying. The findings in effects on rehydration properties may assist dairy powder manufacturers if deciding to add chelators to affect the end product rehydration properties.

Keywords: skim milk powder, chelator, wettability, sinkability, dispersibility, solubility, rehydration properties, reconstitution properties 


\section{ACKNOWLEDGMENTS}

Endless thanks to Dr. Phillip Tong for the opportunity and guidance throughout this project. I would also like to thank Dr. Vincent Yeung and Prof. Heather Smith for their insight, expertise, and time.

In addition, I would like to thank Dr. Rafael Jimenez, Dr. Vandna Sikand, Sean Vink, Paul Lyons, Matt Arnold, Kristen Herbaugh, Andrea Laubscher, Dr. Derek Gragson, Craig Stubler, and Dwayne Jones for the use of their respective laboratories and for always answering my questions.

I would also like to acknowledge the Dairy Research Institute, California State University Grant (SUG), the Hull Graduate Assistantship Award, and the Segal AmeriCorps Education Award for the financial support.

Many thanks to all other Cal Poly graduate students for their understanding and fellowship.

Special thanks to my family and the Ogle family for their love and support. Finally, I would like to thank Ethan Ogle for his patience, encouragement, and faith. 
LIST OF TABLES __ xi

LIST OF FIGURES __ xiii

LIST OF EQUATIONS ___ xvi

CHAPTER

CHAPTER 1: INTRODUCTION___ 1

CHAPTER 2: LITERATURE REVIEW __ 3

2.1 Skim Milk Powder (SMP) __ 3

2.1.1 History and Importance ___ 3

2.1.2 Manufacture of Skim Milk Powder (SMP) __ 4

2.1.3 Casein _ 11

2.1.4 Minerals in Milk _ 15

2.2 Chelators _ـ 16

2.2.1 Overview —16

2.2.2 Disodium Ethylene Diamine Tetraacetic Acid (EDTA) __ 19

2.2.3 Sodium Citrate Dihydrate (SCD)__ 20

2.3 Rehydration Properties __ 21

2.3.1 Overview —22 22

2.3.2 Wettability __ 23

2.3.3 Sinkability _ 24

2.3.4 Dispersibility __ 25

2.3.5 Solubility _ 26 
2.3.6 Calcium and Phosphorus Behavior

2.4 Summary, Hypotheses, and Objectives

CHAPTER 3: MATERIALS AND METHODS

3.1 Ingredients

3.1.1 Pasteurized Fat Free Milk

3.1.2 Chelators

3.2 Powder Making Process

3.2.1 Experimental Design

3.2.2 Chelator Addition into Fat Free Milk

3.2.3 Evaporation into 40\% Total Solids Concentrate

3.2.4 Spray Drying into Powder 38

3.2.5 Cleaning Procedure 39

3.2.6 Powder Storage 40

3.3 Sampling Procedure 40

3.3.1 Preparation for Powder Sample 40

3.3.2 Preparation for 10\% Total Solids Reconstituted Sample 40

3.4 Powder Composition 41

3.4.1 Percent Moisture 41

3.4.2 Percent Ash 41

3.4.3 Percent Fat 42

3.4.4 Percent Protein 42

3.4.5 Percent Lactose 42

3.5 Powder size via Powder Particle Size Analysis (Powder PSA) 42 
3.6 Rehydration Properties

3.6.1 Wettability 44

3.6.1.1 Contact Angle Method Overview 44

3.6.1.2 Preparation of Powder Tablets for Contact Angle

Determination 45

3.6.1.3 Contact Angle Measurement 46

3.6.2 Wettability and Sinkability 47

3.6.2.1 Modified IDF Wettability Method 47

3.6.3 Dispersibility 49

3.6.3.1 Dissolution Rate 49

3.6.4 Solubility 50

3.6.4.1 Reconstituted Particle Size Analysis 50

3.6.4.2 Modified Solubility Index 51

3.6.5 Calcium and Phosphorous Behavior 52

3.6.5.1 Inductively Coupled Plasma Optical Emission Spectrometry (ICP-OES) 52

CHAPTER 4: RESULTS AND DISCUSSION 57

4.1 Powder Making Process Observations 57

4.2 Powder Composition 57

4.3 Powder Size via Powder Particle Size Analysis (Powder PSA) 59

4.4 Rehydration Properties 63

4.4.1 Wettability in Terms of Surface Hydrophobicity via Contact Angle 63

4.4.2 Wettability and Sinkability via Modified IDF Wettability Method 68 
4.4.3 Dissolution Rate 71

4.4.4 Reconstituted Particle Size Analysis 74

4.4.5 Solubility Analysis via Modified Solubility Index 78

4.4.6 Calcium and Phosphorous Behavior via Inductively Coupled Plasma Optical Emission Spectrometry (ICP-OES) 82

CHAPTER 5: CONCLUSIONS AND LIMITATIONS 86

CHAPTER 6: DIRECTIONS FOR FUTURE RESEARCH 89

REFERENCES 91

APPENDICES

APPENDIX A: JMP Output for Volume Mean Diameter [D(4,3)] of Powder 95

APPENDIX B: JMP Output for Volume Median Diameter of Powder 98

APPENDIX C: JMP Output for Contact Angle at 0.5 Seconds 101

APPENDIX D: JMP Output for International Dairy Federation (IDF) Wettability _104 APPENDIX E: JMP Output for Dissolution Rate 107 APPENDIX F: JMP Output for $\log _{10}$ Volume Mean Diameter $[\mathrm{D}(4,3)]$ of Rehydrated Sample 110 APPENDIX G: JMP Output for $\log _{10}$ Volume Median Diameter of Rehydrated Sample 113 APPENDIX H: JMP Output for Solubility Index 116 APPENDIX I: JMP Output for Percent Soluble Calcium (Ca) 119 APPENDIX J: JMP Output for Percent Soluble Phosphorus (P) 122 


\section{LIST OF TABLES}

Table

Page

2.1. Typical composition of milk of various species (\% composition)

(adapted from Chandan and Kilara, 2008) 4

2.2. Typical percent composition of skim milk powder vs. skim milk vs.

bovine milk (Average percentage) (Canadian Dairy Commission, 2011) 5

2.3. Chemical and Physical Standards for SMP from ADPI and from Codex

Alimentarius (Chandan and Kilara, 2008) 7

2.4. Preheating treatment and subsequent WPNI value for powders

(ADPI, 2014) 8

2.5. Casein make up in bovine milk (\% of total protein w/w) (Bylund, 1995) 13

2.6. Calcium partition in bovine milk (adapted from Gaucheron, 2005) 16

3.1. Experimental responses including method and units 33

3.2. Weight $(\mathrm{g})$ of chelator to add for desired concentration $(\mathrm{mM})$ or $\%(\mathrm{w} / \mathrm{w})$ 35

3.3 True concentration $(\mathrm{mM})$ and $\%(\mathrm{w} / \mathrm{w})$ of each chelator type 35

3.4. Spray drying step operating parameters 39

4.1. Mean \pm standard error (S.E.) of the percent composition of the experimental SMPs 58

4.2. Mean and standard error (S.E.) of the volume mean diameter (D4,3) $(\mu \mathrm{m})$ and volume median diameter $(\mu \mathrm{m})$ of the powder particle size distribution for each treatment powder, separated by block 59

4.3. Dunnett procedure to compare the contact angle $\left(^{\circ}\right)$ at 0.5 seconds for the treatments to the contact angle $\left(^{\circ}\right)$ at 0.5 seconds for the control 63 
4.4. Mean and standard error (S.E.) for each treatment for IDF wettability (seconds) and difference between treatment mean minus control mean 68

4.5. Mean and standard error (S.E.) for each treatment of the dissolution rate (O.D./second) and difference between treatment mean minus control mean 72

4.6. Mean and standard error (S.E.) of volume mean diameter (D4,3) $(\mu \mathrm{m})$ mean and standard error (S.E.) of volume median diameter $(\mu \mathrm{m})$ of the rehydrated particle size distribution for each treatment 74

4.7. Mean and standard error (S.E.) for solubility index of each treatment $(\mathrm{mL})$ and difference between treatment mean minus control mean 79

4.8. Single check of total calcium and phosphorus in the water supply 82

4.9. Mean and standard error (S.E.) of \%soluble Calcium (Ca) and \%soluble Phosphorus (P) for all treatments for ICP-OES 83 


\section{LIST OF FIGURES}

Figure

Page

2.1. Flow chart of manufacture of various milk powders

(Chandan and Kilara, 2008)

2.2. Schematic of a casein micelle (Dalgleish and Corredig, 2012) 14

2.3. Fully protonated form of Ethylene Diamine Tetraacetic Acid (EDTA)

(Zeng and Jadir, 2015)

2.4. Schematic of dissolution stages for a standard powder particle showing how different rehydration stages overlap with time (adapted from Fang, 2008) __ 22

3.1. Schematic of the general process to produce the chelated SMP samples 30

3.2. Summary of the Randomized Complete Block Design (RCBD) 31

3.3a. Brookfield Viscometer 34

3.3b. CEM LabWave 9000 34

3.4a. Custom rising film Marriot Walker Evaporator 37

3.4b. Calandria visual inspection 37

3.5. Niro Filter Lab Spray Dryer 38

3.6. Particle size analyzer (PSA) with powder module 42

3.7a. 12 ton hydraulic press 45

3.7b. Contact angle measurement set-up 46

3.7c. Contact angle measurement software 47

3.8. Set up for modified IDF wettability method 48

3.9. Dissolution rate measurement set-up 49

3.10. ICP-OES measured with Horiba Scientific Ultima 2 53 
3.11. Diagram of ICP-OES (USGS, 2013)

4.1a. Powder Particle Size Distribution of Volume (\%) vs

Particle Size Diameter of Disodium Ethylene Diamine Tetraacetic Acid

(EDTA) $10 \mathrm{mM}$, Block 1

61

4.1b. Powder Particle Size Distribution of Number (\%) vs

Particle Size Diameter of Disodium Ethylene Diamine Tetraacetic Acid

(EDTA) $10 \mathrm{mM}$, Block 1

4.2a. Contact angle over time for Control vs Sodium Citrate Dihydrate (SCD), Block 1 65

4.2b. Contact angle over time for Control vs Sodium Citrate Dihydrate (SCD), Block 2 65

4.2c. Contact angle over time for Control vs Disodium Ethylene Diamine Tetraacetic Acid (EDTA), Block 1 66

4.2d. Contact angle over time for Control vs Disodium Ethylene Diamine Tetraacetic Acid (EDTA), Block 2 66

4.3a. Sodium Citrate Dihydrate (SCD) 15 mM Block 1 after timer was stopped for IDF wettability method 70

4.3b. Sodium Citrate Dihydrate (SCD) $10 \mathrm{mM}$ Block 1 after timer was stopped for IDF wettability method 70

4.4. Sodium Citrate Dihydrate (SCD) $10 \mathrm{mM}$, Block 1 for dissolution rate test 73

4.5a. Particle Size Analysis (PSA) for reconstituted samples of Sodium

Citrate Dihydrate (SCD) at $5 \mathrm{mM}, 10 \mathrm{mM}$, and $15 \mathrm{mM}$ vs Control 76 
4.5b. Particle Size Analysis (PSA) for reconstituted samples of Disodium Ethylene Diamine Tetraacetic Acid (EDTA) at $5 \mathrm{mM}, 10 \mathrm{mM}$, and $15 \mathrm{mM}$ vs Control 76

4.6a. Solubility index for Ctrl vs. SCD, Block 1 80

4.6b. Solubility index for Ctrl vs. EDTA, Block 1 80

4.6c. Solubility index for Ctrl vs. SCD, Block 2 80

4.6d. Solubility index for Ctrl vs. EDTA, Block 2 80

4.7. Graph of \%soluble Calcium (Ca) and \%soluble Phosphorus (P) for all treatments for ICP-OES 84 


\section{LIST OF EQUATIONS}

Equation

Page

1. Weight of Disodium Ethylenediaminetetraacetic acid (EDTA) (g) used for $15 \mathrm{mM}$ 34

2. Weight of Sodium Citrate Dihydrate (SCD) (g) used for $5 \mathrm{mM}$ 34

3. Using \%moisture data to calculate the weight $(\mathrm{g})$ to reach $10 \% \pm 0.1$ Total Solids for a $50 \mathrm{~mL}$ reconstituted sample of Control Block 1 at $4.4 \%$ moisture

4. To calculate percent moisture after vacuum oven

5. To calculate percent ash after ash oven 41

6. Calculation for the volume mean diameter, $\mathrm{D}(4,3)$ (Horiba Scientific, 2014)

7. Rate of dissolution calculation 50

8. Calculation of \%soluble Calcium or \%soluble Phosphorus 53 


\section{CHAPTER 1: INTRODUCTION}

Fresh liquid milk is a functional ingredient and good source of nutrition, but can spoil if not maintained properly. Reasons for concentrating milk into powders include to reduce costs for storage and transportation and to reduce water activity in order to increase microbiological and chemical stability. Moreover, milk powder functionality is essential in many applications for nutrition supplementation, browning and flavor development, water binding, emulsification, viscosity modification, and texture. However, poor rehydration properties can impact process efficiency and operating costs of milk powder applications. Thus, it is important to understand and optimize rehydration properties for processing efficiency and for functionality in finished product applications (Bylund, 1995; American Dairy Products Institute, 1990; Chandan and Kilara, 2008).

For different desired functionality, it is possible to disrupt the micelle structure of the most common protein in milk, casein, through the addition of chelators (Gaucheron, 2005). Chelation is defined as the formation of a bond between two or more binding sites within the same compound to a single metal ion, such as the calcium in the casein micelle, to create very stable complexes (IUPAC, 1997). Chelating compounds, or chelators, are legal, safe, and widely used. Thus, calcium chelators can alter the structure and end functionality of casein, which ultimately affects the rehydration properties of SMP.

Rehydration can be described in four stages: wettability, sinkability, dispersibility, and solubility. Wettability is the initial water absorption on the SMP particle surface. Sinkability is when the powder particles drop below the surface of the water, after overcoming the surface tension of the water (Fang, 2008). Sinkability is closely 
associated with wettability, sometimes even interchangeable. (ISO 707 | IDF 50:2014). Dispersibility is defined as the speed with which the powder lumps and agglomerates fall apart when reconstituted with water. The final stage, solubility, is defined as the measure of the final condition of the powder constituents interacting with the water. Overall, the rehydration process is dictated by the functionality of the casein protein, which in turn can be altered by the addition of chelators.

The purpose of this study is to assess the impact of chelators on each rehydration property of SMP. This investigation focuses on the addition of the chelators Disodium Ethylene Diamine Tetraacetic Acid (EDTA) or Sodium Citrate Dihydrate (SCD) at concentrations of 5,10 , and $15 \mathrm{mM}$ to fat free milk prior to evaporating and spray drying. 


\section{CHAPTER 2: LITERATURE REVIEW}

The overall objective of this literature review is to provide background on the importance of skim milk powder and its functional properties with respect to its rehydration properties (wettability, sinkability, dispersibility, and solubility). This review will first define the skim milk powder system, while providing detail on the mineral and protein components and how changes in those two components can affect the rehydration properties. Each rehydration property will be described and methods of measurement for each, as well as a method to determine the mineral behavior, will be analyzed. Finally, an investigation will be proposed to study the effects of the addition of specific chelators at given levels on each rehydration property during reconstitution to $10 \%$ total solids.

\subsection{Skim milk powder (SMP)}

\subsubsection{History and Importance}

Skim milk powder dates back to the $13^{\text {th }}$ century, when Marco Polo reported that the soldiers of Kublai Khan carried sun-dried milk. It was not until the early $19^{\text {th }}$ century that the first patents for the modern production of powdered milk were introduced. Roller drying was the popular method before spray drying was established in the 1960s. Milk powders are now widespread around the globe, with products spanning from infant formula to baked goods to recombined dairy products (Pearce, 2015). Overall, milk powders are easily transported, stored, and incorporated into products such as baked goods, confectionary, and ready-to-use therapeutic foods. Skim milk powder is substantial in the global market where New Zealand and the United States of America (USA) are the largest exporters of skim milk powder. Skim milk powder can sometimes be confused with the term Non Fat Dry Milk but there are differences between the two 
products that will be later described. One of the largest differences is that powder can be standardized to obtain a skim milk product, but with non fat dry milk, no standardization is permitted. In general, the market in the United States recognizes skim milk powder as Non Fat Dry Milk (NFDM). For the USA market, Dairy Management Inc. (DMI) reports that May 2015 was the second highest ever USA export volume of NFDM, only behind June 2014. Moreover, USA dairy exports of nonfat dry milk, whole milk powder, dry whey, whey protein concentrate/ isolate, and lactose reached 414,462 metric tons between March and May 2015 (DMI, 2015). Thus, skim milk powder and non fat dry milk can be seen as substantial in the dairy industry. This research uses the term skim milk powder over nonfat dry milk.

\subsubsection{Manufacture of Skim Milk Powder (SMP)}

The manufacturing of SMP is important in providing the nutritional variety of milk in a shelf-stable manner. Compared to other species for sources of milk, bovine milk is widely accepted in providing nutritional and functional needs. Table 2.1 compares bovine milk percent composition to the percent composition of milk of other species.

Table 2.1. Typical composition of milk of various species (\% composition) (adapted from Chandan and Kilara, 2008)

\begin{tabular}{cccccc}
\hline Species & Water & Fat & Protein & Lactose & Ash \\
\hline Cow & 86.6 & 4.6 & 3.4 & 4.9 & 0.5 \\
Goat & 86.5 & 4.5 & 3.5 & 4.7 & 0.8 \\
Human & 87.7 & 3.6 & 1.8 & 6.8 & 0.1 \\
Mare & 89.1 & 1.6 & 2.7 & 6.1 & 0.5 \\
\hline
\end{tabular}

However, varying seasons can cause fluctuation in milk production and composition but this and other factors can be managed through standardizations of SMP. For Codex 
Alimentarius (2011), SMP has not more than 5.0\% moisture by weight nor more than $1.5 \%$ fat by weight and a minimum protein level of $34.0 \%$. The typical percent composition of SMP compared to skim milk and whole bovine milk is shown in Table 2.2 .

Table 2.2. Typical percent composition of skim milk powder vs. skim milk vs. bovine milk (Average percentage) (Canadian Dairy Commission, 2011)

\begin{tabular}{lccc}
\hline Component & Skim milk powder & Skim milk & Bovine milk \\
\hline Water & 3.7 & 89.0 & 87.6 \\
Lactose & 52.4 & 5.1 & 4.7 \\
Fat & 1.2 & 0.2 & 3.7 \\
Proteins & 34.0 & 4.8 & 3.3 \\
Ash & 8.7 & 0.9 & 0.7 \\
\hline
\end{tabular}

Overall, SMP contains lactose and protein in the same relative proportions as the fresh milk from which it was made (Chandan and Kilara, 2008). Approximately $13 \mathrm{~kg}$ of whole milk powder (WMP) or $9 \mathrm{~kg}$ of skim milk powder (SMP) can be produced from $100 \mathrm{~L}$ of whole milk (Pearce, 2015). The manufacture of various milk powders is shown in Figure 2.1. 


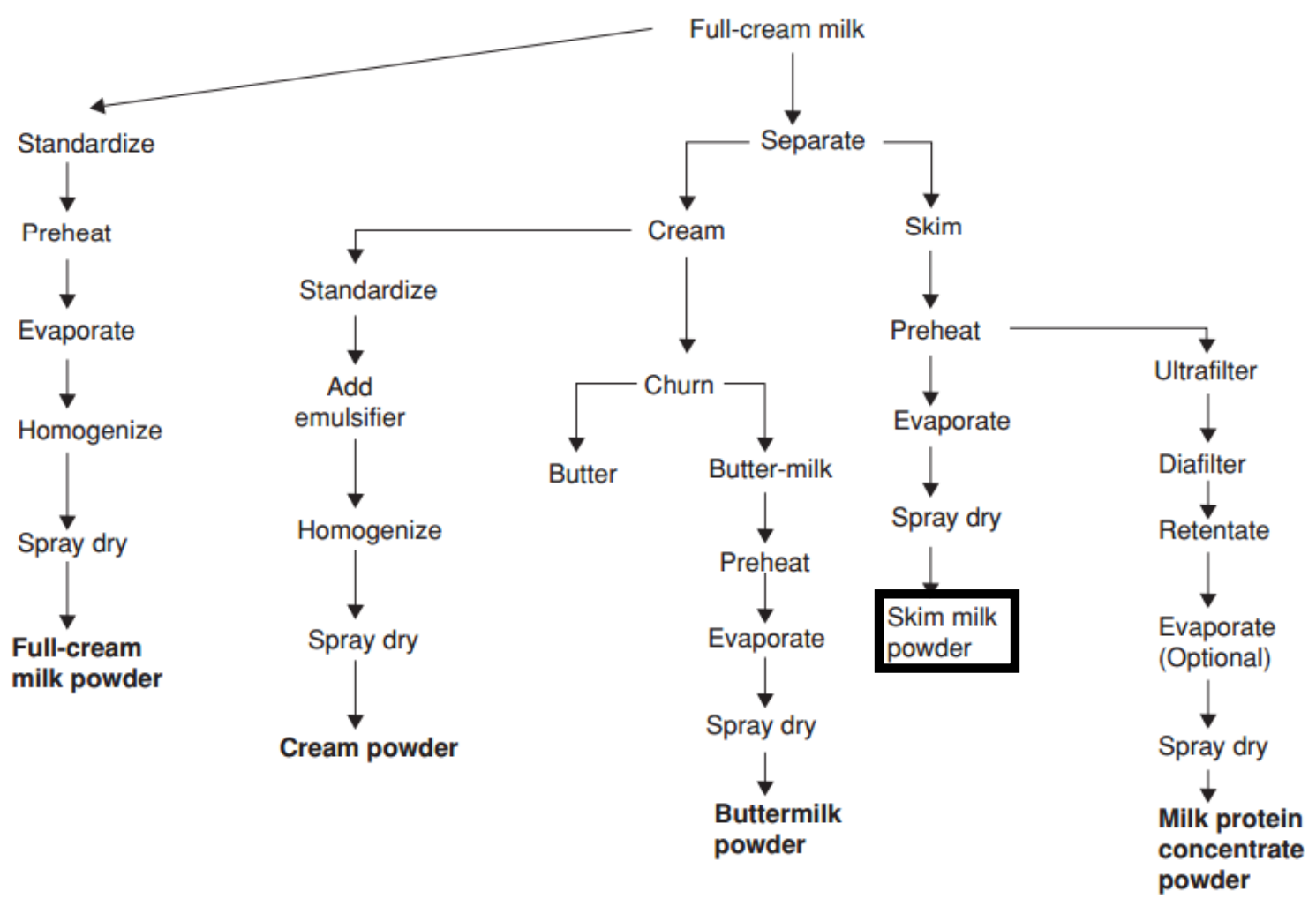

Figure 2.1. Flow chart of manufacture of various milk powders (Chandan and Kilara, 2008)

Generally, the process to manufacture SMP is to preheat, evaporate, and spray dry pasteurized skim milk. Depending on the end goal, SMP is usually classified by preheat treatment into high-, medium-, and low-heat and further classified as instant (agglomerated) and non-instant (regular or non-agglomerated). Non-instant lasts for 1218 months where instant lasts for 6-12 months (ADPI 2005). For NFDM, ADPI further separates products by grade. Extra Grade is the highest quality of NFDM, followed by Standard Grade. Standard Grade are products that fail in one or more requirements of Extra Grade. NFDM that is not assigned a grade may be due to high microbiological activity, high fat, moisture, titratable acidity, solubility index, or scorched particles. 
The first step in the process is to obtain, pasteurize, and separate raw milk into skim milk and cream using a centrifugal cream separator (Pearce, 2015).

The preheating step is important as this is the highest temperature the milk is exposed to throughout the powder making process (Paracha, 2011). Preheating can be direct (i.e. steam injection), indirect (i.e. heat exchanger), or a combination of direct and indirect methods. Effects of preheating include denaturation of whey proteins, decrease in bacteria, inactivation of enzymes, among others (Pearce, 2015).

Regardless of preheat treatments, all powders must abide by the same the chemical and physical standards. Generally, in industry, companies abide by the standards by a large margin so if there are issues such as accidental moisture or fat, the product still meets the standards. Table 2.3 below shows generally accepted standards for SMP manufacture.

\begin{tabular}{lll}
$\begin{array}{l}\text { Table 2.3. Chemical and Physical Standards for SMP from ADPI } \\
\text { and from Codex Alimentarius (Chandan and Kilara, 2008) }\end{array}$ \\
\hline Property & ADPI & Codex Alimentarius \\
\hline Protein - SNF Basis & Min. 34\% & Min. 34\% \\
Moisture & Max. 4.0\% & Max. 5.0\% \\
Fat & Max 1.25\% & Max 1.5\% \\
Titratable Acidity & Max 0.15\% & Max. 18 mL 0.1N \\
& & NaOH/ $10 \mathrm{~g} \mathrm{SNF}$ \\
Scorched Particles & Max. Disc B & Max. Disc B \\
& $(15.0 \mathrm{mg})$ & \\
Solubility Index & Max 1.2 mL & Max. 1.0 mL \\
\hline
\end{tabular}

As Table 2.3 again indicates, for Codex Alimentarius (2011), SMP has not more than $5.0 \%$ moisture by weight nor more than $1.5 \%$ fat by weight and a minimum protein level of $34.0 \%$. Moreover, the titratable acidity, which can measure dissociated and 
undissociated hydrogen ions (i.e. important for weak acids such as lactic acid) is under 0.15\%. Scorched particles (for organoleptic qualities) are under $18 \mathrm{~mL} 0.1 \mathrm{~N} \mathrm{NaOH} / 10 \mathrm{~g}$ SNF. The solubility index is a maximum of $1.0 \mathrm{~mL}$. Finally, all SMP heat treatments share similar sensory standards in terms of odor (fresh, no off odors), appearance (powder, free of lumps), color (white to light cream), and overall flavor (clean, bland, slightly sweet).

Preheating treatments are checked with whey protein nitrogen index (WPNI). Typical processing treatments are shown in Table 2.4 below with the respective whey protein nitrogen index (WPNI) indicative values.

Table 2.4. Preheating treatment and subsequent WPNI value for powders (ADPI, 2014)

\begin{tabular}{llc}
\hline Heat classification & Preheating treatment & WPNI $(\mathrm{mg} \mathrm{N} / \mathrm{g})$ \\
\hline High & $88^{\circ} \mathrm{C}\left(190^{\circ} \mathrm{F}\right)$ for $30 \mathrm{~min}$ & $<1.5$ \\
Medium & $71-79^{\circ} \mathrm{C}\left(160-175^{\circ} \mathrm{F}\right)$ for $20 \mathrm{~min}$ & $1.51-5.99$ \\
Low & Not exceed $71^{\circ} \mathrm{C}\left(160^{\circ} \mathrm{F}\right)$ for $2 \mathrm{~min}$ & $\geq 6.0$ \\
\hline
\end{tabular}

Higher temperatures and/ or extended holding times directly affect whey protein denaturation. Thus, the heat and holding period depends on the end-use. The Whey Protein Nitrogen Index (WPNI) is used to measure the cumulative heat effects during processing. ADPI respective undenatured whey protein nitrogen (WPN) per gram of milk powder are in units of milligram of undenatured whey protein nitrogen per gram of powder (Chandan and Kilara 2008).

Since the highest temperature in powder production is in the preheating step, it important to understand the denaturation of whey protein because of the subsequent interaction with 
casein micelles. The interaction is in the form of disulfide linkages between $\kappa$-casein and $\beta$-lactoglobulin. Moreover, $\beta$-lactoglobulin complexes with $\alpha$-lactoglobulin which, as a whole, can interact with $\kappa$-casein. However, although $\alpha_{\mathrm{s} 2}$-casein has one disulfide bridge, it does not interact with $\beta$-lactoglobulin. During the preheating step, the minor whey proteins (serum albumin and immunoglobulin) start denaturation at $65^{\circ} \mathrm{C}\left(149^{\circ} \mathrm{F}\right)$, which indicates that the minor whey proteins are denatured in all SMP products. However, $\alpha$ lactoglobulin and $\beta$-lactoglobulin begin denaturation at $70^{\circ} \mathrm{C}\left(158^{\circ} \mathrm{F}\right)$. This means that these two major whey proteins may not be fully denatured in low heat SMP. Overall, changes in casein micelle size during the preheating step can be related to the interaction of whey proteins with the caseins (Paracha, 2011).

The different WPNI values listed in Table 4 can indicate the functionality of the powder and thus lead to different applications for each heat treatment. For example, high-heat powder is the most denatured, least soluble, and has the best heat stability; high-heat powder must demonstrate a minimum stability of 40 minutes at $120^{\circ} \mathrm{C}$ without gelation of a $20 \%$ solids solution. Thus, it is generally more suitable for breadmaking because the high-heat treatment enhances water binding and minimizes gluten interference. Mediumor low- heat powder depresses the loaf volume. High-heat powder is also best used in the manufacture of recombined evaporated skim milk.

Low-heat powder is treated as high temperature, short time (HTST) pasteurization which leaves the proteins in their most native state. Thus, low-heat powder is the most soluble and is the most applicable for products that require maximum protein reactivity such as yogurt, cheese, and infant or animal nutrition. The low-heat treatment also optimizes 
sensory properties in dairy foods and beverages. Low-heat powder is the most commonly used in industry.

Since medium-heat powder covers a range in the WPN Index, there is a wide range of heat treatments and the properties can vary from batch to batch with respect to flavor, viscosity, etc. Medium-heat powder has improved heat stability and slightly more developed flavor over low-heat powder. Thus, medium-heat powder applications are generally in confectionary, bakery, meat or UHT products.

Since medium-heat powder characteristics can vary, this research uses low-heat powder. Moreover, for the research conducted here, it was important to use low heat skim milk powder because low heat SMP is closest to skim milk in terms of quality, is the most commonly used, and is the most soluble.

Note that before the evaporation, there is no homogenization step since there is such a low fat level in skim milk. Sometimes reverse osmosis is used to concentrate the milk to about $25 \%$ total solids, which can cut energy costs in the evaporation and spray drying steps. Evaporation is a useful step in minimizing the amount of energy used to manufacture SMP; compared to the spray dryer, in general, evaporators require less energy. Moreover, without the evaporation step, the powder particles would have a high air content, poor wettability, and a short shelf life. Evaporation is considered a gentle concentration process since it is under vacuum - there is little additional heat damage after the preheat treatment because the residence times in each stage of the evaporator is short and the temperature exposure is $72^{\circ} \mathrm{C}$ or less. However, as the milk is more and more concentrated, the viscosity increases and the efficiency of this step decreases rapidly (Chandan and Kilara 2008). 
When the milk concentrate is about $40-50 \%$ total solids, it is then spray dried to powder. Generally, spray drying takes place in three steps. The first step is the dispersion of the concentrate into very fine droplets through the spray atomizer. The second step is the mixing of the finely dispersed concentrate into a stream of hot air which quickly evaporates the water. The final step is the separation of the dry milk particles from the drying air into the cyclone.

At times, there is an extra step involving a fluid (moving) bed where hot air is blown through the powder, to further reduce the moisture content of the powder. Removing the water increases shelf-life because microbial growth is prevented; this eases the distribution and storage of SMP for wide application. Since there are low levels of fat compared to whole milk powder (WMP), skim milk powder has a longer shelf life, lasting for up to 2 years compared to 6-12 months for WMP. (Bylund, 1995; Chandan and Kilara, 2008).

The manufacturing of SMP can influence its rehydration properties through the physical properties as well the chemical properties.

\subsubsection{Casein}

The two main proteins, casein and whey protein, are differentiated by the chemical composition and physical properties. In centrifugation, casein results in a pellet while the supernatant (also called whey or serum), contains water, lactose, and whey protein. Thus, whey proteins are generally soluble while caseins are in suspension. Casein can be differentiated by molecular mass as caseins are usually 25-35 kDa while whey proteins are 14-18 kDa (Bylund, 1995). Forney et al. (2011) note that proteins are complex food molecules. This is because environmental conditions such as $\mathrm{pH}$, mineral concentration, 
and temperature can affect their tertiary structure, which in turn, affects their interaction with other substances such as the interaction with water. Thus, the majority protein, casein, is important as a lot of the functionality of the SMP is influenced by the behavior of the casein.

Casein proteins are found in milk and make up about $80 \%$ of milk proteins. Casein are organized into micelles. There are two main models for the structure of the casein micelle: submicellar, nanocluster, and dual-binding. The submicellar model predicts that micelles formed from submicelles that are linked by CCP. The nanocluster model predicts that there are calcium phosphate/ casein particles linked by noncovalent bonds. However, more recent studies with electron microscopy give images that appear to not support the submicellar model (Dalgleish and Corredig, 2012).

While the micelle structure is not fully understood, there are a few key agreements. First, the micelle is generally seen as a porous, spherical, and non-homogenous structure with an average diameter of $150-200 \mathrm{~nm}$. The micelle is about $94 \%$ protein and $6 \%$ salts on a dry weight basis. The micelles have about $3.5 \mathrm{~kg}$ of water/ $\mathrm{kg}$ of protein. This means that although caseins are about $2.5 \%$ of the total weight of milk, the micelles are about $10 \%$ of the volume. The main salts in the micelle are calcium, phosphorous, magnesium, and citrate; these four ions are known as colloidal calcium phosphate $(\mathrm{CCP})$. The micelle is held together by these $\mathrm{CCP}$ bridges, protein-protein interactions (including electrostatic and hydrophobic interactions), and hydrogen bonding Dalgleish and Corredig, 2012; Chandan and Kilara, 2008). 
Out of twenty-one variants, the four main casein genetic fractions are $\alpha_{\mathrm{s} 1^{-}}, \alpha_{\mathrm{s} 2^{-}}, \beta-$, and $\kappa-$ casein. These four are in a percentage ratio of $4: 1: 4: 1$. Table 2.5 shows the casein make up in milk (\% of total protein w/w).

Table 2.5. Casein make up in bovine milk (\% of total protein w/w) (Bylund, 1995)

\begin{tabular}{lc}
\hline Casein component & $\%(\mathrm{w} / \mathrm{w})$ \\
\hline Total casein in milk & $79.5 \%$ \\
$\alpha_{\mathrm{s} 1}$-casein & 30.6 \\
$\alpha_{\text {s } 2 \text {-casein }}$ & 8.0 \\
$\beta$-casein & 30.8 \\
$\kappa$-casein & 10.1 \\
\hline
\end{tabular}

$\alpha_{\mathrm{s} 1^{-}}, \alpha_{\mathrm{s} 2^{-}}$, and $\beta$-casein proteins are almost insoluble in water whereas $\kappa$-casein is readily soluble in water; it follows that the more hydrophilic $\kappa$-casein is found on the outside of the micelle. Since $\kappa$-casein is found on the outside of the micelle, the whole micelle is soluble as a colloid. The proportion of $\kappa$-casein indicates average size of the micelles; higher proportion leads to a smaller average diameter of casein micelle. Furthermore, on the $\kappa$-casein, there is carbohydrate group with a strong negative charge projecting from the exterior of the micelle to stabilize the micelle. This protein-protein interaction, plus the combination of the calcium phosphate and the hydrophobic interactions between submicelles, hold together the fairly heat stable casein micelle structure (Dalgleish and Corredig, 2012; Bylund, 1995). Figure 2.2 below shows the schematic of a casein micelle. 


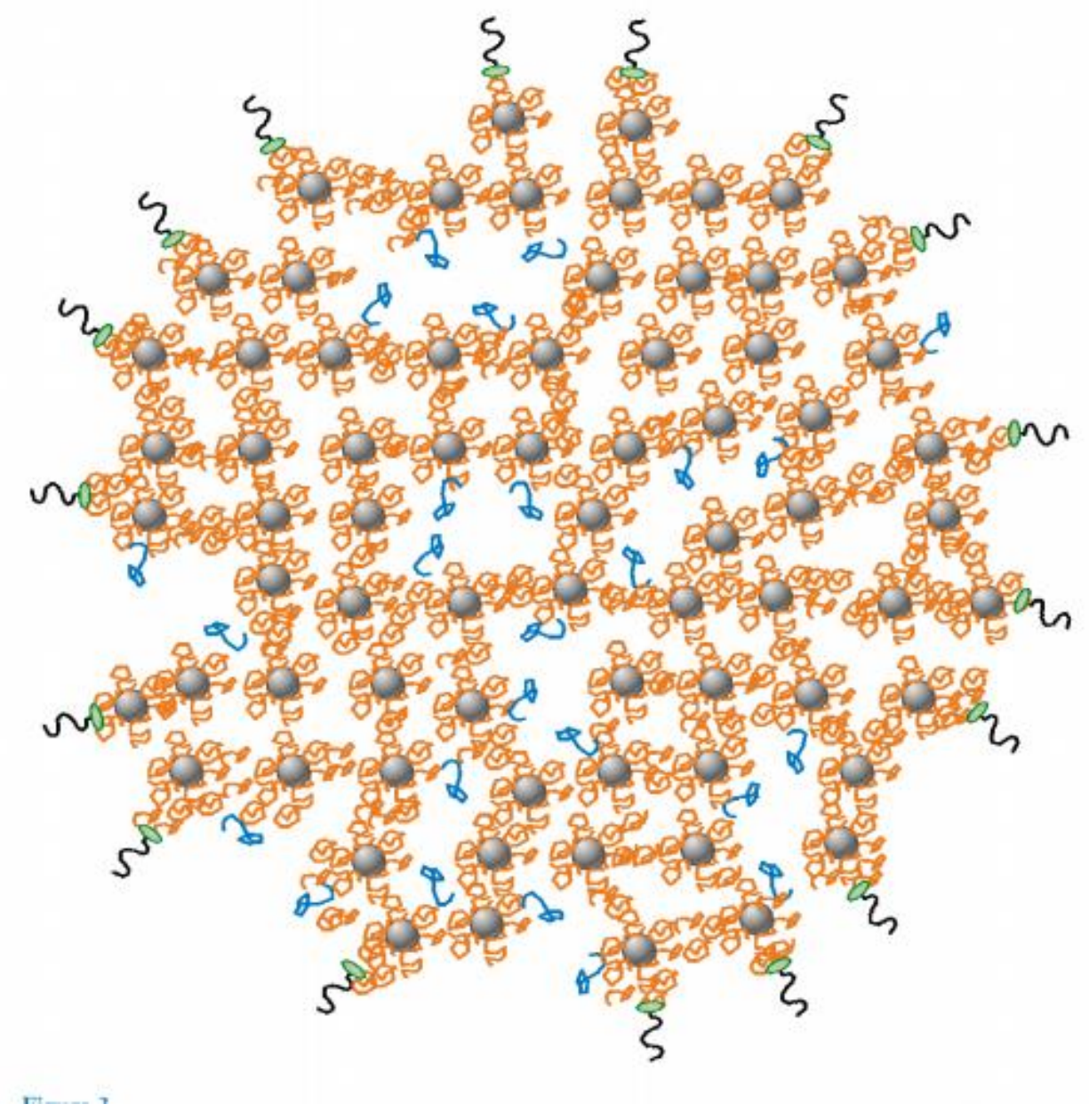

Figure 2.2. Schematic of a casein micelle (Dalgleish and Corredig, 2012)* *The $\alpha_{\mathrm{s} 1}-, \alpha_{\mathrm{s} 2}-$, and $\beta$-caseins (orange) are attached to the calcium phosphate nanoclusters (gray). Some $\beta$-caseins (blue) are binded via hydrophobic interactions to other caseins. $\kappa$ casein (green) and the caseinomacropeptide chains (black) are on the surface of the micelle.

The $\alpha_{\mathrm{s} 1^{-}}, \alpha_{\mathrm{s} 2^{-}}$, and $\beta$-caseins (orange) are attached to the calcium phosphate nanoclusters (gray). Some $\beta$-caseins (blue) are binded via hydrophobic interactions to other caseins. $\kappa$ casein (green) and the caseinomacropeptide chains (black) are on the surface of the micelle. It appears that the $\kappa$-casein prevent aggregation and the caseinomacropeptide chains create a layer, estimated to be 5-10 nm thick which provides steric stabilization and prevents micelles from getting to close to other micelles. 
Most of the functionality of the casein micelle depend on the properties of the surface of the micelle, rather than the interior. This is because different methods cause different changes to the caseinomacropeptide chains layer, the "hairy" layer, which can affect the stability of the micelle in different ways (Dalgleish and Corredig, 2012). For different desired functionality, it is possible to adjust the structure of the casein through various methods such as acidification, heat treatment, or addition of chelators, among other methods (Gaucheron, 2005). These changes are described further in Section 2.2 and Section 2.3.

\subsubsection{Minerals in Milk}

Milk is a nutritious fluid delivered to offspring from the female mammal. Milk is about $87.6 \%$ water, $4.7 \%$ lactose, $3.7 \%$ fat, $3.3 \%$ proteins, and $0.7 \%$ ash. Overall, the more abundant minerals in skim milk powder are potassium, calcium, phosphorous, sodium, and magnesium. Potassium, sodium, and chloride ions are essentially diffusible while calcium, phosphate, and magnesium are non-diffusable. Non-diffusable indicates that the ions are partly bound to the casein micelles. Calcium and phosphorous are important because of their roles with the casein protein - about two-thirds of the total calcium and about half the inorganic phosphate are found in the casein micelle structure (Gaucheron, 2005). Minerals are also found in whey protein. Cations can form an ionic bridge between adjacent carboxyl groups from different peptide chains in whey protein. The minerals in milk are dynamic between the serum and the micelle (Udabage et al., 2000). By centrifugation and subsequent analysis of the supernatant, it is possible to measure the calcium activity in the serum phase. Table 2.6 shows the calcium partition in 
bovine milk, noting that $31 \%$ of the total calcium is in the serum and $69 \%$ of the total calcium is in the micelle.

Table 2.6. Calcium partition in bovine milk (adapted from Gaucheron, 2005)

\begin{tabular}{ll}
\hline Component & Concentration \\
\hline Casein & $26.1 \mathrm{~g} / \mathrm{L}$ \\
Total Ca & $29.4 \mathrm{mM}$ \\
Soluble & $9.2 \mathrm{mM}$ \\
$\%$ of soluble Ca & $31 \%$ \\
Miceller Ca & $20.2 \mathrm{mM}$ \\
$\%$ of Total Ca that is in casein & $69 \%$ \\
Micellar calcium x g & -1 of casein \\
\hline
\end{tabular}

The minerals can be influenced to migrate between the serum and the micelle by changes in temperature, $\mathrm{pH}$, or the addition of chelators. By the addition of $10 \mathrm{mM} \mathrm{CaCl}_{2}$, Udabage et al. (2000) measured $72 \%$ of the added calcium was found in the pellet. Moreover, $59 \%$ of the added calcium was found in the pellet via the addition of $30 \mathrm{mM}$ $\mathrm{CaCl}_{2}$. Therefore, chelators affect the calcium equilibrium, which affects the casein micelle structure.

\subsection{Chelators}

\subsubsection{Overview}

It is possible to adjust the micelle structure of the most common protein in milk, casein, through various methods such as acidification, heat treatment, or addition of chelators, among other methods (Gaucheron, 2005). Chelating compounds, or chelators, are legal, safe, and widely used. Chelation is defined as the formation a bond between two or more binding sites within the same compound to a single metal ion, such as calcium, to create 
very stable complexes (IUPAC, 1997). Chelators tend to be thermodynamically stable and displace other ligands in entropy-favoring reactions (Zeng and Jadir, 2015). The Greek word "chele" means the pincers of crabs, lobsters, and scorpions. This image indicates the shape and tight grip of the formation of bonds between a chelator and an ion (Flora and Pachauri, 2010). Chelators can be classified as strong or weak depend on the ion-binding capacity. The $\mathrm{pH}$ of the system also has an effect on chelators, as chelators can be unstable at low $\mathrm{pH}$. In general, chelators are in the form of a salt and are thus known as chelating salts. In Codex Alimentarius (2011), chelating salts listed under food additives include trisodium citrate, tricalcium citrate, dicalcium phosphate, and tripotassium phosphate; these chelators are used as emulsifying salts, stabilizers, or thickeners. Sodium citrates are allowed as a stabilizer additive and potassium phosphates are allowed as acidity regulators. Both are allowed at a maximum level of 5,000 mg/kg $(0.5 \%)$ or in combination (Codex Alimentarius, 2011). As for the effect on dietary bioavailability, certain chelating salts such as tricalcium citrate are used for fortification of beverages such as orange juice or grape juice. Tricalcium citrate has a high calcium level $(31 \%)$ and moderate solubility $(0.9 \mathrm{~g} / \mathrm{L})$; its solubility improves at $\mathrm{pH}$ below 4.5 and at low temperatures (Gerstner, 2002) Furthermore, chelating salts have been used in dairy for decades. Thus, certain chelating salts are ideal to try to alter the reconstitution properties of SMP, such as a higher wettability, sinkability, dispersibility, and solubility. When chelating salts are added to casein micelle, the chelator can alter the functionality. For example, Sikand et al. (2013) noted that lower values for solubility index were observed for SMP samples with 5mM EDTA and 5mM sodium polyphosphate as compared to the control sample with no chelators. Schuck et a.l (2002) found that adding 
citrate or phosphate prior to drying or adding $\mathrm{NaCl}$ during reconstitution improves the rehydration process of the powder. Furthermore, Konstance and Strange (1991) showed that the solubility of sodium caseinate and calcium caseinate improved when sodium phosphate was added. These changes in functionality may be due to the idea that chelators can cause a mineral imbalance between the minerals in the micelle and the minerals in the serum, namely of the mineral, calcium. For example, Sikand et al. (2011) associated the differences in the solubility of milk protein concentrate (MPC) and milk protein isolate (MPI) with differences in mineral composition. It is generally believed that the chelators first bind to the calcium in the serum. To return to equilibrium, the calcium inside the micelle migrate into the serum; this causes the CCP bridges, which hold the micelle structure together, to collapse. In theory, the micelle separate into smaller, negatively charged micelle structures, which repel each other. The repulsion could affect the reconstitution properties such as dispersibility; since water is polar and the small micelles are negatively charged, there would be a stronger interaction than the one between the water and an average micelle. Gaucheron (2005) notes that the modification of casein micelles by the addition of chelators is irreversible. Thus, by adjusting the concentration of calcium in the solution via chelator addition, we may alter the interaction of calcium in the casein micelle. By understanding the casein micelle structure and by controlling the structural changes, rehydration properties of chelated SMP may be higher compared to SMP without chelator.

Three major groups of chelators include phosphates, Ethylene Diamine Tetraacetic Acid (EDTA), and citrates. In general, polyphosphates are variable and the system cannot be easily defined. Thus, this study only utilizes and discusses EDTA and citrate. 


\subsubsection{Disodium Ethylene Diamine Tetraacetic Acid (EDTA)}

EDTA is a hexadentate chelating agent with a molecular weight of $372.2 \mathrm{~g} / \mathrm{mol}$. The chemical formula of a typical EDTA salt, Disodium EDTA, is $\mathrm{C}_{10} \mathrm{H}_{14} \mathrm{~N}_{2} \mathrm{O}_{8} \mathrm{Na}_{2} \cdot 2 \mathrm{H}_{2} \mathrm{O}$. Hexadentate indicates that there are six spots per EDTA molecule to bind with calcium ions: 4 oxygens and 2 nitrogens (Zeng and Jadir, 2015). Figure 2.3 shows the fully protonated form of EDTA.

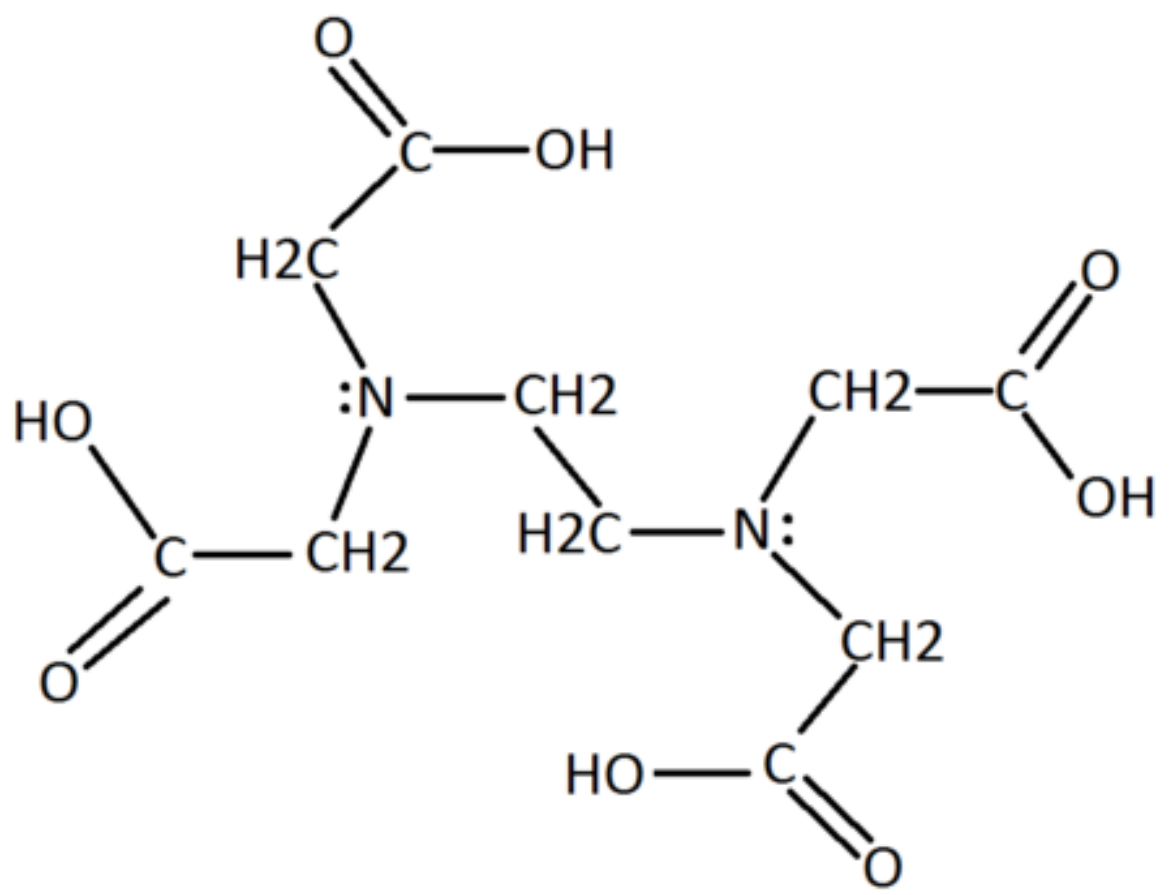

Figure 2.3. Fully protonated form of Ethylene Diamine Tetraacetic Acid (EDTA) (Zeng and Jadir, 2015)

As EDTA has a strong ion-binding capacity, EDTA has applications to prevent undesired metals from reacting. For example, in personal care products and laundry detergents, EDTA binds to free metal ions such as calcium and magnesium to reduce the hardness in water in order for the other ingredients in those products to work more efficiently (Zeng and Jadir, 2015). Although Disodium EDTA is GRAS, it is not allowed in milk powders. However, EDTA is allowed in food products such as cabbage, fermented malt beverages, 
and mayonnaise to promote color retention, as a preservative, to promote stability, and more (CFR 21, 2015). In the casein micelle, EDTA dissolves the calcium phosphate so that nanoclusters in the casein micelle do not exist (Dalgleish and Corredig, 2012). Odagiri and Nickerson (1965) observed that, when Disodium EDTA was added, the pH of milk decreased, probably because the uptake of protons by the phosphate ions was overshadowed by the liberation of protons. EDTA is most commonly used as a chelating salt form, Disodium EDTA (Zeng and Jandir, 2015). Overall, EDTA is considered a stronger chelator than sodium citrate dehydrate (SCD). Sikand et al. (2013) noted that lower values for solubility index were observed for SMP samples with 5mM EDTA as compared to the control sample with no chelators. However, Sikand et al. (2013) did not study the effect of EDTA on all stages of rehydration properties. Furthermore, Sikand et al. (2013) showed that the chelator addition step was to reconstituted SMP, which was evaporated and spray dried a second time. Thus, this investigation further analyzes the effect of EDTA on the rehydration properties of SMP, when the EDTA is added to the fat free milk prior to evaporation and spray drying.

\subsubsection{Sodium Citrate Dihydrate (SCD)}

Citrates are commonly used in the dairy industry and one of the most commonly used chelating salt is Sodium Citrate Dihydrate. SCD is a conjugate base of a weak acid with a molecular weight of $294.1 \mathrm{~g} / \mathrm{mol}$. The chemical formula is $\mathrm{Na}_{3} \mathrm{C}_{6} \mathrm{H}_{5} \mathrm{O}_{7}$. SCD is allowed in milk products as a stabilizing agent, up to $5,000 \mathrm{mg} / \mathrm{kg}$ or $0.5 \%$. 


\subsection{Rehydration Properties}

Forny et al. (2011) noted that in real reconstitution processes, the rehydration properties cannot be clearly isolated from the others. The following methods were developed to attempt to separately measure each rehydration property of wettability, sinkability, dispersibility, and solubility.

Wettability has been measured via the Washburn equation but there can be nuances due to the complex milk system. Therefore, the contact angle measurement test is used in this study to measure "surface hydrophobicity", rather than the traditional idea of wettability (Crowley, 2015). Since wettability and sinkability are closely tied in the IDF Wettability method, this method is used to relate to the contact angle method for wettability as well as to provide information on wettability and sinkability. Dispersibility is measured via dissolution rate measurements via spectrophotometry and particle size analysis (Ferrer et al, 2008; Millqvist et al., 2001). Solubility is measured by particle size analysis of a rehydrated sample and by the solubility index (ADPI, 2002). Furthermore, the effects on the rehydration properties are theorized to be caused by changes in the calcium balance between the serum and the micelle. Thus, the total calcium and the calcium in the serum after centrifugation is measured by inductively coupled plasma optical emission spectroscopy (ICP-OES). 


\subsubsection{Overview}

Skim milk powder rehydration takes place in four stages: wettability, sinkability, dispersibility, and solubility (Fang, 2008). Figure 4 below illustrates how the stages overlap and are not necessarily discrete.

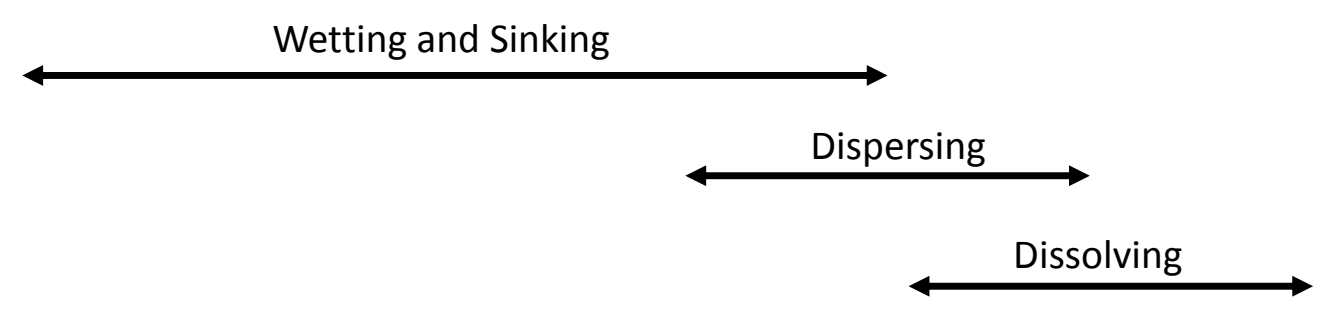

Figure 2.4. Schematic of dissolution stages for a standard powder particle showing how different rehydration stages overlap with time (adapted from Fang, 2008)

Chandan and Kilara (2008) note that it is important to understand the physical properties of the powder and how they may affect the rehydration properties. This can be done by measuring bulk density, which is the weight of powder that in a fixed volume container. There are various standard methods to measuring bulk density, including one manual method outlined by ADPI (2002) and one automated method such as the Stampvolumeter. Typical results for skim milk powder are in the range of 0.58-0.68 $\mathrm{g} / \mathrm{mL}$. Bulk density measures occluded air, interstitial air, and the distribution of the size and shape of the powder particles. For example, powder particles, as measured by a particle size analyzer, that are more homogenous in shape, have higher bulk densities and powder particles that are more homogenous in size, have smaller bulk densities. In general, lower bulk density values are desired. Since bulk density is generally most influenced by the concentrate characteristics, atomization methodology, drying 
parameters, and the extent of whey protein denaturation, all of these factors are kept constant throughout manufacturing of the samples. For example, after evaporation and prior to spray drying, all the concentrates are standardized to $40 \%$ total solids. For this study, only particle size analysis is utilized for information on the physical properties of the powders.

\subsubsection{Wettability}

Wettability is the water absorption on the SMP particle surface. This includes the ability of the powder particles to overcome the water surface tension. If the powder cannot overcome the surface tension sufficiently, the powders may stick to the walls of the container and layers form.

Gaiani (2005) notes that, for whey powders, the controlling stage is the wetting stage, but in contrast, the controlling stage of casein proteins is the dispersion. Schuck et al (2007) showed that the low solubility index of micellar casein powder was the result of a slow rate of rehydration rather than the consequence of a high content of insoluble material. Overall, there are many factors that can affect wettability. In general, wettability is lower during storage for six months or more (Litman and Ashworth, 1957). While wettability is most influenced by free fat content of the powder and the state of the lactose, SMP does not have enough free fat on the surface to have large effects for oxidation, so there is minimal alteration of the wettability functionality (Paracha, 2011). Moreover, wettability can be influenced by spray drying atomization methodology and other spray drying parameters so these are kept constant across all samples during manufacturing. Also, wettability is affected by the air between the powder particles, known as interstitial air. In general, wettability is reduced when there is an increase in interstitial air between the 
powder particles because the water is more easily diffused through the more porous structure (Fang, 2008). Finally, wettability is dependent on powder particle size (Vega and Roos, 2006), which will be measured in this study.

Studies to measure wettability are usually derived from the Washburn equation (Fang, 2008). From the Washburn equation, wettability can be higher if there are large pores in large particles and high porosity in the particles as well as a small contact angle. However, the equation may not fit the milk system because the surface tension changes due to the different components in milk that dissolve, including lactose, whey protein, and salts (Fang, 2008). Thus, the contact angle measurement test adapted from pharmaceutical use is used in this study to measure surface hydrophobicity, rather than the traditional idea of wettability (Crowley, 2015). This method is discussed more in detail in Section 3.6.1.1. Overall, a treated sample will show less surface hydrophobicity over untreated SMP if the sample has a smaller contact angle than that for untreated SMP.

\subsubsection{Sinkability}

Sinkability is when the powder particles drop below the surface of the water (Fang, 2008). Thus, the surface area characteristics are critical in sinkability. The ability to sink is a function of specific volume, density, and particle size. Agglomerated powders normally have the best ability to sink (Bylund, 1995). Sinkability is closely associated with wettability, sometimes even interchangeable. For example, in the International Dairy Federation (IDF) wettability method, the wettability time (wetting time) is defined as "the time required for all the particles of the sample to become wetted, i.e. to sink below the surface of the water and any remaining on the surface to assume a typical "wet" 
appearance" (ISO 707 | IDF 50:2014). The biggest influences for sinkability are particle density and occluded air (air content enclosed within the powder particle. Higher density particles with less occluded air are more likely to sink in water due to water more easily diffusing through the porous structure. Since wettability and sinkability are closely tied in the IDF Wettability method, this method is used to relate to the contact angle method for wettability as well as to provide information on sinkability. Since this IDF method can vary widely from sample to sample, it is recommended to analyze in triplicates and to report each time, as well as the mean. Thus, SMP with chelator will show higher sinkability if the powder with chelator shows a smaller mean time to "wet" than the SMP without chelator.

\subsubsection{Dispersibility}

Dispersibility is defined as the speed with which the powder lumps and agglomerates fall apart when reconstituted with water. In other words, good dispersibility is seen when powders in water are distributed as single particles, leaving no lumps (i.e. scum). Dispersibility is dependent on the casein dispersing because casein is the non-soluble protein. Moreover, a powder with a high content of denatured proteins is very difficult to disperse (Fang, 2008). Thus, minimizing preheat treatment leads to higher dispersibility (Paracha, 2011; Bylund, 1995). Dispersibility can be measured via dissolution rate measurements via spectrophotometry in units of Optical Density per second (O.D./ second) (Ferrer et al, 2008; Millqvist-Fureby et al., 2001). If SMP with chelators had a higher dispersibility, the dissolution rate (O.D./ second) would be higher than SMP without chelator. 


\subsubsection{Solubility}

Solubility is defined as the measure of the final condition of the powder constituents interacting with the water. In other words, solubility describes how well the powders dissolve and form a stable suspension. Solubility is important because, if the powder is not completely solubilized, there are can be problems in processing such as clogging of filters. Solubility is considered the most important property of the rehydration process as it is the final stage (Bylund, 1995; Fang, 2008). To measure solubility, the solubility index is used (ADPI 2002). In this test, the insoluble material is generally denatured protein ( $\beta$-lactoglobulin), casein, and lactose. Solubility is mostly influenced by preheat treatment, atomization type, the physical properties of the concentrate prior to drying such as viscosity, and the temperature of rehydration. Thus, the preheat treatment, and atomization type, and temperature of rehydration are controlled factors during this testing. The maximum solubility for SMP without chelator is $1.0 \mathrm{~mL}$. Thus, higher solubility would be if SMP with chelators had solubility index levels lower than solubility index levels for SMP without chelator.

Moreover, particle size distribution analysis is conducted of fully solubilized reconstituted treatment samples. Thus, treated powders with higher solubility would show powders that are smaller and more homogenous in size than the data for skim milk powder without chelator.

\subsubsection{Calcium and Phosphorus Behavior}

When rehydrating the samples, the water quality is important. During evaporation, the milk has been rid of pure (distilled) water. Therefore, the water used to rehydrate the samples must be low in hardness expressed as calcium carbonate $\left(\mathrm{CaCO}_{3}\right)$, i.e. $<100$ 
mg/L. An excessive mineral content will jeopardize the salt balance of the reconstituted product (Bylund, 1995). Thus, this study also utilizes the ICP-OES to measure the calcium and phosphate levels in the water used for manufacturing powders and in the water used for rehydrating powders, in addition to measuring the total and serum mineral levels in the samples.

\subsection{Summary, Hypotheses, and Objectives}

From the literature review, Sikand et al. (2013) noted that lower values for solubility index were observed for SMP samples with 5mM EDTA and 5mM sodium polyphosphate as compared to the control sample with no chelators. However, the study had not focused on rehydration properties of SMP. Moreover, the manufacturing process was reconstituting SMP to $30 \% \mathrm{TS}$, adding chelator, then evaporating and spray drying. Thus, the focus of this study expands upon the observations of Sikand et al. (2013) by adding chelators to fat free milk prior to evaporating and spray drying and subsequently analyzing the powder on rehydration properties.

The hypotheses of this study are as follows:

1) Powder produced from chelated skim milk have higher wettability, sinkability, dispersibility, and solubility than SMP not treated with chelators

2) Chelators affect the rehydration properties of SMP by altering the calcium balance between the serum and the casein micelle The objectives of this study are as follows:

1) To incorporate the chelating salts Disodium EDTA or Sodium Citrate Dihydrate at concentrations of 5,10 , and $15 \mathrm{mM}$ to skim milk prior to evaporating and spray drying. 
2) To determine the effects of the chelator additions on each SMP rehydration property (wettability, sinkability, dispersibility, and soluibility) during reconstitution to $10 \%$ total solids, compared to the control (SMP with no chelator added) in order to assess changes in rehydration properties.

3) To quantify the calcium behavior in the system, for understanding as to how chelators affect the SMP system. 


\section{CHAPTER 3: MATERIALS AND METHODS}

\subsection{Ingredients}

\subsubsection{Pasteurized Fat Free Milk}

Grade A, Pasteurized, Homogenized, Vitamin A\&D, fat free milk was obtained from Producers Dairy Foods, Inc. (Fresno, CA 93701) for each block in 6 gallon packages. All packages were stored in $2^{\circ} \mathrm{C}\left(36^{\circ} \mathrm{F}\right)$ refrigerator.

\subsubsection{Chelators}

The Dissolvine NA 2-P product provided by Akzo Nobel Functional Chemicals LLC (Chicago, IL) (Batch 610E2013) was the chemical Disodium Ethylenediaminetetraacetic acid (EDTA). The chemical formula was $\mathrm{C}_{10} \mathrm{H}_{14} \mathrm{~N}_{2} \mathrm{O}_{8} \mathrm{Na}_{2} \cdot 2 \mathrm{H}_{2} \mathrm{O}$.

Sodium Citrate Dihydrate (SCD) was obtained from Tate \& Lyle (Lot \#GC1F27BK5A). The chemical formula was $\mathrm{Na}_{3} \mathrm{C}_{6} \mathrm{H}_{5} \mathrm{O}_{7}$.

Both chelators were stored at room temperature, $20-25^{\circ} \mathrm{C}\left(68-77^{\circ} \mathrm{F}\right)$.

\subsection{Powder Making Process}

Generally, to produce the chelated skim milk powder samples for this study, the chelator was added to the skim milk. The $\mathrm{pH}$ was adjusted with acid or base and the liquid mixture was hydrated overnight in a refrigerator. After a minimum of 14 hours, the mixture was evaporated and the resulting concentrate was adjusted to $40 \%$ total solids (\%TS). Finally, the concentrate was spray dried, cooled, and stored until analysis. Figure 3.1 shows a schematic of the general process to produce the chelated SMP samples for this study. Process details are found in Section 3.2.2-3.2.6. 
Chelator added

into fat free milk

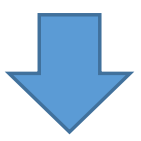

Overnight hydration in $2^{\circ} \mathrm{C}$

$\left(36^{\circ} \mathrm{F}\right)$ refrigerator

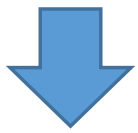

Adjusted $\mathrm{pH}$ to $6.65 \pm 0.05$ with $1.0 \mathrm{~N} \mathrm{HCl}$ or $1.0 \mathrm{~N} \mathrm{NaOH}$

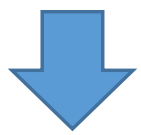

Evaporation

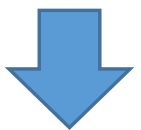

Adjust to $40 \pm 1 \%$ total solids

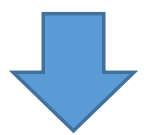

Spray dry

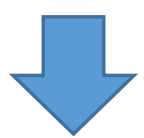

Packaging/ storage

Figure 3.1. Schematic of the general process to produce the chelated SMP samples 


\subsubsection{Experimental Design}

This was a randomized complete block design (RCBD). There were two experimental factors of chelator type and chelator concentration. There was one blocking factor with 2 levels. As fat free milk had a two-week shelf life, the powder samples were prepared in blocks where each sample was made in each block to account for any differences in the fat free milk supply. Within each block, there were 7 treatment combinations. The 7 treatment combinations are as follows: 6 combinations (chelator type at 2 levels: EDTA or SCD with chelator concentration at 3 levels: $5 \mathrm{mM}, 10 \mathrm{mM}$, and $15 \mathrm{mM}$ ) plus the control treatment. This was done in duplicate for a total of 14 samples. Figure 3.2 below shows a summary of the RCBD.

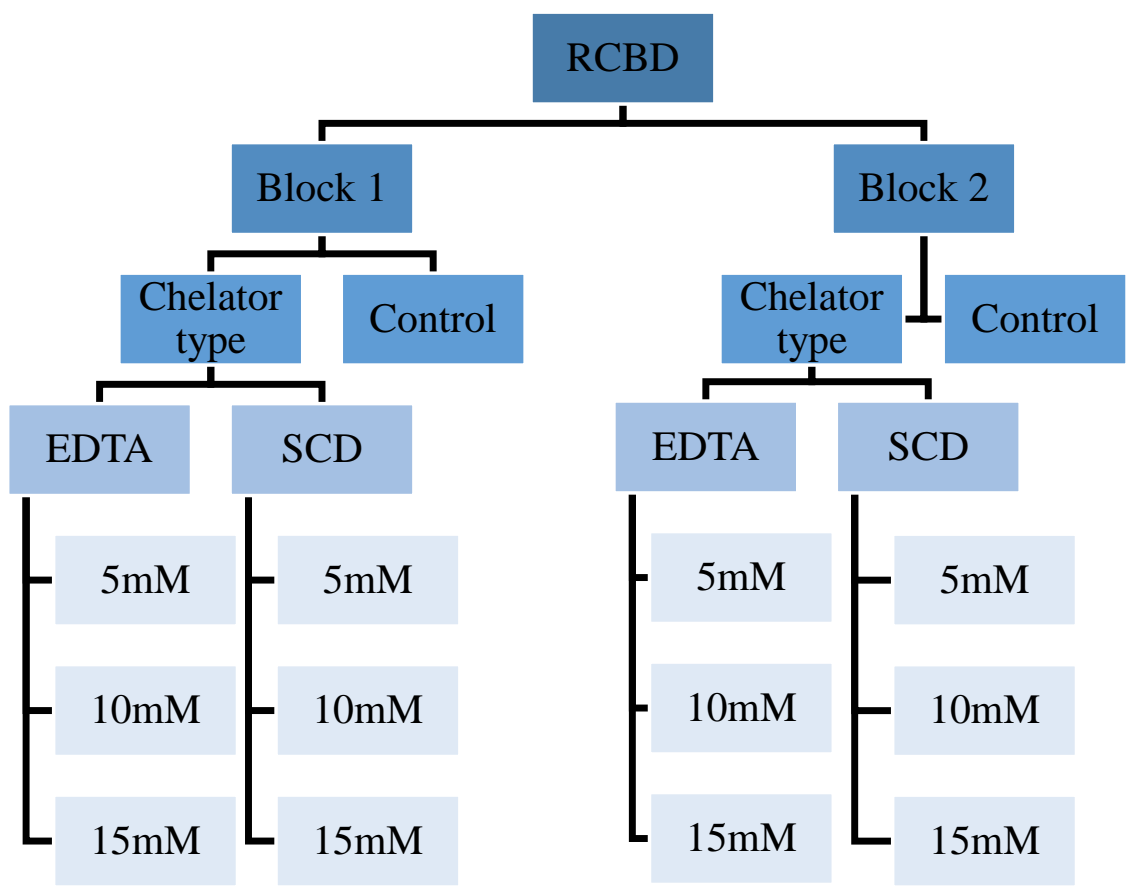

Figure 3.2. Summary of the Randomized Complete Block Design (RCBD)* *EDTA=Disodium Ethylene Diamine Tetraacetic Acid, SCD=Sodium Citrate Dihydrate 
Once all the samples were produced, the results of the response factors were analyzed as a RCBD using two-factor ANOVA with Dunnett comparisons comparing each of the 6 treatments to the control as this study is focused on having higher levels of each rehydration property compared to the control, not between treatments. Results were expressed as a mean with standard error (S.E.). All graphs for the raw data can be found in the Appendix as noted. Two-way analysis of variance (ANOVA) was carried out by JMP Pro 12.1. Assumptions for each response were checked for the following criteria: 1) each sample is independent and was randomly assigned for testing 2) the distribution of the residuals followed a normal distribution and 3) population variances were equal across responses. Differences were considered to be significant at $\mathrm{p}$-value $<0.05$. If statistically different, JMP was used to conduct multiple comparisons of treatments versus control using Dunnett's procedure. Differences were considered to be significant with a family wise error rate (FWER) of $\alpha=0.05$.

The responses for the 14 samples can be organized into two categories: powder composition and rehydration properties. The responses are summarized in Table 3.1 below. 
Table 3.1. Experimental responses including method and units

\begin{tabular}{|c|c|c|c|}
\hline Property & Sample & Response & Units \\
\hline \multirow{3}{*}{$\begin{array}{l}\text { Powder } \\
\text { properties }\end{array}$} & \multirow{3}{*}{$\begin{array}{l}\text { Powder } \\
\text { sample }\end{array}$} & $\%$ moisture, \%ash, \%protein & $\%$ \\
\hline & & \%protein & $\%$ \\
\hline & & Mean particle size of powder & $\mu \mathrm{m}$ \\
\hline \multirow{6}{*}{$\begin{array}{l}\text { Rehydration } \\
\text { properties }\end{array}$} & \multirow{3}{*}{$\begin{array}{l}\text { Powder } \\
\text { sample }\end{array}$} & Contact angle & Degrees \\
\hline & & IDF wetting time & Seconds \\
\hline & & Dissolution rate & O.D./sec \\
\hline & \multirow{3}{*}{$\begin{array}{c}\text { Reconstituted } \\
\text { SMP } \\
\text { Sample } \\
(10 \% \mathrm{TS})\end{array}$} & $\begin{array}{l}\text { Mean particle size of reconstituted } \\
\text { sample }\end{array}$ & $\mu \mathrm{m}$ \\
\hline & & Insoluble sediment & $\mathrm{mL}$ \\
\hline & & $\begin{array}{c}\text { \%soluble calcium and \%soluble } \\
\text { phosphorus }\end{array}$ & $\%$ \\
\hline
\end{tabular}

From Table 3.1, for powder composition, the responses were mean particle size, percent moisture, percent ash, and percent protein. Two samples were selected for percent fat and percent lactose. For rehydration properties, the responses analyzed with the powder were contact angle, wetting time, and dissolution rate. The responses that were analyzed with a $10 \%$ reconstituted SMP sample were mean particle size, solubility index, \%soluble calcium, and \%soluble phosphorus.

\subsubsection{Chelator Addition into Fat Free Milk}

For each sample, $59.9 \mathrm{~kg}$ (132 lbs) of free fat milk was weighed out. Using an Orion 350 Advanced PerpHecT LogR pH meter, the $\mathrm{pH}$ was measured as a check for microbiological quality. The CEM LabWave 9000 (Figure 3.3a.) was used to measure percent total solids (\%TS) with power setting of $45 \%$ and a sample size of 2-3 grams for a 5-minute run. The Brookfield DV-II+ Pro Model D (Serial No. 8544431) with spindle 
62 at 60 RPM (Figure 3.3b.) was used to measure viscosity of a $200.0 \mathrm{~mL}$ sample. \%TS and viscosity of the liquid fat free milk were checked once per block with a temperature range of $4.0 \pm 1.0^{\circ} \mathrm{C}$.

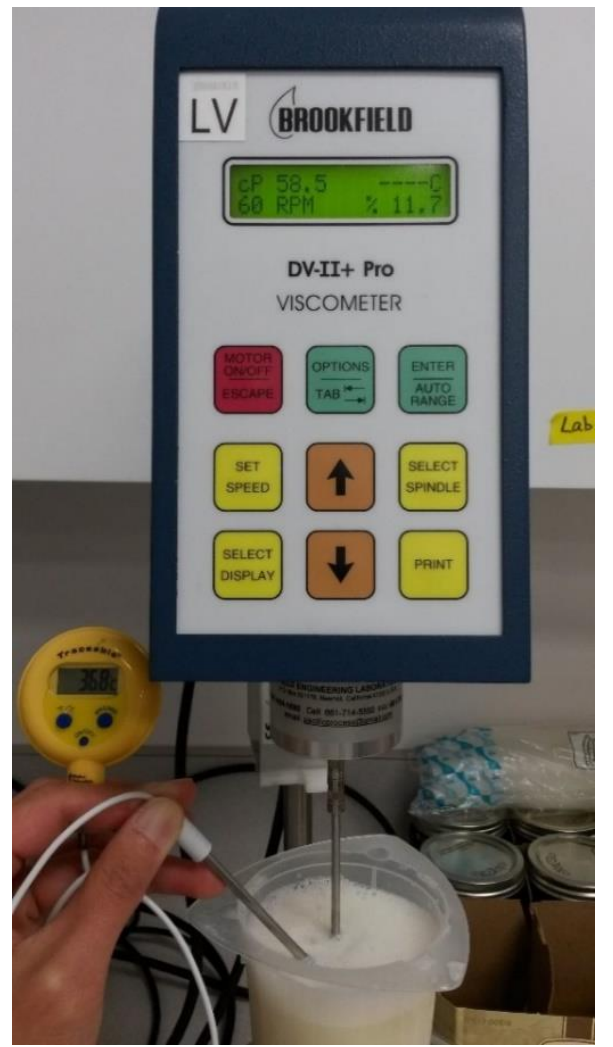

Figure 3.3a. Brookfield Viscometer

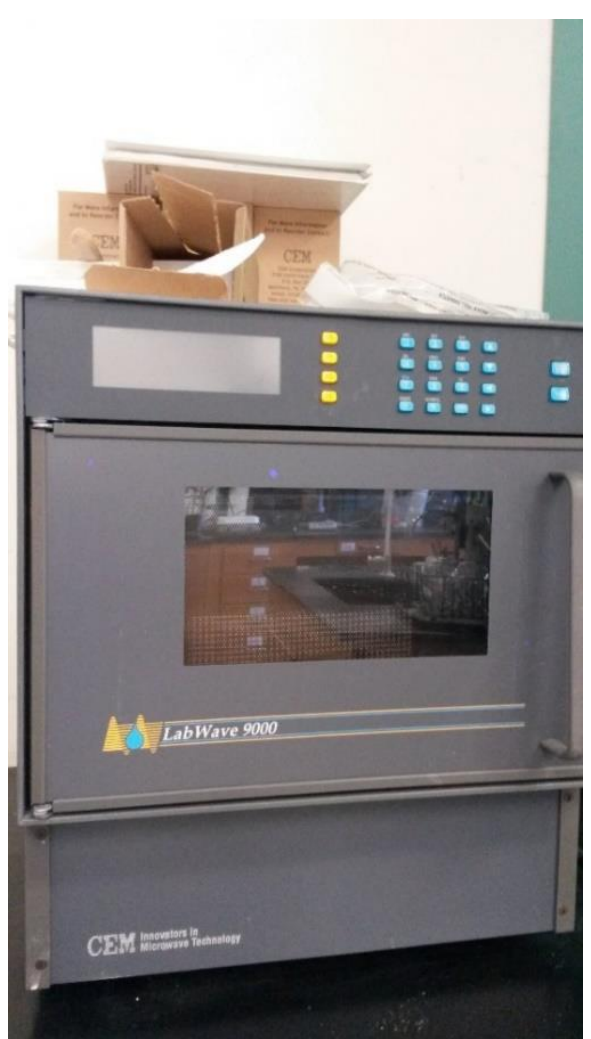

Figure 3.3b. CEM LabWave 9000

Over one minute, one chelator (EDTA or SCD) at concentration of 5,10 , or $15 \mathrm{mM}$ was stirred into the free fat milk with a stirring wand. The calculations for the weight of each chelator to add was as follows:

Equation 1. Weight of Disodium Ethylenediaminetetraacetic acid (EDTA) (g) used for $15 \mathrm{mM}$

$58.1 \mathrm{~L}$ x $0.015 \mathrm{M} \times 372.2 \mathrm{~g} / \mathrm{mol}=324.4 \mathrm{~g}$ EDTA

Equation 2. Weight of Sodium Citrate Dihydrate (SCD) (g) used for $5 \mathrm{mM}$

$58.1 \mathrm{~L}$ x $0.005 \mathrm{M}$ x $294.1 \mathrm{~g} / \mathrm{mol}=85.4 \mathrm{~g}$ Citrate 
Table 3.2 is a summary of the calculated amounts in grams at the desired concentrations of each chelator type.

Table 3.2. Weight $(\mathrm{g})$ of chelator to add for desired concentration $(\mathrm{mM})$ or $\%(\mathrm{w} / \mathrm{w})^{*}$

\begin{tabular}{|l|l|l|l|}
\cline { 2 - 4 } \multicolumn{1}{c|}{} & \multicolumn{3}{l|}{ Desired concentration $(\mathrm{mM})$ or $\%(\mathrm{w} / \mathrm{w})$} \\
\hline Chelator type & $5 \mathrm{mM}$ or $0.18 \%$ & $10 \mathrm{mM}$ or $0.36 \%$ & $15 \mathrm{mM}$ or $0.54 \%$ \\
\hline EDTA & $108.1 \mathrm{~g}$ & $216.2 \mathrm{~g}$ & $324.4 \mathrm{~g}$ \\
\hline Chelator type & $5 \mathrm{mM}$ or $0.14 \%$ & $10 \mathrm{mM}$ or $0.28 \%$ & $15 \mathrm{mM}$ or $0.43 \%$ \\
\hline SCD & $85.4 \mathrm{~g}$ & $170.9 \mathrm{~g}$ & $256.3 \mathrm{~g}$ \\
\hline
\end{tabular}

*EDTA=Disodium Ethylene Diamine Tetraacetic Acid, SCD=Sodium Citrate Dihydrate

It is important to note that at the time of manufacturing, the \%moisture of the EDTA and SCD samples were not accounted for in the calculation of weight ( $\mathrm{g}$ ) of chelator to add to obtain desired concentration (mM). As EDTA was 10\% moisture and SCD was $13 \%$ moisture, the true concentrations of the samples are presented in the following table.

Table 3.3. True concentration $(\mathrm{mM})$ and $\%(\mathrm{w} / \mathrm{w})$ of each chelator type*

\begin{tabular}{|l|l|l|l|l|l|l|}
\hline Chelator type & \multicolumn{3}{|l|}{ Concentration $(\mathrm{mM})$} & \multicolumn{2}{l|}{$\%(\mathrm{w} / \mathrm{w})$} \\
\hline EDTA & 4.5 & 9.0 & 13.5 & 0.16 & 0.32 & 0.49 \\
\hline SCD & 4.3 & 8.8 & 13.2 & 0.12 & 0.25 & 0.37 \\
\hline
\end{tabular}

*EDTA=Disodium Ethylene Diamine Tetraacetic Acid, SCD=Sodium Citrate Dihydrate

After all the chelator was mixed into the milk, the mixture was stirred for an additional 2 minutes, then rehydrated for 30 minutes before the $\mathrm{pH}$ was adjusted. Another important factor in casein and chelator behavior is the $\mathrm{pH}$ level. The $\mathrm{pH}$ levels are affected by the 
addition of chelator. Chandan and Kilara (2008) note that the concentration causes transfer of calcium and phosphate to the colloidal phase of milk, causing a reestablishment of the mineral salt equilibria, with the release of hydrogen ions. For example, when $5 \mathrm{mM}$ of EDTA is added to a $10 \%$ reconstituted SMP system, the $\mathrm{pH}$ lowers to 6.36 from 6.68. Thus, it is important to adjust the $\mathrm{pH}$ of samples back to $6.65 \pm$ 0.05 after the addition of chelator.The $\mathrm{pH}$ was adjusted to ensure that the only difference between samples was the chelator. The addition of EDTA decreased $\mathrm{pH}$ while the addition of SCD increased $\mathrm{pH}$. The decrease in $\mathrm{pH}$ by EDTA may be due to the release of hydrogen ions as EDTA dissolves (Figure 2.3). Adding SCD initially increases the $\mathrm{pH}$ of the liquid skim milk. The general reaction producing this increased $\mathrm{pH}$ is thought to be due to destruction of the colloidal tricalcium phosphate by formation of the calcium complex salt and liberation of phosphate ions. Acid phosphate ions would be formed by ionic equilibria through uptake of protons and result in a concomitant $\mathrm{pH}$ rise (Odagiri and Nickerson, 1965).

Thus, the $\mathrm{pH}$ was adjusted to $6.65 \pm 0.05(6.60-6.70)$ by stirring in $70.0-1000.0 \mathrm{~mL}$ of 1.0 M Hydrochloric acid $(\mathrm{HCl})$ or 1.0 M Sodium Hydroxide $(\mathrm{NaOH})$. The $1.0 \mathrm{M}$ hydrochloric acid was prepared by diluting concentrated $(12.1 \mathrm{M}) \mathrm{HCl}$. A $1.0 \mathrm{~L}$ volumetric flask was filled almost to the top with DI water and $82.64 \mathrm{~mL}$ conc. $\mathrm{HCl}$ was added before filling the volumetric flask to the line with DI water. The $1.0 \mathrm{NaOH}$ was prepared in a $1.0 \mathrm{~L}$ volumetric flask that was filled with DI water. $40.0 \mathrm{~g}$ of $\mathrm{NaOH}$ pellets (Fisher Scientific Lot 146052) were dissolved before filling the volumetric flask to the line with DI water. After the $\mathrm{pH}$ was adjusted, each sample was rehydrated in a $2^{\circ} \mathrm{C}$ $\left(36^{\circ} \mathrm{F}\right)$ refrigerator overnight, for a minimum of 14 hours prior to use. 


\subsubsection{Evaporation into 40\% Total Solids Concentrate}

Before evaporation, the samples were stirred for 4 minutes to ensure homogenous solution prior to evaporation. Viscosity and $\mathrm{pH}$ were measured with a temperature range of $5.0 \pm 2.0^{\circ} \mathrm{C}$, as described in Section 3.2.2, to ensure no changes during storage. Each sample was introduced into the Custom rising film Marriot Walker Evaporator (Birmingham, MI) (Figure 3.4a).
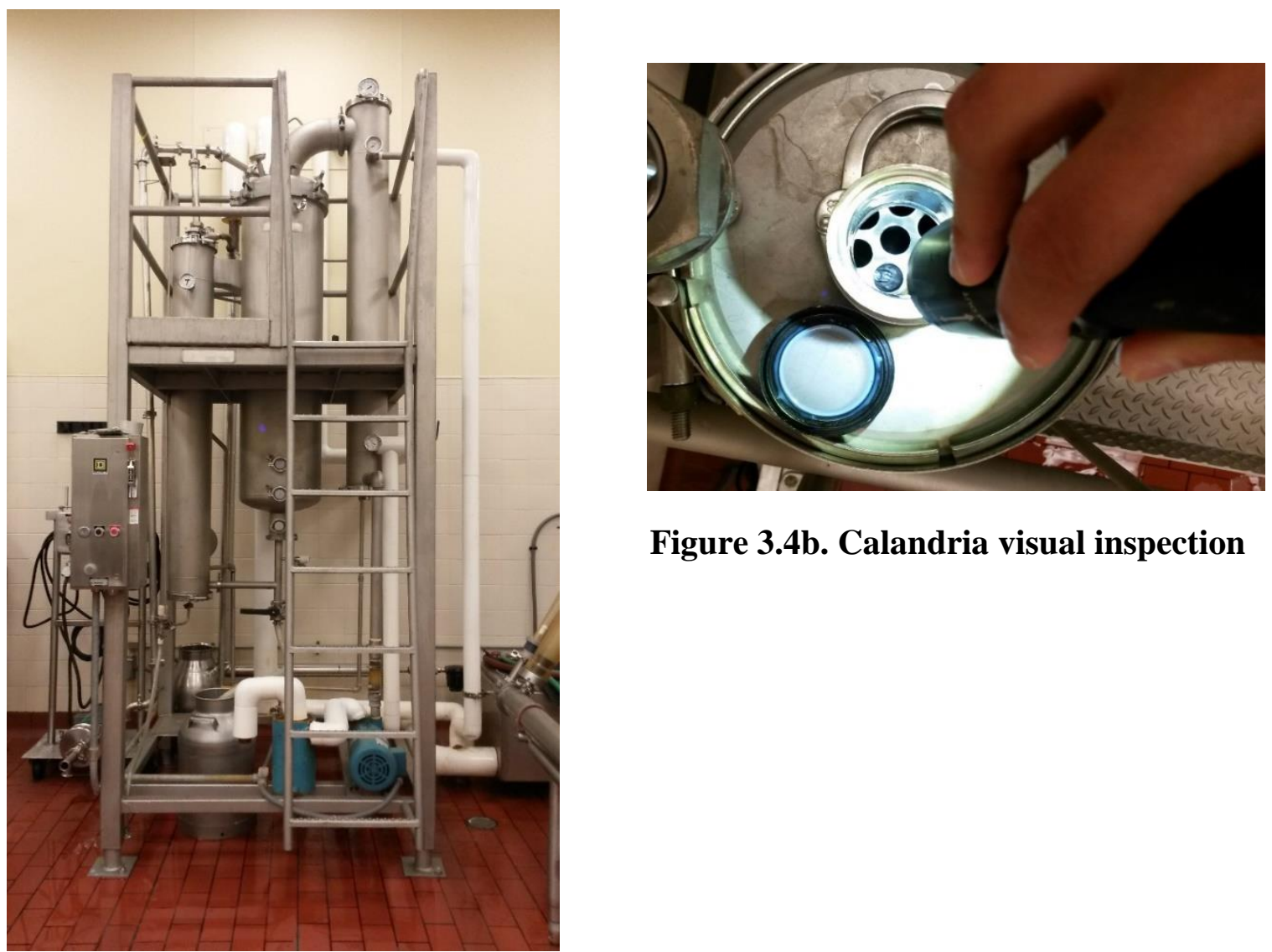

Figure 3.4b. Calandria visual inspection

Figure 3.4a. Custom rising film Marriot Walker Evaporator

The evaporation temperature was set at $49^{\circ} \mathrm{C}\left(120^{\circ} \mathrm{F}\right)$ and the vacuum pressure was 28 inHg. The process took about 3 minutes to stabilize the temperature although about 30 minutes were needed to pump all of the sample into the evaporator. Evaporation step was 
completed when the temperature began increasing, the level in the glass was getting low, and the boiling over slowed down. The evaporation process was completed in about 60 minutes. Prior to cleaning the evaporator, the calandria was visually inspected with a flashlight after each run to check for differences in fouling patterns (Figure 3.4b).

\subsubsection{Spray Drying into Powder}

Prior to spray drying, the $\%$ TS was measured and standardized to $40 \pm 1 \%$ as necessary with the softened pilot plant water. Also, the viscosity of the concentrate was checked with a temperature range of $39.0 \pm 2.0^{\circ} \mathrm{C}$, as described in Section 3.2.2. A Niro Filter Lab Spray Dryer (Figure 3.5) was used for the spray drying process, which took about 15 minutes for each trial.

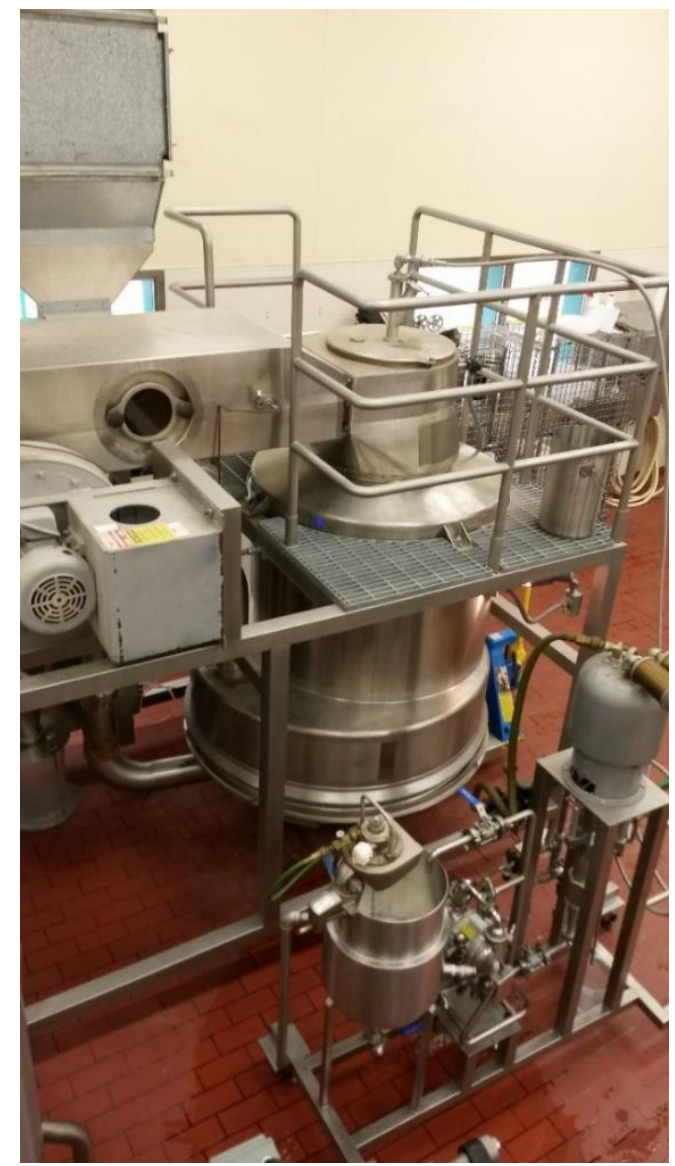

Figure 3.5. Niro Filter Lab Spray Dryer 
The feed rate was $500 \mathrm{psi}$, the inlet air temperature was $204 \pm 3.9^{\circ} \mathrm{C}\left(400 \pm 25^{\circ} \mathrm{F}\right)$, and the outlet air temperature was $82^{\circ} \mathrm{C}\left(180^{\circ} \mathrm{F}\right)$. The settings for the spray drying step are summarized in Table 3.3 below.

Table 3.4. Spray drying step operating parameters

\begin{tabular}{|c|c|}
\hline Operating variable & Setting \\
\hline Feed pressure & $500 \mathrm{psi}$ \\
\hline Inlet air temperature & $204 \pm 3.9^{\circ} \mathrm{C}\left(400^{\circ} \mathrm{F} \pm 25^{\circ} \mathrm{F}\right)$ \\
\hline Outlet air temperature & $82^{\circ} \mathrm{C}\left(180^{\circ} \mathrm{F}\right)$ \\
\hline Atomizer nozzle & Type SX, Orifice No. 67, Core No. 20 \\
& (Spraying Systems Co., Wheaton, IL) \\
\hline
\end{tabular}

Prior to collecting the powder from the spray dryer, the powder was allowed to cool in the cyclone to less than $38^{\circ} \mathrm{C}\left(100^{\circ} \mathrm{F}\right)$, or a minimum of 30 minutes.

\subsubsection{Cleaning Procedure}

For the evaporator, the cleaning procedure was to rinse out the system with warm water for about 20 minutes, caustic wash (Sodium Hydroxide $\mathrm{pH}>10$ ) for 60 minutes, rinse with water for 10 minutes, acid wash (Phosphoric Acid $\mathrm{pH}<4$ ) for 30 minutes, and rinse with water again for 15 minutes. The evaporating system was run prior to introduction of feed to reach temperature settings. For the spray dryer, the cleaning procedure was to rinse thoroughly with hot water until no traces of powder remain. The feed assembly was rinsed with hot water for 10 minutes, then a caustic wash (Sodium Hydroxide $\mathrm{pH}>10$ ) for 30 minutes, and rinsed for 10 minutes. The spray drying system was started up prior to introduction of feed to dry out system and reach equilibrium. After SMP production and cleaning procedure, system air dried overnight, minimum of 14 hours. 


\subsubsection{Powder Storage}

All powder was stored in 1-2 freezer gallon bags that were each about $3 / 4$ full. The freezer bag was placed in a Mylar bag at room temperature. The maximum temperature during transport/ storage was $30^{\circ} \mathrm{C}\left(86^{\circ} \mathrm{F}\right)($ ISO $707 \mid$ IDF 50:2014).

\subsection{Sampling Procedure}

\subsubsection{Preparation for Powder Sample}

Before opening each bag of powder for analysis, it was made more homogenous by shaking or by inverting container repeatedly (AOAC, 1995a). A clean, dry trier of stainless steel was passed steadily through powder at an even rate of penetration. When the trier reached the bottom of the container, the contents were withdrawn and discharged immediately into a sample container. Care was taken to not touch the powder with fingers, by wearing gloves (AOAC, 1995b). Care was also taken to avoid sampling on excessively hot or rainy days (i.e. when the temperature or humidity was high). If lumps were present, sample was sifted through a No. 20 sieve. The sample was rubbed through the sieve with gloved hands, and the sieve was tapped vigorously to obtain as much sample as possible (AOAC, 1995a).

\subsubsection{Preparation for 10\% Total Solids Reconstituted Sample}

Powder was prepared as in Section 3.3.1. The \%moisture data (procedure described in Section 3.4.1) was used to calculate the weight in grams to reach $10 \pm 0.1 \%$ Total Solids for each sample. An example calculation is seen in Equation 3 with Control Block 1, which had $4.4 \%$ moisture. 
Equation 3. Using \% moisture data to calculate the weight (g) to reach $10 \pm 0.1 \%$ Total Solids for a $50 \mathrm{~mL}$ reconstituted sample of Control Block 1 at $4.4 \%$ moisture

$[10 \% /(1.000-0.044)] /[100 \mathrm{~mL} / 50 \mathrm{~mL}]=5.2301 \mathrm{~g} \mathrm{SMP}+44.7699 \mathrm{~g}$ deionized water

Weighed out water was added to the weighed out powder in a $100 \mathrm{~mL}$ beaker. The mixture was stirred with a 1" stir bar at $700 \mathrm{rpm}$ for one hour. The sample was hydrated overnight in a $39^{\circ} \mathrm{F}$ refrigerator for a minimum of 14 hours. Prior to analysis, samples were brought to room temperature by stirring at $700 \mathrm{rpm}$ for 1.5 hours.

\title{
3.4 Powder Composition
}

\subsubsection{Percent Moisture}

Percent moisture was determined using Moisture in Dried Milk (AOAC, 1995c) and calculated using Equation 3 below. Measurements were carried out in duplicate.

\author{
Equation 4. To calculate percent moisture after vacuum oven \\ $\%$ moisture $=100-[100 \mathrm{x}$ (final sample weight $(\mathrm{g}) /$ original sample weight $)]$
}

\subsubsection{Percent Ash}

Percent ash was determined using Ash of Dried Milk (AOAC, 1995d) and calculated using Equation 4 below. Samples used for percent moisture could be further used to determine percent ash. Measurements were carried out in duplicate.

\section{Equation 5. To calculate percent ash after ash oven}

$$
\% \text { ash }=100-[100 \mathrm{x}(\text { Final sample weight }(\mathrm{g}) / \text { original sample weight })]
$$




\subsubsection{Percent Fat}

Percent fat method was determined using Fat in Dried Milk (AOAC, 1995e).

Measurements for selected samples were carried out in duplicate.

\subsubsection{Percent Protein}

Percent protein was determined using Protein in Dried Milk (AOAC, 1995f) with the Nitrogen (Total) in Milk, Block Digestor/ Steam Distillation Method (AOAC, 1995g). Measurements were carried out in duplicate.

\subsubsection{Percent Lactose}

Percent lactose was calculated as the difference $[100 \%-(\%$ moisture $+\%$ ash $+\%$ fat + \%protein)].

\subsection{Powder Size via Powder Particle Size Analysis (Powder PSA)}

A Beckman Coulter LS230 with powder module was used to measure the powder particle size distribution (Figure 3.6). The LS230 measures particle diameter from $0.4 \mu \mathrm{m}$ to 2000 $\mu \mathrm{m}$ by light diffraction of laser light at wavelength of $750 \mathrm{~nm}$. To measure particles 0.04 $\mu \mathrm{m}$ to $0.4 \mu \mathrm{m}$, the Polarization Intensity Differential Scattering (PIDS) mode was used. PIDS uses an incandescent tungsten-halogen lamp combined with three sets of polarized filters to provide light at the following wavelengths: $450 \mathrm{~nm}$ (blue), $600 \mathrm{~nm}$ (orange), and $900 \mathrm{~nm}$ (near-infrared, invisible).

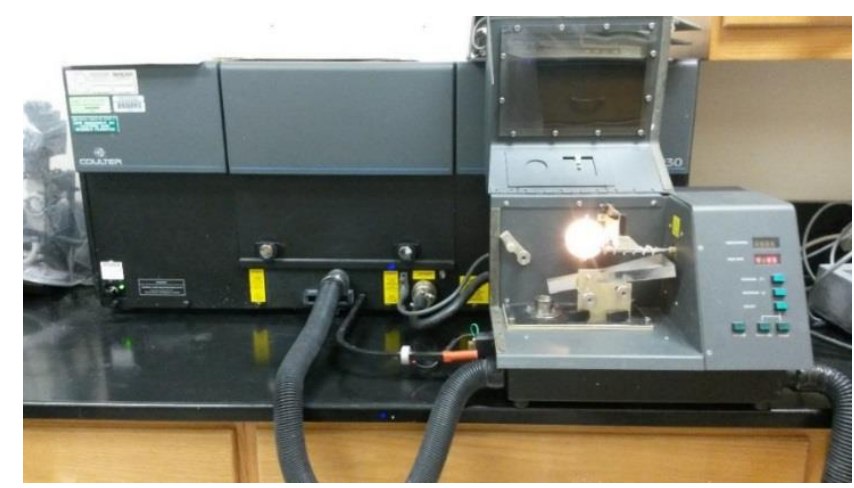

Figure 3.6. Particle size analyzer (PSA) with powder module 
The instrument was adjusted for electrical offsets, the laser was aligned, and the background was measured prior to each sample measurement. Sample was placed into the sifter with a spatula and entered the sample entry port by gravity and the vibrator was applied to maintain obscuration of 40-60\%. As it is difficult to describe a particle size distribution with a single number, the data was analyzed by comparing the volume mean diameter, the volume median diameter, and the overall shape of the Volume (\%) vs Particle Diameter distribution curve. $\mathrm{D}(4,3)(\mu \mathrm{m})$ is the volume mean diameter. Horiba Scientific (2014) explain the calculation of the volume mean diameter by imagining a histogram table showing the upper and lower limits of " $n$ " size channels along with the percent within this channel. The $\mathrm{D}_{\mathrm{i}}$ represents the geometric mean for each channel. $\mathrm{D}(4,3)$ is calculated by taking the $\mathrm{D}_{\mathrm{i}}$ to fourth power times the percent in that channel, summed over all the channels and taking the $\mathrm{D}_{\mathrm{i}}$ to the third power times the percent in that channel, summed over all the channels and dividing. This is shown in Equation 5.

\section{Equation 6. Calculation for the volume mean diameter, $D(4,3)($ Horiba Scientific, 2014)$$
D(4,3)=\frac{\sum_{1}^{n} D_{i}^{4} v_{i}}{\sum_{1}^{n} D_{i}^{3} v_{i}}
$$

The volume median diameter $(\mu \mathrm{m})$ represents a central point within the distribution. In other words, where half the population resides above this point and the other half falls below this point (Horiba Scientific, 2014). Measurements were carried out in duplicates.

\subsection{Rehydration Properties}

Forny et al. (2011) noted that in real reconstitution processes, the rehydration properties cannot be clearly isolated from the others. The following methods were developed to 
attempt to separately measure each rehydration property of wettability, sinkability, dispersibility, and solubility.

\subsubsection{Wettability}

\subsubsection{Contact Angle Method Overview}

Contact angle is a commonly used index for wetting behavior in pharmaceutical sciences. Contact angle is in terms of surface hydrophobicity, not exactly wettability (Crowley et al., 2015). This is because wettability usually defined as the water absorption on the SMP particle surface. This includes the ability of the powder particles to overcome the water surface tension (Fang, 2008).

Contact angle measures the initial contact of compressed powder with water, prior to the sinking, dispersion, and solubilization steps. A droplet of water falls $90^{\circ}$ to the normal onto the solid surface of a powder tablet. An interaction develops between the water and the surface molecules. If the interaction is strong, the water spreads across the surface but if the interaction is weak, the water will minimize surface contact. Contact angle measures this solid-liquid interface, where a smaller contact angle means that the interaction between the water and surface is strong, implying that the surface is more hydrophilic (Kim et al. 2002). The compression of powders into tablets minimized the influence of powder cake topography because the surface was more continuous and there were fewer air pockets between particles. 


\subsubsection{Preparation of Powder Tablets for Contact Angle Determination}

Measurements of contact angle were carried out on tablets of the powder samples.

Powder samples were compressed into tablets using a 12-ton hydraulic press (Figure 3.7a).

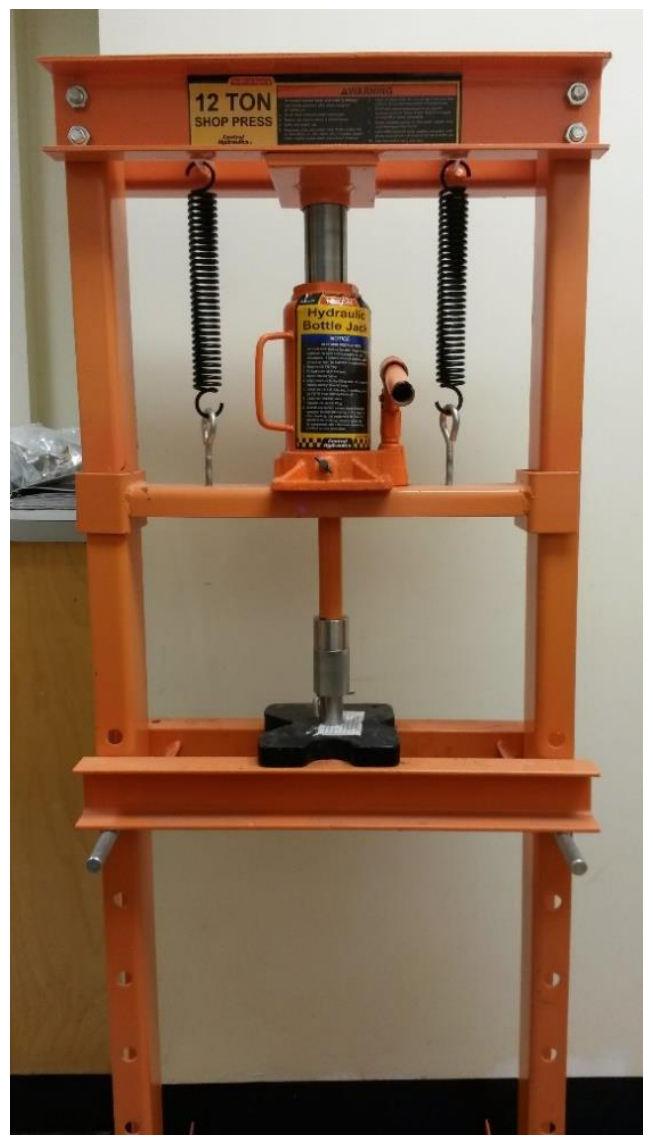

Figure 3.7a. 12 ton hydraulic press.

$2.5 \mathrm{~g}$ of powder was measured into the die. The crank was pumped, until it was aligned with the die and then the crank was pumped 16 times, until enough pressure was applied to compress the powders. At least 6 tablets were compressed per sample. 


\subsubsection{Contact Angle Measurement}

Once the tablet was made, one droplet of $5 \mu \mathrm{L}$ of deionized water was dropped onto the surface using a Microliter $® \# 710$ Pat.No. $293308770.1 \mathrm{~mL}$ syringe. Measurements were carried out in triplicate, where each measurement was a single droplet onto a different tablet. CAM 101 software (Figure 3.7b and Figure 3.7c) was used to take pictures. Contact angle was measured in degrees, and calculated every $990 \times 10^{-4}$ seconds for 40 frames (Figure 3.7c)

Figure 3.7b. Contact angle measurement set-up

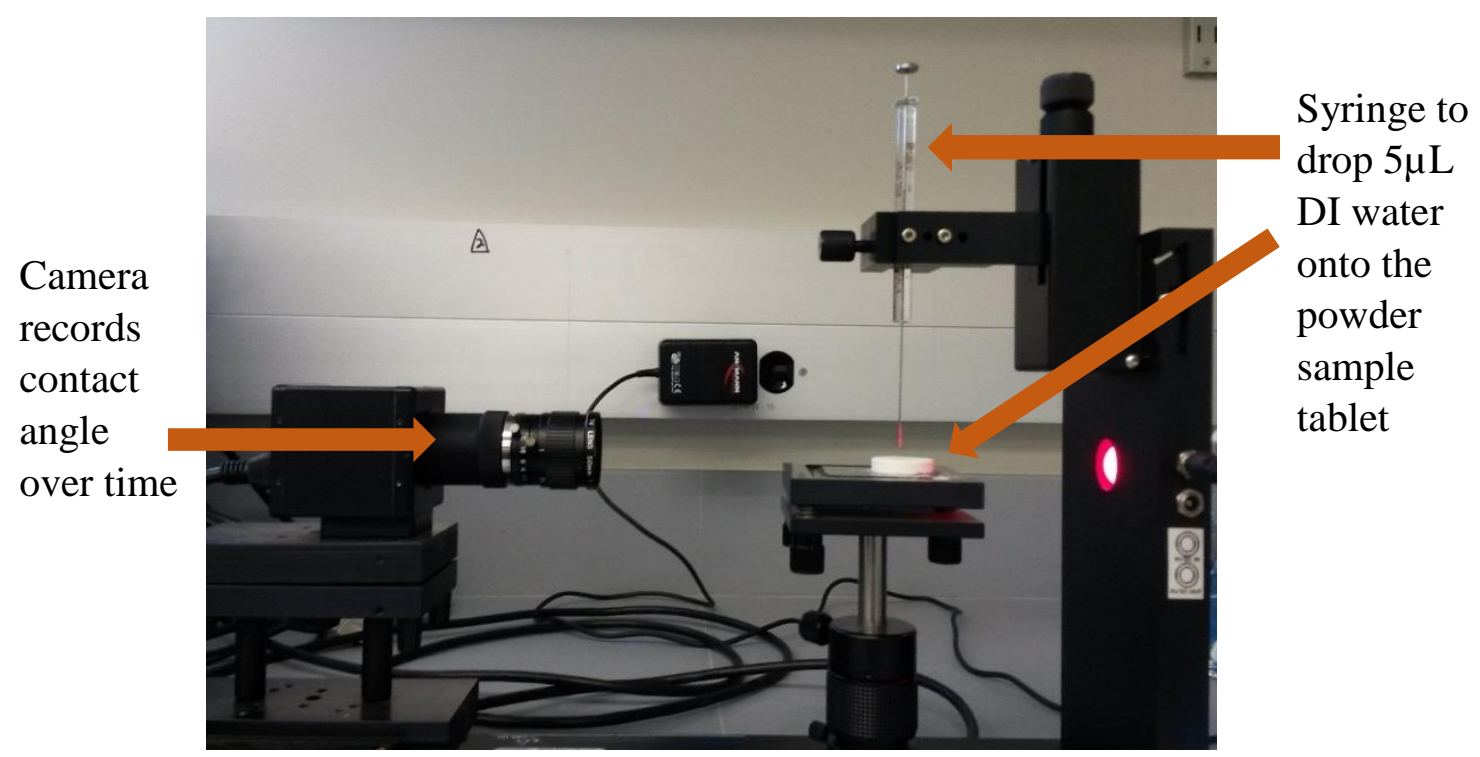




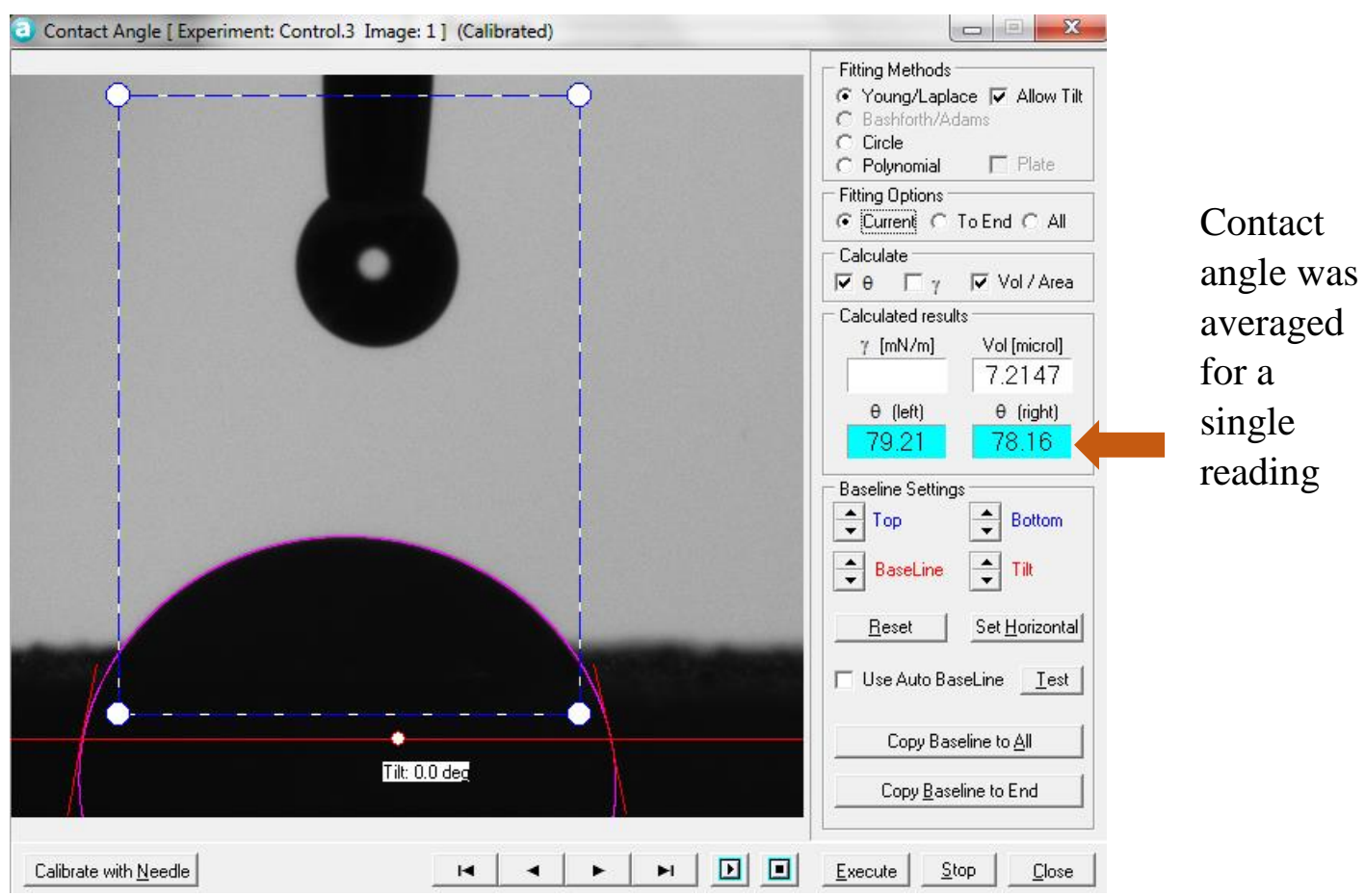

Figure 3.7c. Contact angle measurement software

Also seen in Figure 3.7c, the contact angle was measured for the right side and the left side; the single reading in degrees $\left(^{\circ}\right)$ taken for this study was the median of the two.

\subsubsection{Wettability and Sinkability}

\subsubsection{Modified IDF Wettability Method}

The wettability and sinkability method was modified from the Determination of the wettability (wetting time) of instant dried milk procedure set forth by ISO and IDF, Annex B (2014). The modification was the sample preparation. It was noted that the powder sample would form a film along the water surface and not wet nor sink in a timely manner ( $\leq 12$ hours). Freudig (1999) notes that there are issues in sinkability if there are very fine particles, if the particles are hollow from the spray drying process, or if swelling occurs in the wetting stage. Thus, to correct for the possibility of one of these issues, a 2" stir bar was placed at the bottom and set to $450 \mathrm{rpm}$. This speed was selected 
to ensure no incorporation of air or formation of bubbles. Furthermore, $300.0 \mathrm{~g}$ deionized water were weighed into a $600.0 \mathrm{~mL}$ beaker instead of $250.0 \mathrm{~mL}$ also to ensure no incorporation of air. Figure 3.8 is a visual of the experimental setup.

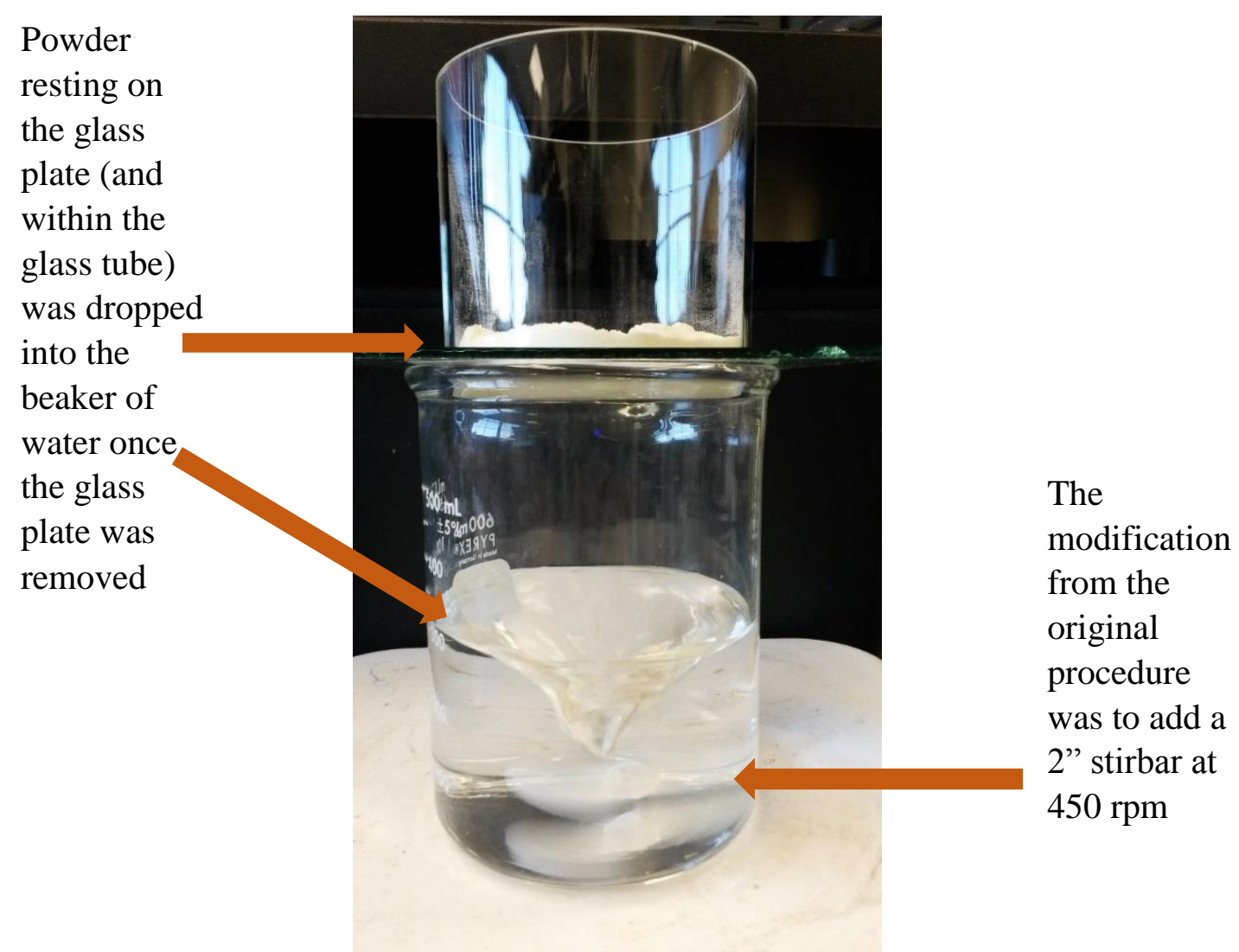

Figure 3.8. Set up for modified IDF wettability method

The wettability time was defined as the time once all the powder was wetted, i.e. sunk below the surface of the water and any remaining on the surface assumed a typical "wet" appearance. The wettability time (in seconds) was the time once all the powder was wetted minus the initial 60 second wait period. Duplicates were carried out for each sample. 


\subsubsection{Dispersibility}

\subsubsection{Dissolution Rate}

Dissolution rate can provide insight on the dispersibility of powders since good dispersbility is seen when powders in water are distributed as single particles, leaving no lumps. For example, after the addition of powder to water, a powder would disperse into smaller particles and saturate the water, thereby increasing the optical density over time, known as dissolution rate. A treated powder with higher dispersibility might be indicated by a higher dissolution rate, as the powder is able to disperse and saturate the water at a faster rate, thus increasing the optical density over less time (compared to the behavior of a control powder). The dissolution rate method used in this study was modified from the method used by Millqvist-Fureby et al. (2001). The dissolution rate was observed with the Ocean Optics USB 4000 spectrophotometer/ Spectra Suite (Figure 3.9).

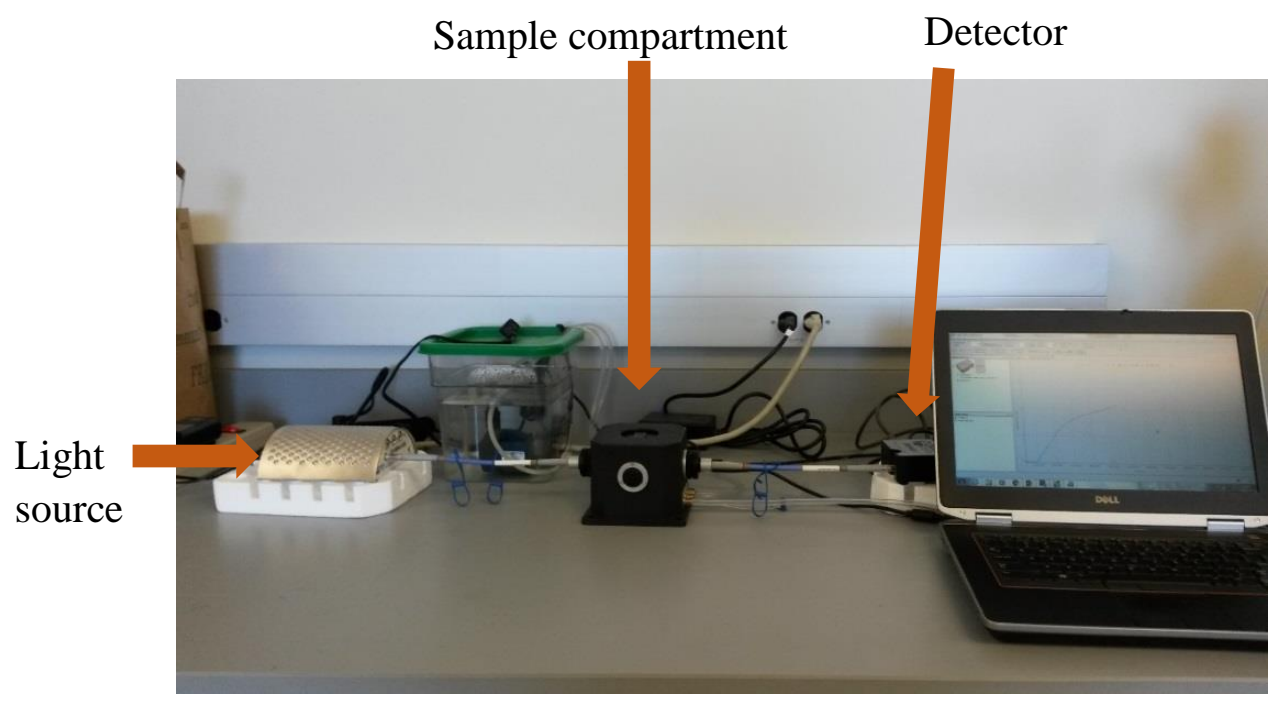

Figure 3.9. Dissolution rate measurement set-up

A powder sample of $20.0 \pm 0.5 \mu \mathrm{g}$ powder was carefully dropped into a cuvette $(1 \mathrm{x} 1 \mathrm{~cm}$ cross section), which contained $1.75 \mathrm{~mL}$ DI water at room temperature and a stirbar at 
$1400 \mathrm{rpm}$. The rate of dissolution was observed as optical density per second (O.D./ sec) and was calculated as shown in Equation 6.

\author{
Equation 7. Rate of dissolution calculation \\ Rate of dissolution $=\frac{[\text { Optical density (O.D.) }]}{[\text { time }(\text { seconds })]}$
}

The integration time was set to 10 milliseconds. The scans to average was set to 5 . The boxcar width was set to 4 . The wavelength was set at $620.13 \mathrm{~nm}$ as it is long enough to measure light scattering with minimal absorption. The slope (O.D./second) was calculated and compared to the control in order to determine if any of the experimental treatments showed a higher or lower rate of dissolution. Samples were completed in duplicate.

\title{
3.6.4 Solubility
}

\subsubsection{Reconstituted Particle Size Analysis}

Mimouni et al. (2009) noted that measuring changes in particle size during powder rehydration mostly used a single mean diameter which was not reflective of the sample as a whole. Thus, Mimouni et al. (2009) monitored the particle size distribution in volume as a function of time. Similar to the methods for particle size analysis for powder samples in this study as described in Section 3.6.5, the particle size analysis of the reconstituted samples in this study were measured as $\mathrm{D}(4,3)$, median, and the overall shape of the Volume (\%) vs Particle Diameter distribution curve. The three measurements taken from the reconstituted samples after a rehydration period of at least 14 hours, which can be seen as the final solubilization stage. Similar work was carried out by Crowley et al. 
(2015). Crowley et al. (2015) employed liquid PSA measurements for particle size distribution measurements in milk protein concentrate suspensions after rehydration for 90 minutes and compared to the particle size distribution measurements after 24 hours. Sample was prepared as a $10 \%$ TS solution, rehydrated overnight for a minimum of 14 hours. Liquid particle size analysis was carried out with the Beckman Coulter LS230 with liquid module. The instrument adjusted for electrical offsets, the laser was aligned, and the background was measured prior to each sample measurement. The samples were placed into the loading cell with a pipette and entered the sample entry port to maintain obscuration of 40-45\%. Light passed through the sample cell stand during measurement. Data were analyzed by comparing $\mathrm{D}(4,3)(\mu \mathrm{m})$, median $(\mu \mathrm{m})$, and the overall shape of the particle size distribution pattern (Volume vs Diameter). Measurements were carried

out in triplicates. All samples were compared to the measurements for the control in order to determine which sample had higher or lower end point solubility.

\subsubsection{Modified Solubility Index}

Solubility index is a commonly used procedure to measure the solubility of dried milk. In general, the procedure is to mix powder sample with water and centrifuge the reconstituted mixture. The solubility index is the volume of sediment (in $\mathrm{mL}$ ). Since the solubility index measures the insoluble portion of the reconstituted mixture, the method has sometimes been termed "Insolubility index." Thus, higher levels for the solubility index method indicate lower solubility.

The solubility analysis method used for this study was a modified procedure from the one set forth by the Solubility Index Procedure Standards for Grade of Dry Milks (ADPI, 2009). The modification was the sample preparation. It was noted that the powder sample 
would stick to the walls of the blender jar, and lead to inaccurate and inconsistent results. Thus, the powder was reconstituted as follows.

On day 1 , the order of sample preparation was randomized. $50 \mathrm{~mL}$ of a $10 \% \mathrm{w} / \mathrm{w} \mathrm{TS}$ solution of each solution in a $100.0 \mathrm{~mL}$ beaker was prepared, adding DI water into the powder sample. Each mixture was stirred with a thin spatula to ensure that the powder was mixed with the water, not stuck to the sidewall, etc. Then, a one-inch stir bar was used to remove sample from the spatula and the sample was then stirred at $700 \mathrm{rpm}$ for 60 minutes. The samples were stored in the $4^{\circ} \mathrm{C}\left(39^{\circ} \mathrm{F}\right)$ refrigerator overnight for a minimum of 14 hours.

On day 2, the samples were brought to room temperature by stirring at $700 \mathrm{rpm}$ for at least 90 minutes but no more than 2 hours. Then, the standard solubility index procedure was adhered to for the remaining steps. As the Eppendorf Centrifuge $5810 \mathrm{R}$ radius was 13 inches in diameter, the centrifuge settings were $940 \mathrm{rpm}$ at $20^{\circ} \mathrm{C}$ for 5 minutes, both ramp (up and down) set at max at level 9. Each sample was measured to the nearest 0.1 mL. Measurements were completed in duplicate.

\subsubsection{Calcium and Phosphorous Behavior}

\subsubsection{Inductively Coupled Plasma Optical Emission Spectrometry (ICP-OES)}

In addition to analyzing any differences that the addition of chelators to SMP may have on rehydration properties, it was important to note the effect of the chelators on the system and the mechanism to which the chelators may be influencing the changes in rehydration properties. Thus, ICP-OES results may provide insight on the behavior of the chelators. For example, Udabage et al. (2000) found in their work that a high level of non-pelleted calcium was approximately equal to the amount of added EDTA. Thus, by 
analyzing the calcium behavior, it was possible to elucidate the effect of the chelators. The calcium behavior was measured via inductively coupled plasma optical emission spectrometry (ICP-OES). Phosphorus was also measured as about half of the phosphorus is in the micelle, in a calcium-phosphate bridge.

The total phosphorus and total calcium (in $\mathrm{mg} / \mathrm{L}$ ) was measured for each reconstituted sample. The serum phosphorus and serum calcium (in $\mathrm{mg} / \mathrm{L}$ ) was measured for each centrifuged reconstituted sample (Udabage, 2000). Measuring both the total and serum levels allowed for calculation for \%soluble, as shown in Equation 7 below.

\section{Equation 8. Calculation of \% soluble Calcium or \%soluble Phosphorus}

$$
\% \text { soluble Calcium (or Phosphorus) }=\frac{\left[\operatorname{serum} \text { Calcium }\left(\frac{\mathrm{mg}}{\mathrm{L}}\right)\right]}{\left[\operatorname{total} \text { Calcium }\left(\frac{\mathrm{mg}}{\mathrm{L}}\right)\right]}
$$

ICP-OES is a rapid and precise technique to monitor trace elements. This study utilized the Horiba Scientific Ultima 2 for the measurements (Figure 3.10).

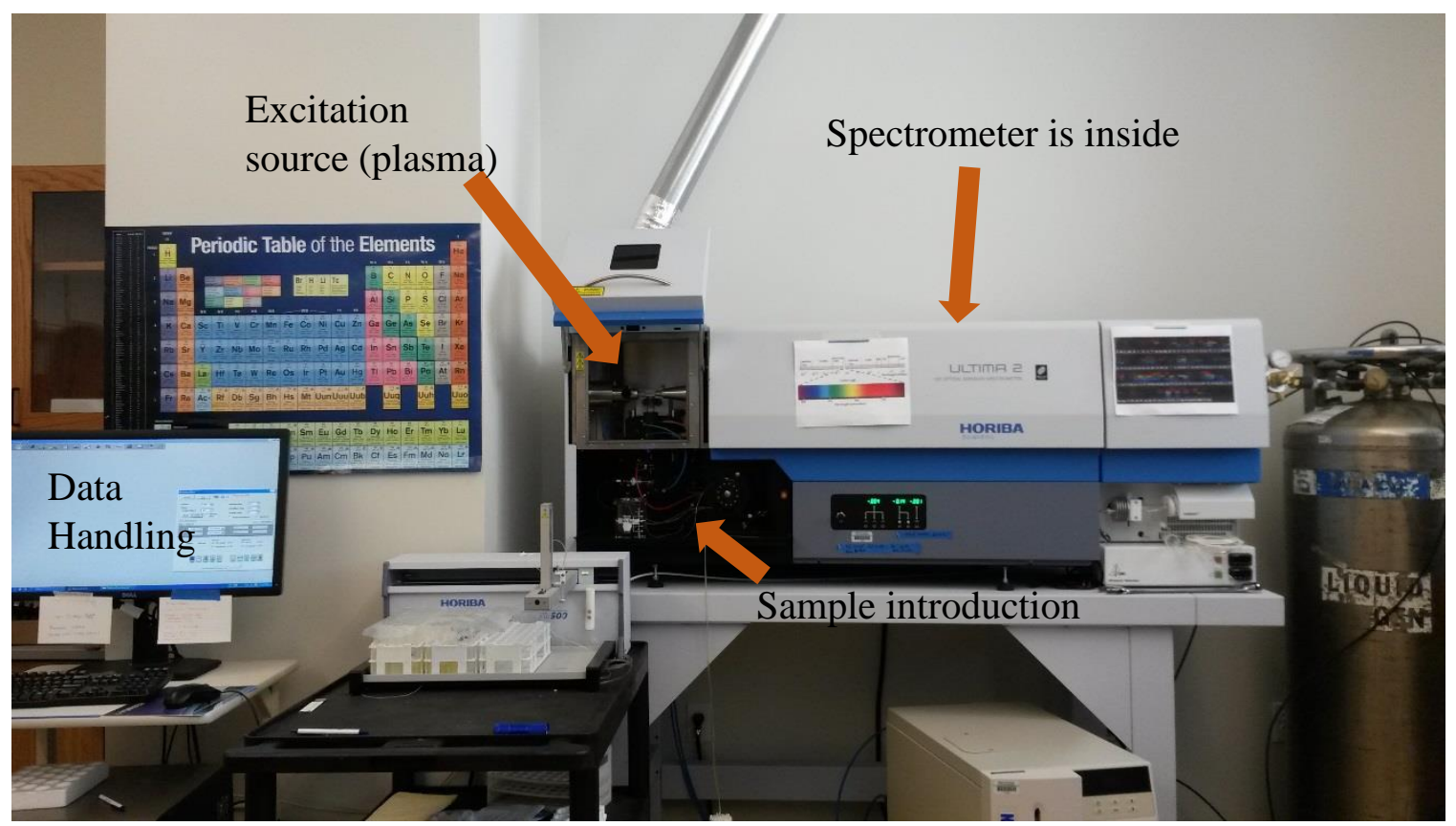

Figure 3.10. ICP-OES measured with Horiba Scientific Ultima 2 
Inductively coupled plasma (ICP) is the source to excite electrons in samples. Optical emission spectrometry (OES), sometimes known as atomic emission spectrometry (AES), separates the emitted light from the ICP to discrete wavelength. Since each element in the periodic table has its own set of emission wavelengths, the output is compared and the mass fraction of the desired element in the sample can be calculated (Boss and Fredeen, 2004). In this study, Calcium (Ca) and Phosphorous (P) were the desired elements.

Figure 3.11 shows a basic diagram of how ICP-OES works.

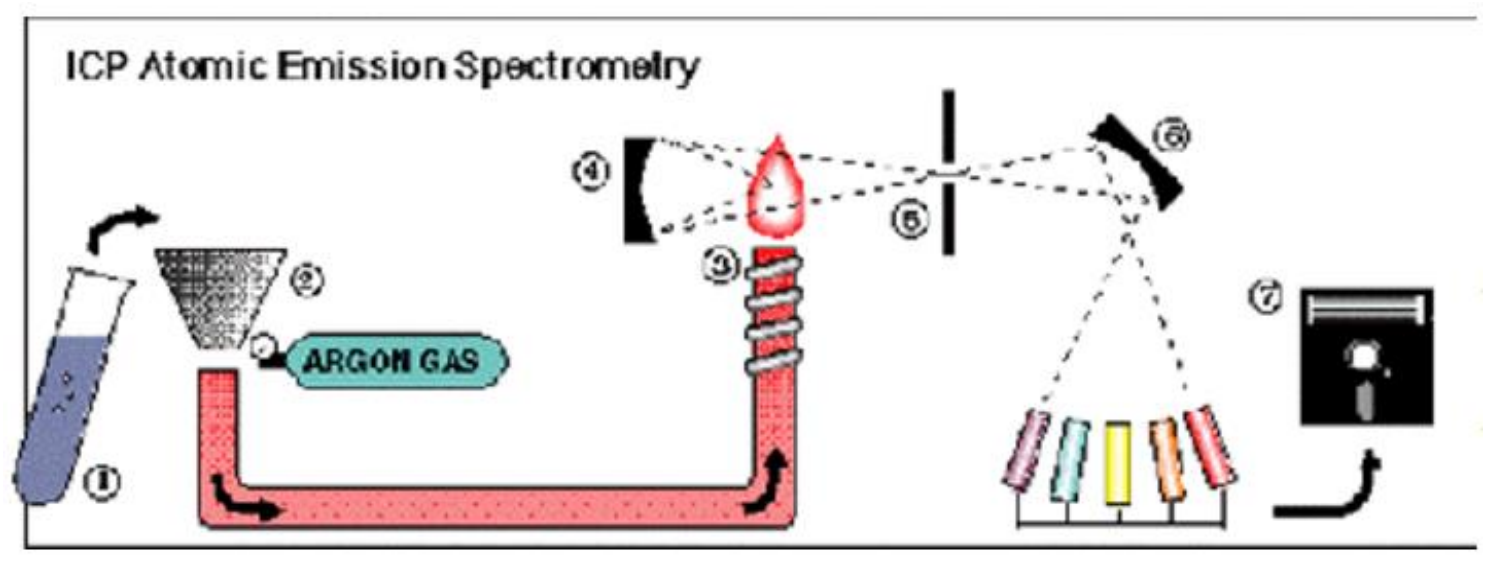

Figure 3.11. Diagram of ICP-OES (USGS, 2013)

In general, ash is collected from the samples and mixed with $0.4 \%$ nitric acid. This solution is atomized into a mist that reacts with a stream of argon gas into the argon plasma, reaching temperatures up to $7,000^{\circ} \mathrm{C}$. At this temperature, the outer-shell electrons of the elements in the sample are excited and emit light wavelengths which are characteristic of the respective element. The spectrometer for the Horiba Scientific Ultima 2 uses a 1-meter optical pathway with dual monochromator gratings to separate the emitted wavelengths onto the photomultiplier tube (PMT) detector. The detector reads the wavelengths and respective intensity sequentially. The intensity of the light dictates the concentration of each desired element. Thus, this signal is converted through a 
calibration curve by the computer to produce the concentration of each element in the ash of the samples (USGS, 2013). Overall, the data from ICP-OES can help elucidate the concentration of the calcium between the serum and the colloid and possibly provide insight as to the effects of the chelators on the skim milk mineral system.

The calibration standards for ICP-OES for Calcium $(\mathrm{Ca})$ and Phosphorus $(\mathrm{P})$ were prepared using an ICP Certified Ca standard of $1000 \mathrm{mg} / \mathrm{L}(1000 \mathrm{mg} / \mathrm{L}$ Ca Lot 18 85CAY by SPEX CertiPrep, Metuchen, NJ) or ICP Certified P standard of 1000 ppm (Phosphorus for ICP - CGP1-1 by Inorganic Ventures, Christiansburg, VA).

Three 1.0 L volumetric flasks of diluted nitric acid $\left(\mathrm{HNO}_{3}\right)$ were prepared by adding 4.0 $\mathrm{mL}$ concentrated $\mathrm{HNO}_{3}$ into a $1.0 \mathrm{~L}$ volumetric flask and diluted with deionized water to make a $0.4 \%$ solution. (AOAC 991.25).

The P calibration standards were $0,5,10,25,50,75,100 \mathrm{ppm}$. The standards were made by adding $0.0,0.5,1.0,2.5,5.0,7.5$, or $10.0 \mathrm{~mL}$ of the $\mathrm{P}$ standard into $100.0 \mathrm{~mL}$ volumetric flasks and diluting with $0.4 \% \mathrm{HNO}_{3}$. The Ca calibration standards were $0,5,25,50,100,150,200 \mathrm{ppm}$. The standards were made by adding $0.0,0.5,2.5,5.0,10.0,15.0$, or $20.0 \mathrm{~mL}$ of the $\mathrm{C}$ standard into $100.0 \mathrm{~mL}$ volumetric flasks and diluting with $0.4 \% \mathrm{HNO}_{3}$.

It took three days to prepare each sample and testing was on the fourth day, with the procedure as outlined below (AOAC 984.27; AOAC 991.25; AOAC 645.46). On day 1, samples were randomized for order of preparation and prepared in triplicates. $80.0 \mathrm{~mL}$ of $10 \% \mathrm{w} / \mathrm{w}$ TS solutions of each sample was prepared by reconstituting water into powder and stirring at $700 \mathrm{rpm}$ for 1 hour. The samples were stored in the $4^{\circ} \mathrm{C}\left(39^{\circ} \mathrm{F}\right)$ refrigerator overnight, for a minimum of 14 hours. On day 2, the samples were stirred at $700 \mathrm{rpm}$ for 
1.5 hours. For total $\mathrm{P}$ or $\mathrm{Ca}, 5.0 \mathrm{~g}$ was weighed into a crucible. For soluble $\mathrm{P}$ or $\mathrm{Ca}$, at least $40 \mathrm{~mL}$ of sample was centrifuged at 18,000 rpm (test tube maximum $=39,000 \mathrm{x} \mathrm{g}$ ) for 60 minutes at $4^{\circ} \mathrm{C} .5 .0 \mathrm{~g}$ of supernatent was carefully pipetted into a crucible. All samples were placed in a vacuum oven with vacuum at $25 \mathrm{inHg}$ at $100^{\circ} \mathrm{C}$ for 4 hours. Then, all samples were placed in an ash oven at $525^{\circ} \mathrm{C}$ overnight, minimum of 16 hours. On day 3 , the ash oven was turned off and allowed to cool to $100^{\circ} \mathrm{C}(\sim 4.5$ hours). Samples were transferred to a dessicator and cooled to room temperature for 30 minutes. An addition of $0.2 \mathrm{~mL}$ concentrated $\mathrm{HNO}_{3}$ was made to each container to dissolve the ash. Finally, the mixture was transferred to a $50.0 \mathrm{~mL}$ volumetric flask and diluted to volume with diluted $(0.4 \%) \mathrm{HNO}_{3}$. On day 4 , the operating parameters for ICP-OES were as follows: for P, wavelength $213.618 \mathrm{~nm}$ and for Ca, wavelength $317.993 \mathrm{~nm}$. An initial calibration was performed for each element using the previously mentioned standards. A minicalibration was performed after every 10 samples to correct for the drift in measurement over time. The minicalibration included measuring the $50 \mathrm{ppm} \mathrm{P}$ calibration standard and the 100 ppm Ca calibration standard. Then, the instrument would adjust the calibration curve to account for drift over time. Four duplicates were also added at the end to remeasure the four samples and ensure consistency. All measurements were in $\mathrm{mg} / \mathrm{L}$. 


\section{CHAPTER 4: RESULTS AND DISCUSSION}

\subsection{Powder Making Process Observations}

Prior to treatment, the fat free milk was a steady $\mathrm{pH}$ of $6.75 \pm 0.02$ over the two weeks, per block. The \% total solids (\%TS) was $9.66 \pm 0.22 \% \mathrm{TS}$. Thus, the quality of the milk was deemed suitable and consistent.

All treatments within each block were produced from the same milk supply. All treatments were evaporated to $40 \pm 1 \% \mathrm{TS}$ at a temperature $38 \pm 2^{\circ} \mathrm{C}$.

Post evaporation, the calandria was visually inspected with a flashlight to check for differences in fouling patterns. No fouling was observed for any treatment.

For spray drying, the outlet air temperature was set to $82^{\circ} \mathrm{C}\left(180^{\circ} \mathrm{F}\right)$. For this spray dryer, only the outlet air temperature could be controlled. The inlet air temperature was maintained by the outlet air temperature setting, the feed rate, the \% TS of the concentrate, and the overall composition of the concentrate. Since the feed rate, \%TS, and overall composition of the concentrate was as uniform as possible, the outlet temperature had to be adjusted at times to $85^{\circ} \mathrm{C}\left(185^{\circ} \mathrm{F}\right)$ to maintain the inlet air temperature. The burner heated the intake air to about $204^{\circ} \mathrm{C}\left(400^{\circ} \mathrm{F}\right)$. The hot air entered the top of the drying chamber, and pulled out at the bottom of the chamber and exhausted as the air cooled. The inlet air temperature range was usually $193-204^{\circ} \mathrm{C}\left(380-400^{\circ} \mathrm{F}\right)$. However, for each control treatment in each block, the range was slightly but noticeably lower, at $191-202^{\circ} \mathrm{C}\left(375-395^{\circ} \mathrm{F}\right)$.

\subsection{Powder Composition}

Percent composition was measured for the powder samples (Table 4.1). Note that only a selection of samples was used to find the full percent composition. 
Table 4.1. Mean \pm standard error (S.E.) of the percent composition of the experimental SMPs*

\begin{tabular}{|c|c|c|c|c|c|c|c|c|c|c|}
\hline \multirow[b]{2}{*}{ Treatment } & \multicolumn{5}{|c|}{ Block 1} & \multicolumn{5}{|c|}{ Block 2} \\
\hline & Moisture & Ash & Fat & Protein & Lactose & Moisture & Ash & Fat & Protein & Lactose \\
\hline Control & $4.40 \pm 0.36$ & $7.31 \pm 0.01$ & $\begin{array}{c}1.26 \pm \\
0.21\end{array}$ & $34.7 \pm 0.2$ & 52.33 & $3.43 \pm 0.36$ & $7.55 \pm 0.01$ & $\begin{array}{c}0.99 \\
\pm 0.21\end{array}$ & $34.9 \pm 0.2$ & 53.13 \\
\hline $\mathrm{SCD} 5 \mathrm{mM}$ & $4.54 \pm 0.33$ & $7.83 \pm 0.01$ & 1 & $34.5 \pm 0.2$ & 2 & $3.63 \pm 0.33$ & $8.08 \pm 0.01$ & 1 & $33.8 \pm 0.2$ & 2 \\
\hline SCD 10mM & $4.15 \pm 0.18$ & $8.48 \pm 0.04$ & 1 & $33.8 \pm 0.1$ & 2 & $4.27 \pm 0.18$ & $8.65 \pm 0.04$ & 1 & $33.9 \pm 0.1$ & 2 \\
\hline SCD $15 \mathrm{mM}$ & $4.06 \pm 0.27$ & $9.45 \pm 0.17$ & 1 & $33.3 \pm 0.1$ & 2 & $4.36 \pm 0.27$ & $9.36 \pm 0.17$ & 1 & $33.4 \pm 0.1$ & 2 \\
\hline EDTA $5 \mathrm{mM}$ & $4.52 \pm 0.10$ & $8.96 \pm 0.14$ & 1 & $35.8 \pm 0.2$ & 2 & $4.07 \pm 0.10$ & $8.03 \pm 0.14$ & 1 & $35.2 \pm 0.2$ & 2 \\
\hline EDTA $10 \mathrm{mM}$ & $4.61 \pm 0.10$ & $8.10 \pm 0.67$ & 1 & $34.6 \pm 0.4$ & 2 & $4.23 \pm 0.07$ & $8.63 \pm 0.67$ & 1 & $36.3 \pm 0.4$ & 2 \\
\hline EDTA $15 \mathrm{mM}$ & $3.91 \pm 0.40$ & $7.70 \pm 0.59$ & 1 & $36.0 \pm 0.1$ & 2 & $4.47 \pm 0.40$ & $9.28 \pm 0.59$ & 1 & $35.9 \pm 0.1$ & 2 \\
\hline
\end{tabular}

Data shown as mean \pm standard error (S.E.)

*EDTA $=$ Disodium Ethylene Diamine Tetraacetic Acid, SCD = Sodium Citrate Dihydrate

${ }^{1}$ Denotes that the \%fat was not measured for the sample.

${ }^{2}$ Denotes that the \%lactose could not be calculated since the \%fat was not measured for the sample.

Pooled standard error for $\%$ moisture $=0.10$, Pooled standard error for $\%$ ash $=0.13$, Pooled standard error for $\%$ protein $=0.2$

Differences in \%composition properties were seen in Table 4.1. For example, the sample with the smallest mean amount of protein was SCD $15 \mathrm{mM}$ Block 1 at $33.3 \%$ while the sample with the largest mean amount of protein was EDTA $10 \mathrm{mM}$ Block 2 at $36.3 \%$. Differences may be due to differences in initial weighing of liquid fat free milk sample. Moreover, the Kjeldahl method, which was used to measure \%protein includes non-protein nitrogen in its measurement, such as the extra amine's in EDTA and in urea, which could lead to slightly inaccurate results. 


\subsection{Powder Size via Powder Particle Size Analysis (Powder PSA)}

The physical property of the powders in term of particle size may have an effect on the rehydration properties, specifically wettability. For example, Kim et al. (2002) noted that wetting may be higher for powders with large particles that contain large pores. Table 4.2 shows the mean and standard error (S.E.) for the volume mean diameter $(\mathrm{D} 4,3)$ and the volume median diameter of the powder particle size distribution.

Table 4.2. Mean and standard error (S.E.) of the volume mean diameter $(D 4,3)(\mu \mathrm{m})$ and volume median diameter $(\mu \mathrm{m})$ of the powder particle size distribution for each treatment powder, separated by block*

\begin{tabular}{|r|cc|cc|cc|cc|}
\cline { 2 - 9 } \multicolumn{1}{c|}{} & \multicolumn{4}{c|}{ Block 1 } & \multicolumn{4}{c|}{ Block 2 } \\
\cline { 2 - 9 } \multicolumn{1}{c|}{} & \multicolumn{1}{c|}{$\mathrm{D}(4,3)(\mu \mathrm{m})$} & \multicolumn{2}{c|}{ Median $(\mu \mathrm{m})$} & $\mathrm{D}(4,3)(\mu \mathrm{m})$ & \multicolumn{2}{c|}{ Median $(\mu \mathrm{m})$} \\
\hline Treatment & Mean & S.E & Mean & S.E & Mean & S.E & Mean & S.E \\
\hline Control & $14.88^{\mathrm{a}}$ & 0.41 & $39.99^{\mathrm{a}}$ & 0.05 & $17.96^{\mathrm{a}}$ & 0.08 & $49.84^{\mathrm{a}}$ & 0.11 \\
\hline $5 \mathrm{mM}$ & $16.21^{\mathrm{b}}$ & 0.10 & $47.02^{\mathrm{b}}$ & 0.40 & $19.12^{\mathrm{b}}$ & 0.04 & $51.21^{\mathrm{b}}$ & 0.199 \\
SCD 10mM & $17.13^{\mathrm{b}}$ & 0.33 & $45.75^{\mathrm{a}}$ & 2.26 & $18.79^{\mathrm{b}}$ & 0.37 & $51.02^{\mathrm{a}}$ & 0.94 \\
$15 \mathrm{mM}$ & $18.45^{\mathrm{b}}$ & 0.25 & $51.13^{\mathrm{b}}$ & 0.77 & $19.92^{\mathrm{b}}$ & 0.13 & $54.48^{\mathrm{b}}$ & 0.04 \\
\hline $5 \mathrm{mM}$ & $16.56^{\mathrm{a}}$ & 0.27 & $46.35^{\mathrm{b}}$ & 1.67 & $18.20^{\mathrm{a}}$ & 0.12 & $51.56^{\mathrm{b}}$ & 0.08 \\
EDTA 10mM & $17.28^{\mathrm{b}}$ & 0.06 & $48.75^{\mathrm{b}}$ & 1.09 & $18.79^{\mathrm{b}}$ & 0.24 & $54.51^{\mathrm{b}}$ & 0.66 \\
$15 \mathrm{mM}$ & $16.53^{\mathrm{a}}$ & 0.10 & $46.24^{\mathrm{a}}$ & 0.29 & $17.59^{\mathrm{a}}$ & 0.05 & $47.65^{\mathrm{a}}$ & 0.23 \\
\hline
\end{tabular}

*EDTA=Disodium Ethylene Diamine Tetraacetic Acid, SCD=Sodium Citrate Dihydrate ${ }^{a, b}$ Different superscripts denote results that are statistically significantly different from the control according to Dunnett procedure with a family wise error rate of $\alpha=0.05$ Pooled standard error for $\mathrm{D}(4,3)=0.25$

Pooled standard error for Median $=0.89$

For $\mathrm{D}(4,3)$, analyzing all the data with a two-way ANOVA on JMP obtained a treatment $\mathrm{p}$-value of $<0.0001$. This $\mathrm{p}$-value reflected that there is a significant difference in mean $\mathrm{D}(4,3)$ between some of the treatment powders compared to the control. With Dunnett procedure, all the treatments were compared to the control. SCD $15 \mathrm{mM}, \mathrm{SCD} 10 \mathrm{mM}$, SCD $5 \mathrm{mM}$, and EDTA $10 \mathrm{mM}$ had significant differences in $\mathrm{D}(4,3)$ compared to the 
control. The 95\% confidence intervals were constructed to analyze the average amount by which treatments would differ from the control mean volume mean diameter. The interval for SCD $15 \mathrm{mM}$ had the largest increase and was in the range of increasing the control mean volume mean diameter by between $1.78 \mu \mathrm{m}$ and $3.75 \mu \mathrm{m}$. Higher mean volume mean diameters compared to control may be seen as higher wettability. For the volume median diameter, analyzing the data with a two-way ANOVA on JMP obtained a treatment $\mathrm{p}$-value of $<0.0001$. This $\mathrm{p}$-value reflected that there is a significant difference in mean volume median diameter between some of the treatment powders compared to the control. With Dunnett multiple comparisons, all the treatments were compared to the control. SCD $15 \mathrm{mM}$, EDTA $10 \mathrm{mM}$, SCD $5 \mathrm{mM}$, and EDTA $5 \mathrm{mM}$ had significant differences in mean volume median diameter compared to the control. The 95\% confidence intervals were constructed to analyze the average amount by which treatments would differ from the control mean volume median diameter. The intervals for SCD $15 \mathrm{mM}$ and EDTA $10 \mathrm{mM}$ had the largest increase. The interval for SCD $15 \mathrm{mM}$ is in the range of increasing the control mean volume median diameter by between $4.37 \mu \mathrm{m}$ and $11.41 \mu \mathrm{m}$. The interval for EDTA $10 \mathrm{mM}$ is in the range of increasing the control mean volume median diameter by between $3.20 \mu \mathrm{m}$ and $10.23 \mu \mathrm{m}$. Higher mean volume median diameters compared to control may be seen as higher wettability.

Although for some of the treatments, the mean volume mean diameter and mean volume median diameter were significantly different than the control, all the treatments agreed with literature that spray-dried powder particles usually have a diameter of 10 to $250 \mu \mathrm{m}$ (Caric, 1994). 
The particle size distribution graphs show that the powders have similar trends in their distribution. Figure 4.1a shows the overall shape of the Volume (\%) vs Particle Diameter distribution curve for EDTA $10 \mathrm{mM}$ Block 1, which is similar to the distribution of all the other powders.

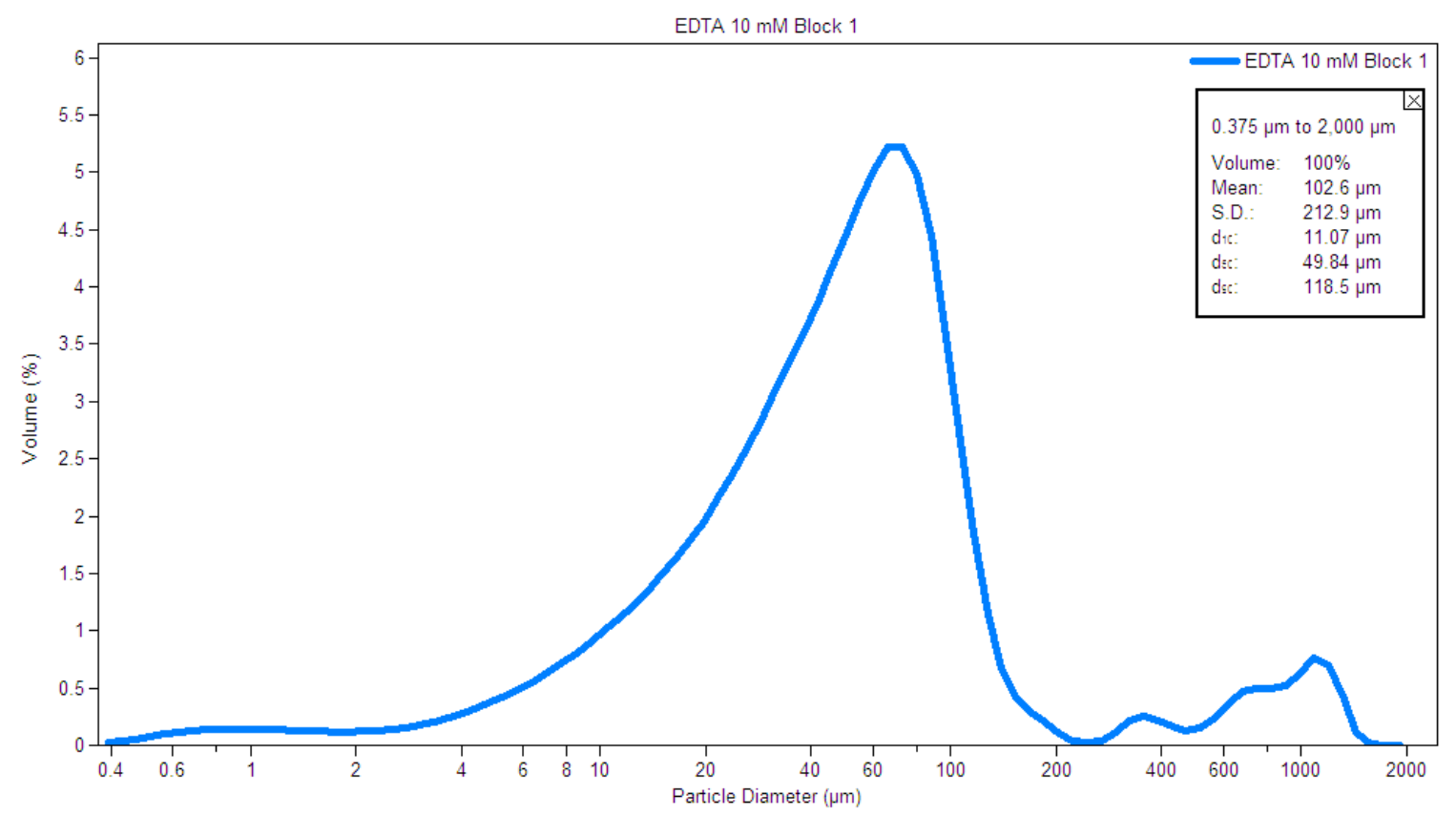

Figure 4.1a. Powder Particle Size Distribution of Volume (\%) vs Particle Size Diameter of Disodium Ethylene Diamine Tetraacetic Acid (EDTA) 10 mM, Block 1

As seen in Figure 4.1a, there are two main peaks in the Volume (\%) vs Particle Diameter distribution curve for EDTA $10 \mathrm{mM}$ Block 1, which is similar of all the other experimental powders. There are different sizes of powders due to the time at which the individual powder particles were exposed to the fluctuating drying conditions. The first peak (around $60 \mu \mathrm{m}$ ) agrees with literature that spray-dried powder particles usually have a diameter of 10 to $250 \mu \mathrm{m}$ (Caric, 1994). The second peak (around $1000 \mu \mathrm{m}$ ) may be due to slight differences of drying conditions experienced by those individual particles. 
For example, slightly higher outlet temperatures can produce slightly larger powder particle sizes (Keogh et al., 2004). Figure 4.1b shows the Number (\%) vs Particle Diameter distribution curve and indicates that there may be very few particles with diameter around $1000 \mu \mathrm{m}$.

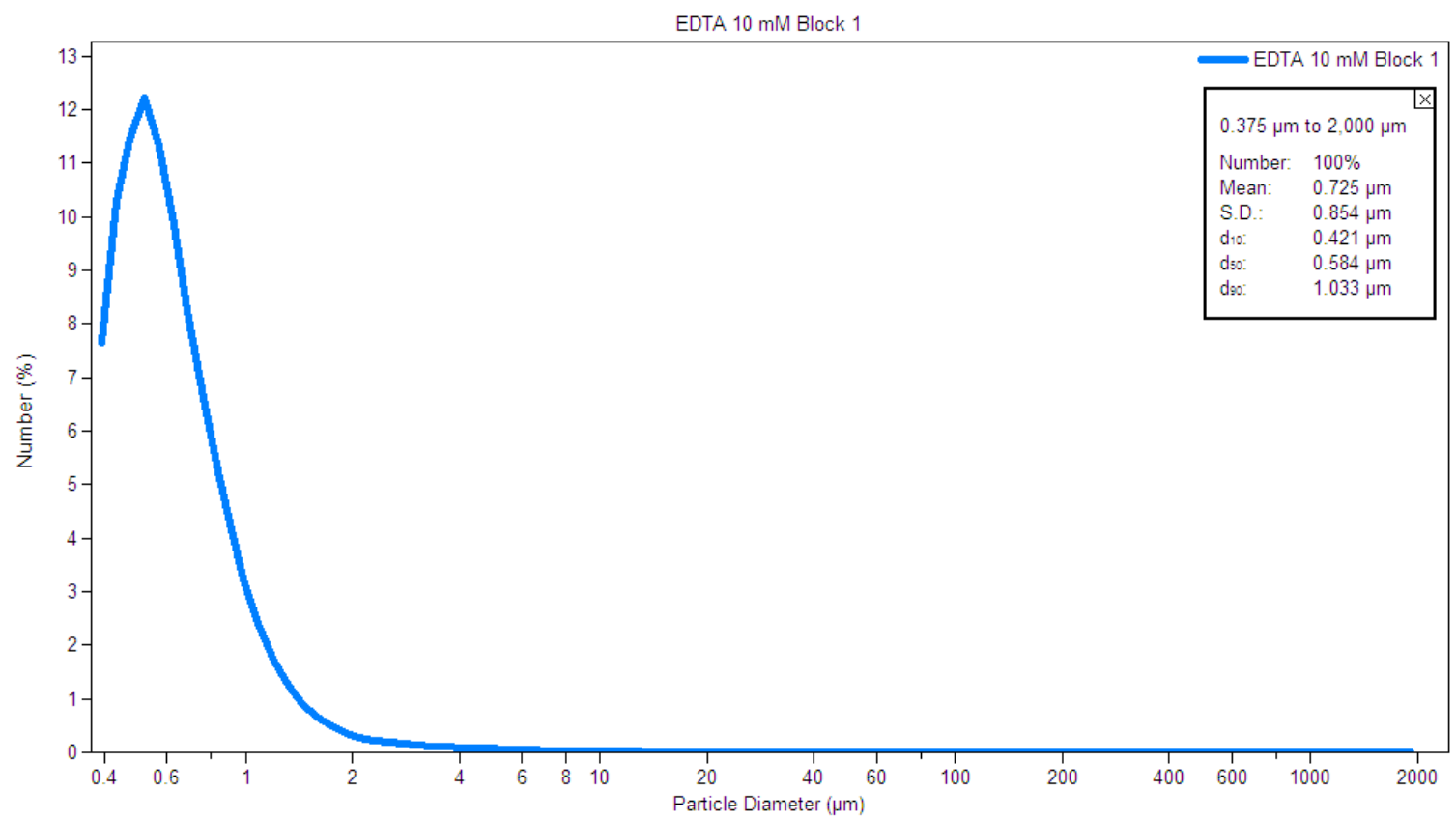

Figure 4.1b. Powder Particle Size Distribution of Number (\%) vs Particle Size Diameter of Disodium Ethylene Diamine Tetraacetic Acid (EDTA) 10 mM, Block 1

Overall, while the volume mean diameter and volume median diameter data showed significant differences between some of the treated powders and the control, the powder samples were deemed suitable for testing, because all the powders were still within range of the average particle size as discussed in the literature.

Also from the JMP analysis, both volume mean diameter and volume median diameter data showed a significant block effect, both had a block p-value of $<0.0001$. This may be due to many factors in processing, including but not limited to, differences in fat free 
milk supply, differences in the operation of the evaporator or spray dryer, or differences in milk powder storage.

\subsection{Rehydration Properties}

\subsubsection{Wettability in Terms of Surface Hydrophobicity via Contact Angle}

Kim et al. (2002) and Crowley et al. (2015) noted that a smaller contact angle can indicate higher wettability. Initial wettability was measured by the contact angle method at 0.5 seconds. Analyzing the data with a two-way ANOVA on JMP obtained a treatment $\mathrm{p}$-value of $<0.0001$. This $\mathrm{p}$-value reflected that there is a significant difference in mean initial contact angle at 0.5 seconds between some of the treatment powders compared to the control. Table 4.3 shows the difference between treatment sample mean initial contact angle and control sample mean initial contact angle.

Table 4.3. Dunnett procedure to compare the contact angle $\left(^{\circ}\right)$ at 0.5 seconds for the treatments to the contact angle $\left(^{\circ}\right)$ at 0.5 seconds for the control ${ }^{\mathrm{a} *}$

\begin{tabular}{cc}
\hline Treatment & $\begin{array}{c}\text { Difference between treatment } \\
\text { mean minus control mean }\end{array}$ \\
\hline EDTA $15 \mathrm{mM}$ & $+8.1^{\mathrm{b}}$ \\
EDTA $10 \mathrm{mM}$ & $+7.2^{\mathrm{b}}$ \\
SCD $15 \mathrm{mM}$ & $+3.0^{\mathrm{a}}$ \\
SCD $5 \mathrm{mM}$ & $-2.1^{\mathrm{a}}$ \\
EDTA $5 \mathrm{mM}$ & $-5.8^{\mathrm{b}}$ \\
SCD $10 \mathrm{mM}$ & $-7.2^{\mathrm{b}}$ \\
\hline
\end{tabular}

*EDTA=Disodium Ethylene Diamine Tetraacetic Acid, SCD=Sodium Citrate Dihydrate

${ }^{a, b}$ Different superscripts denote results that are statistically significantly different from the control $^{\text {a }}$ according to Dunnett procedure with a family wise error rate of $\alpha=0.05$

Pooled standard error $=1.0$ 
From Table 4.3 the sample mean contact angles for EDTA $15 \mathrm{mM}$ and EDTA $10 \mathrm{mM}$ are larger than the sample mean contact angle for the control (no chelator treatment) by $8.1^{\circ}$ and $7.2^{\circ}$, respectively (Table 4.3). EDTA $5 \mathrm{mM}$ and SCD $10 \mathrm{mM}$ have smaller sample mean contact angles than the sample mean contact angle for the control by $5.8^{\circ}$ and $7.2^{\circ}$, respectively (Table 4.3). With Dunnett multiple comparisons, all the treatments were compared to the control. The differences in sample means were found to be statistically significant. The $95 \%$ confidence intervals were constructed to analyze the average amount by which treatments would differ from the control mean initial contact angle. The interval for EDTA $15 \mathrm{mM}$ is in the range of increasing the control mean initial contact angle by between $4.1^{\circ}$ and $12.1^{\circ}$. The interval for EDTA $10 \mathrm{mM}$ is in the range of increasing the control mean initial contact angle by between $3.2^{\circ}$ and $11.1^{\circ}$. This data may indicate that higher concentrations of EDTA $(15 \mathrm{mM}$ and $10 \mathrm{mM})$ show a lower initial wettability compared to the control.

The interval for EDTA $5 \mathrm{mM}$ is in the range of decreasing the control mean initial contact angle by between $1.8^{\circ}$ and $9.8^{\circ}$. The interval for SCD $10 \mathrm{mM}$ is in the range of decreasing the control mean initial contact angle by between $3.2^{\circ}$ and $11.2^{\circ}$. This data may indicate that EDTA $5 \mathrm{mM}$ and SCD $10 \mathrm{mM}$ show a higher initial wettability compared to the control.

Figure 4.2a-d depict the visual representation of the contact angle over time for the treatments, separated by block and chelator type. 


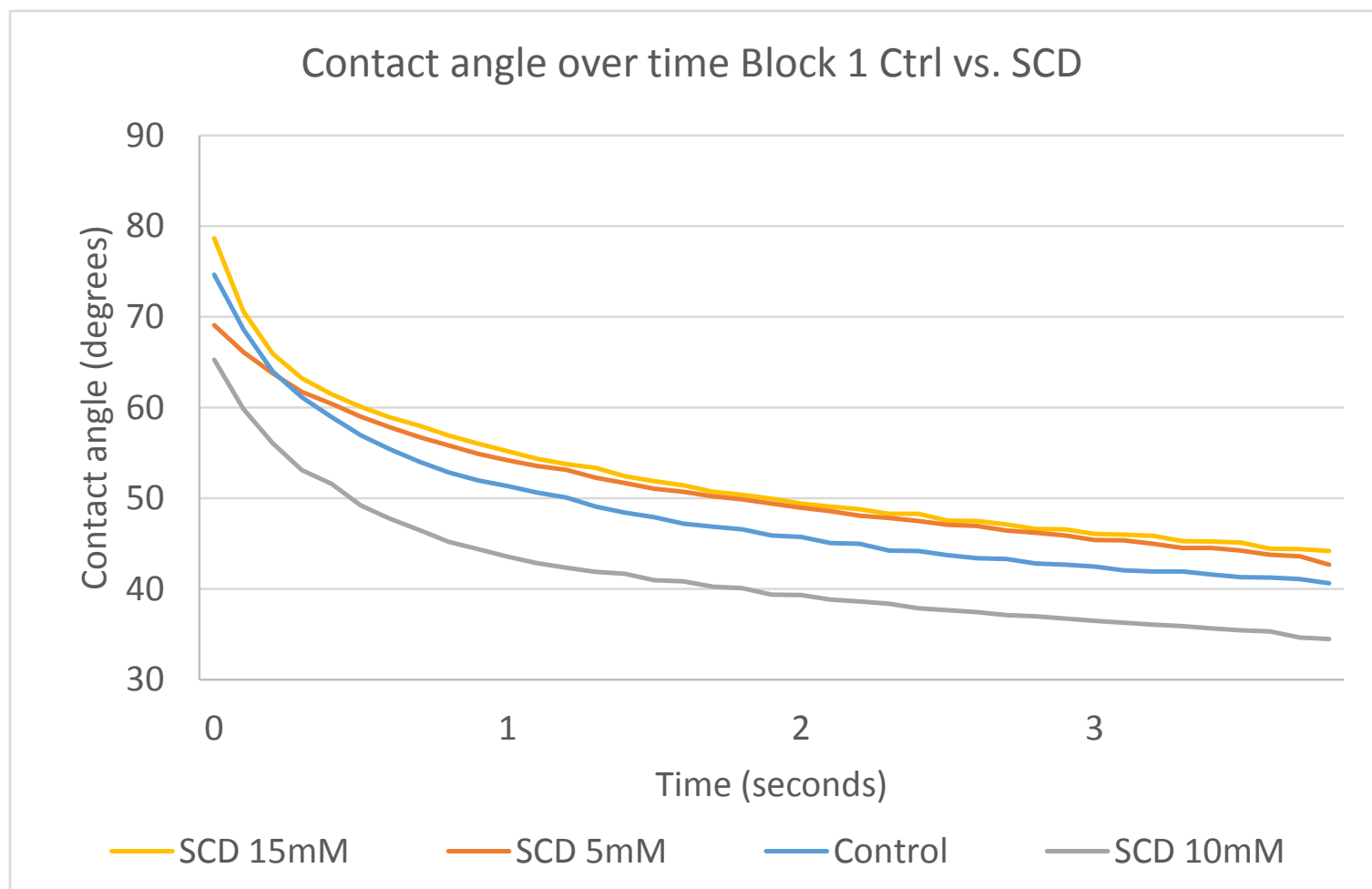

Figure 4.2a. Contact angle over time for Control vs Sodium Citrate Dihydrate (SCD), Block 1

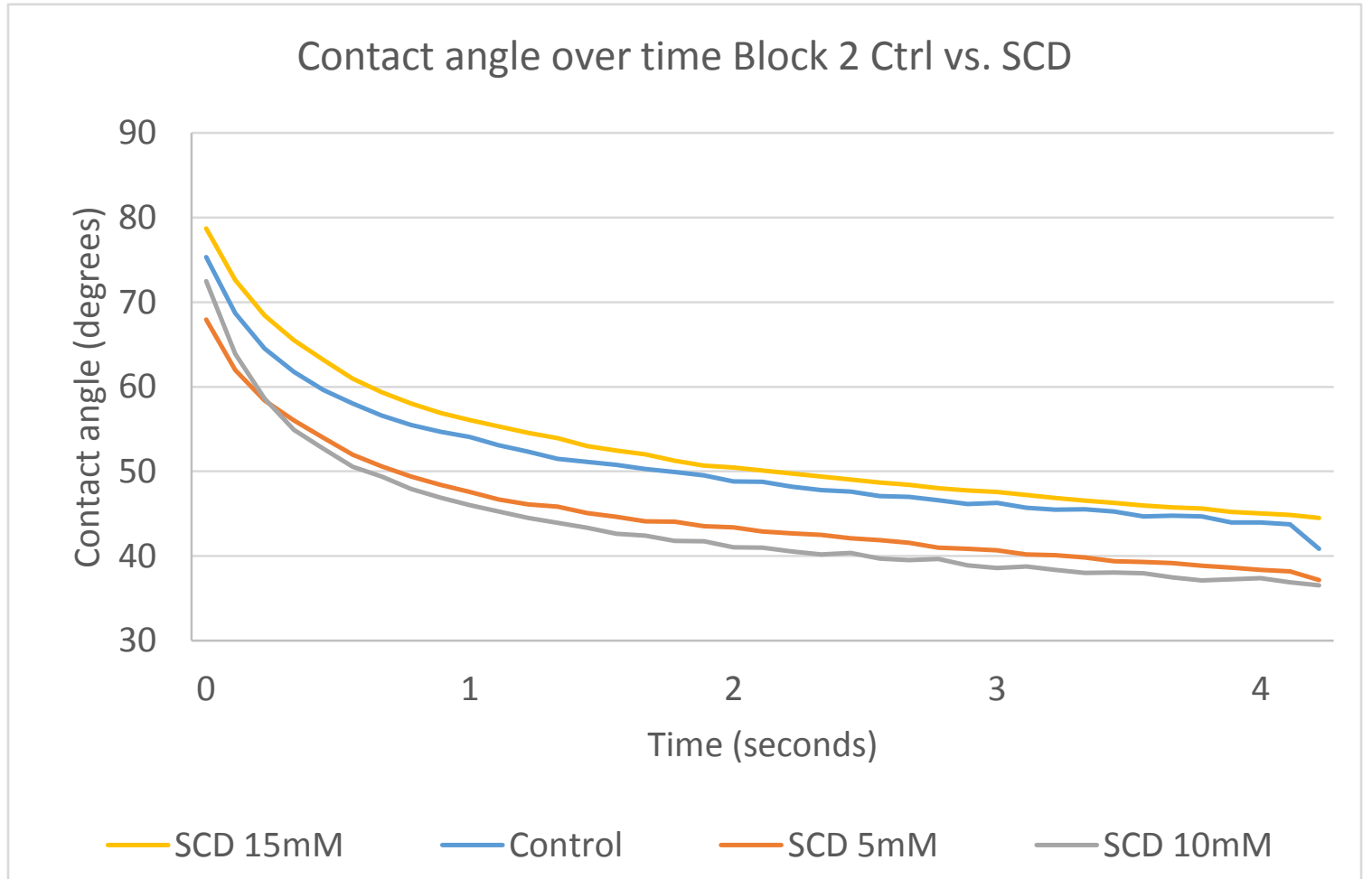

Figure 4.2b. Contact angle over time for Control vs Sodium Citrate Dihydrate (SCD), Block 2 


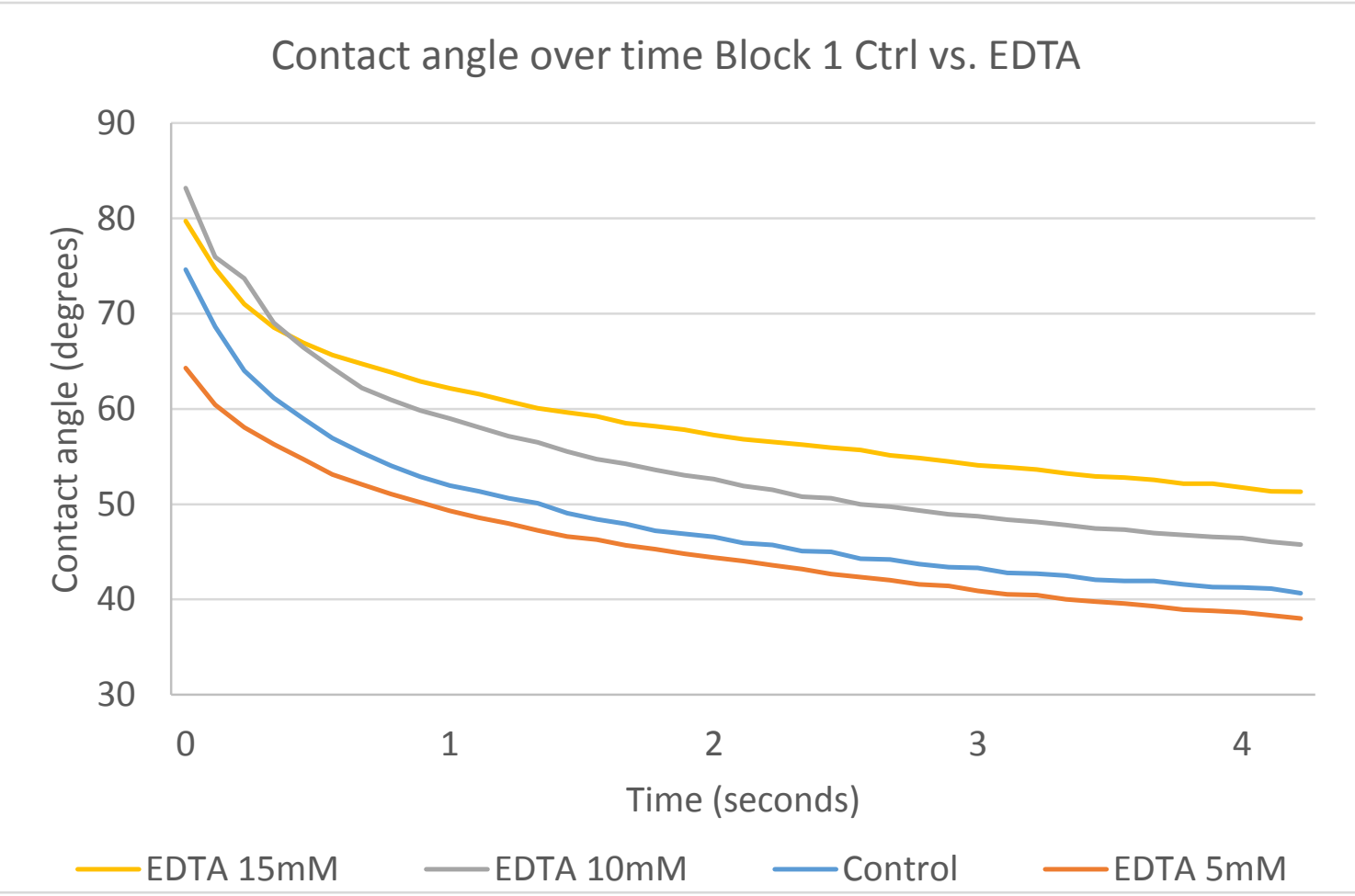

Figure 4.2c. Contact angle over time for Control vs Disodium Ethylene Diamine Tetraacetic Acid (EDTA), Block 1

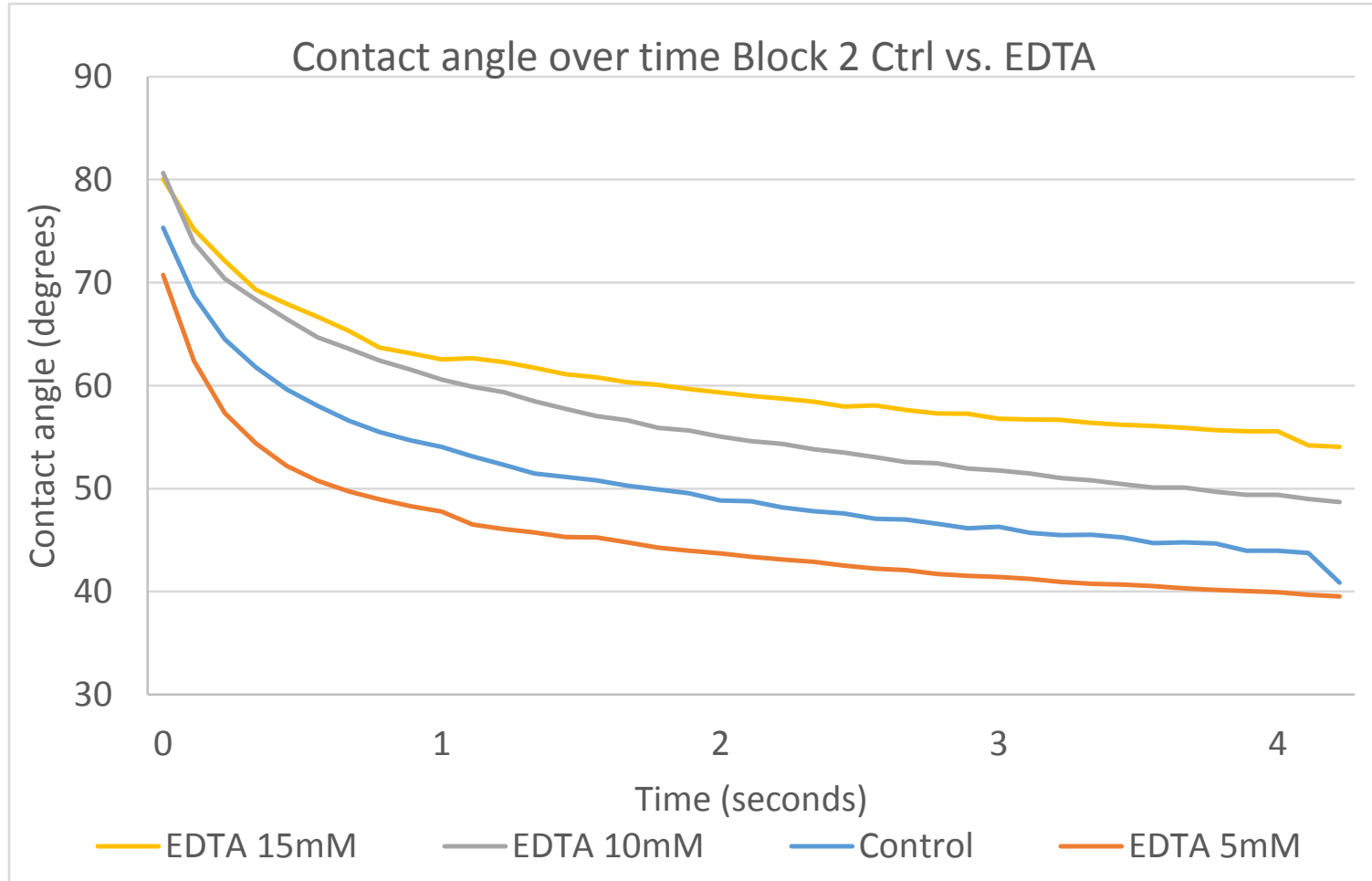

Figure 4.2d. Contact angle over time for Control vs Disodium Ethylene Diamine Tetraacetic Acid (EDTA), Block 2 
In Figure 4.2a and 4.2b, it is clear that SCD $15 \mathrm{mM}$ (yellow line) showed a significant lower contact angle for initial wettability compared to the control (blue line), indicating higher wettability. In Figure 4.2c and Figure 4.2d, it is also clear that EDTA $5 \mathrm{mM}$ (orange line) had a significant lower contact angle for initial wettability compared to the control (blue line), indicating higher wettability. It is also clear that EDTA $15 \mathrm{mM}$ (yellow line) and EDTA $10 \mathrm{mM}$ (gray line) showed a significant higher contact angle for initial wettability compared to the control (blue line), indicating lower wettability. Overall, it is interesting that SCD $15 \mathrm{mM}$ showed a higher initial wettability as measured by contact angle compared to the control treatment. This is interesting because this treatment had a significantly higher average level in the volume median diameter of the powder particle size compared to the control. This is in agreement with Kim et al. (2002) that fast wetting may occur with large particles that contain large pores. However, EDTA $10 \mathrm{mM}$ had a lower initial wettability as measured by contact angle compared to the control treatment but had a significantly lower average level in the volume median diameter of the powder particle size compared to the control. Furthermore, although EDTA $15 \mathrm{mM}$ had lower initial wettability as measured by contact angle compared to the control, EDTA $15 \mathrm{mM}$ did not have a significant difference in average level of volume median diameter of the powder particle size compared to the control. Thus, the significant differences in powder particle size may not have been a good indicator for initial wettability as measured by contact angle, for this study. 


\subsubsection{Wettability and Sinkability via Modified IDF Wettability Method}

As the contact angle method is in terms of surface hydrophobicity, not exactly wettability, the IDF method for measuring wettability was also used. Contact angle measurement was a more controlled system as the powders were compressed into tablets with the same press and the same syringe was used, so water droplet size was consistent. This is compared to the IDF method set forth by ISO and IDF, Annex B (2014) which was a comparably more subjective measurement in deciding when all powder particles had sunk below the surface of the water. Thus, it was interesting to run and compare both tests. As discussed in Section 3.6.2.1, the procedure set forth by ISO and IDF, Annex B (2014) was slightly modified. The mean and standard error (S.E.) results are shown in

Table 4.4. Table 4.4 also shows the difference between treatment sample mean IDF wettability and control sample mean IDF wettability.

Table 4.4. Mean and standard error (S.E) for each treatment for IDF wettability (seconds) and difference between treatment mean minus control mean ${ }^{\text {a* }}$

\begin{tabular}{|c|c|c|c|}
\cline { 2 - 3 } \multicolumn{1}{c|}{} & \multicolumn{2}{|c|}{ Wettability $(\mathrm{sec})$} & \multirow{2}{*}{$\begin{array}{c}\text { Difference between treatment } \\
\text { mean minus control mean }\end{array}$} \\
\hline Treatment & Mean & S.E & $+4^{\mathrm{a}}$ \\
\hline CCD $5 \mathrm{mM}$ & 173 & 22 & 14 \\
\hline SCD $10 \mathrm{mM}$ & 223 & 21 & $+50^{\mathrm{a}}$ \\
\hline SCD $15 \mathrm{mM}$ & 243 & 11 & $+70^{\mathrm{a}}$ \\
\hline EDTA $5 \mathrm{mM}$ & 241 & 15 & $+68^{\mathrm{a}}$ \\
\hline EDTA $10 \mathrm{mM}$ & 333 & 40 & $+160^{\mathrm{b}}$ \\
\hline EDTA $15 \mathrm{mM}$ & 440 & 45 & $+267^{\mathrm{b}}$ \\
\hline
\end{tabular}

*EDTA=Disodium Ethylene Diamine Tetraacetic Acid, $\mathrm{SCD}=$ Sodium Citrate Dihydrate

${ }^{a, b}$ Different superscripts denote results that are statistically significantly different from the control $^{\mathrm{a}}$ according to Dunnett procedure with a family wise error rate of $\alpha=0.05$ Pooled standard error $=28$ 
All data was analyzed with a two-way ANOVA on JMP and obtained a treatment p-value of $<0.0001$. This $p$-value reflected that there is a significant difference in mean IDF wettability between some of the treatment powders compared to the control. With Dunnett procedure, all the treatments were compared to the control. As seen by the superscripts in Table 4.4, only EDTA $15 \mathrm{mM}$ and EDTA $10 \mathrm{mM}$ were significantly different from the control. The $95 \%$ confidence intervals were constructed for the treatments to analyze the average amount by which these two treatments would differ from the control mean IDF wettability method response. The interval for EDTA $15 \mathrm{mM}$ is in the range of increasing the control mean IDF wettability method response by between 157 seconds and 376 seconds. The interval for EDTA $10 \mathrm{mM}$ is in the range of increasing the control mean IDF wettability method response by between 50 seconds and 269 seconds. This data may indicate that EDTA $15 \mathrm{mM}$ and EDTA $10 \mathrm{mM}$ show a lower initial wettability compared to the control. However, while EDTA $5 \mathrm{mM}$ and SCD 10 $\mathrm{mM}$ had no statistically significant effect on wettability in this IDF method, observations indicate that the IDF method may not have been able to capture the significant lower contact angle (i.e. higher initial wettability) compared to the control. For example, Figure 4.3a shows a photo of SCD $15 \mathrm{mM}$ Block 1 after the timer was stopped. This photo shows how not all the powder was incorporated with the water. This is compared to Figure $4.3 \mathrm{~b}$ which is a photo of SCD $10 \mathrm{mM}$, Block 1 after timer was stopped for the IDF wettability method. Figure $4.3 \mathrm{~b}$ represents how the powder particles for most samples were incorporated into the water before the timer stopped. 


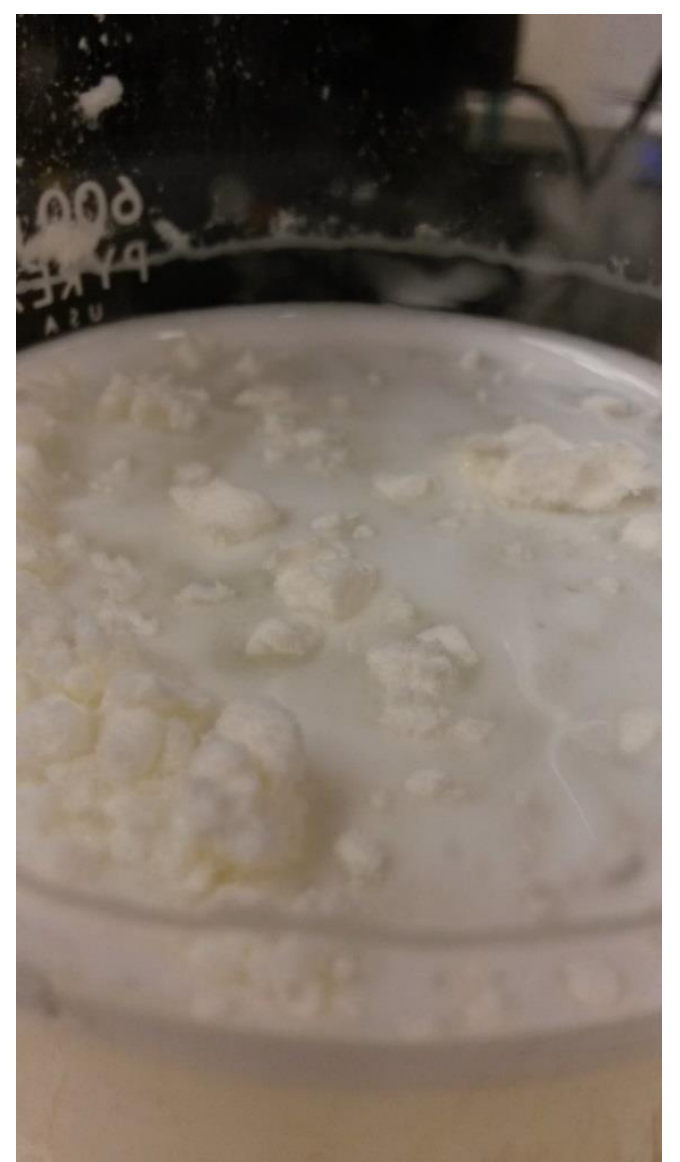

Figure 4.3a. Sodium Citrate Dihydrate (SCD) $15 \mathrm{mM}$ Block 1 after timer was stopped for IDF wettability method

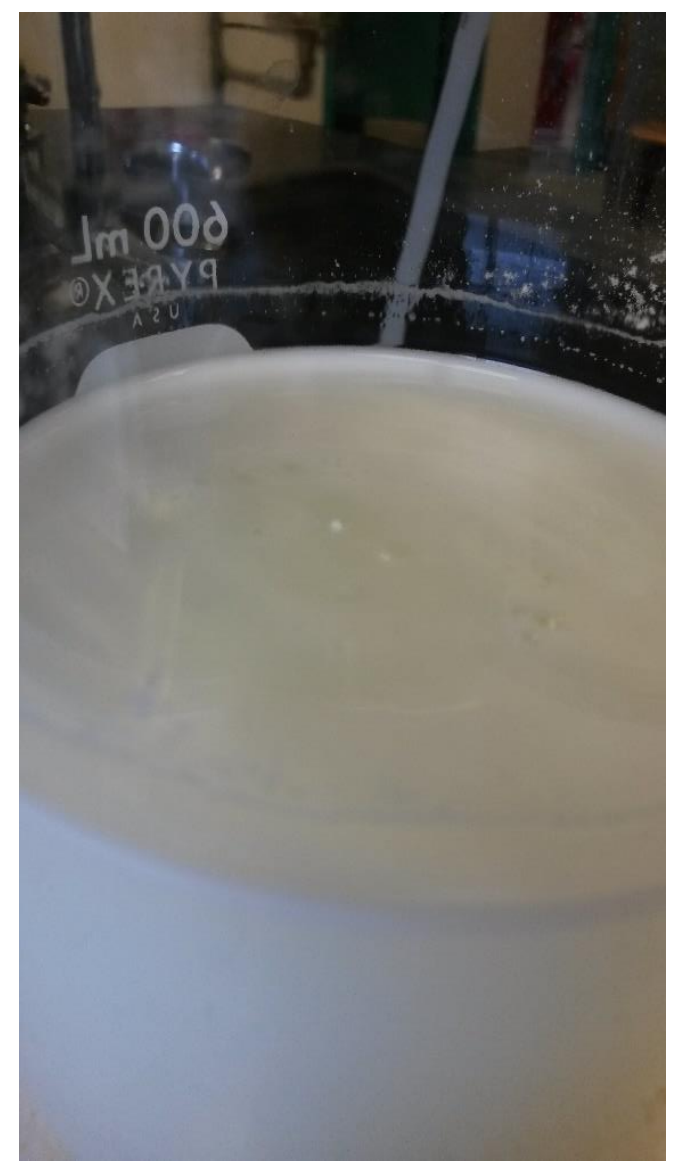

Figure 4.3b. Sodium Citrate Dihydrate (SCD) $10 \mathrm{mM}$ Block 1 after timer was stopped for IDF wettability method

Again, the IDF method was not able to capture that both EDTA $5 \mathrm{mM}$ and SCD $10 \mathrm{mM}$ had significantly higher initial wettability as measured by the contact angle method compared to the control.

Comparing the two wettability methods, both the contact angle method and the IDF wettability method indicated that EDTA $15 \mathrm{mM}$ and EDTA $10 \mathrm{mM}$ had lower initial wettability compared to the control. The IDF wettability method did not indicate that EDTA $5 \mathrm{mM}$ and SCD $10 \mathrm{mM}$ had higher wettability, while the contact angle method did indicate that EDTA $5 \mathrm{mM}$ and SCD $10 \mathrm{mM}$ had higher wettability. Observations during 
the IDF wettability method indicate that the IDF method may not have been able to capture the significant difference for EDTA $5 \mathrm{mM}$ and SCD $10 \mathrm{mM}$ in wettability that was measured by the contact angle method. This may be because the IDF method is not as sensitive of a test as contact angle or possibly more replicates may have been necessary to find more significant differences. On the other hand, contact angle may have captured statistically significant differences that are not practically significant. For example, in industry, a high shear mixer is used to incorporate bulk powder into liquid, negating slight differences in wettability. All in all, the IDF method may not be as sensitive of a method as contact angle, but is a simpler method if less precise measurements are acceptable to the researcher. At the same time, although the IDF method is widely used and is known as a standard method for measuring wettability, the results in this study may indicate that the IDF method may need further refinement to acquire as sensitive wettability insight as the more complex contact angle method.

\subsubsection{Dissolution Rate}

The mean and standard error (S.E.) results for dissolution rate (O.D./ second) are shown in Table 4.5. The difference between treatment sample mean dissolution rate minus control sample mean dissolution rate is also shown in Table 4.5. 
Table 4.5. Mean and standard error (S.E.) for each treatment of the dissolution rate (O.D./second) and difference between treatment mean minus control mean ${ }^{\text {a* }}$

\begin{tabular}{|c|c|c|c|}
\hline & \multicolumn{2}{|c|}{$\begin{array}{l}\text { Dissolution rate } \\
\text { (O.D./second) }\end{array}$} & \multirow{3}{*}{$\begin{array}{l}\text { Difference between } \\
\text { treatment mean minus } \\
\text { control mean }\end{array}$} \\
\hline Treatment & Mean & S.E & \\
\hline Control & 0.072 & 0.007 & \\
\hline SCD $5 \mathrm{mM}$ & 0.051 & 0.001 & $-0.021^{b}$ \\
\hline $\mathrm{SCD} 10 \mathrm{mM}$ & 0.050 & 0.004 & $-0.022^{b}$ \\
\hline $\mathrm{SCD} 15 \mathrm{mM}$ & 0.006 & 0.003 & $-0.066^{\mathrm{b}}$ \\
\hline EDTA $5 \mathrm{mM}$ & 0.055 & 0.002 & $-0.017^{b}$ \\
\hline EDTA $10 \mathrm{mM}$ & 0.033 & 0.003 & $-0.039^{b}$ \\
\hline EDTA $15 \mathrm{mM}$ & 0.004 & 0.003 & $-0.068^{b}$ \\
\hline
\end{tabular}

*EDTA=Disodium Ethylene Diamine Tetraacetic Acid, SCD=Sodium Citrate Dihydrate ${ }^{a, b}$ Different superscripts denote results that are statistically significantly different from the control $^{\mathrm{a}}$ according to Dunnett procedure with a family wise error rate of $\alpha=0.05$ Pooled standard error $=0.004$

As seen in Table 4.5, EDTA $15 \mathrm{mM}$ had a sample mean dissolution rate that was 0.068 O.D./ second lower than the control sample mean dissolution rate. Analyzing the data with a two-way ANOVA on JMP obtained a treatment p-value of $<0.0001$. This p-value reflected that there is a significant difference in mean dissolution rate between some of the treatment powders compared to the control. With Dunnett multiple comparisons, all the treatments were compared to the control. All treatments were significantly different from control as indicated in Table 4.5 . The $95 \%$ confidence intervals were constructed to analyze the average amount by which treatments would differ from the control mean dissolution rate. All treatments showed a decrease in the mean rate of dissolution compared to the control. This may indicate that all treated SMPs show lower dispersibility compared to the control, as discussed in Section 3.6.3.1. However, this method may not have been able to capture true significant differences in dissolution rate. 
For example, Figure 4.4 shows that the dissolution rate did not measure all the SCD 10 $\mathrm{mM}$, Block 1 powder because there was some powder that was not incorporated into the water, despite the use of a stirbar.

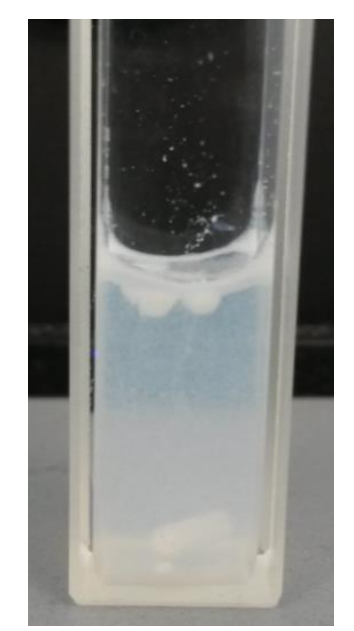

Unincorporated powder

Figure 4.4. Sodium Citrate Dihydrate (SCD) $10 \mathrm{mM}$, Block 1 for dissolution rate test

Thus, the measured dissolution rates, although statistically significant, may not have captured the true dissolution rate behavior of the powder. This may due in part to the changes in wettability and sinkability properties due to the treatments. Millqvist-Fureby et al. (2001) interpreted the results in their study that lower dissolution rates reflected lower wettability. This is compared to this study where the measured average dissolution rates that were lower compared to the control dissolution rate may have been due to lower wettability, although the results are not reflective of wettability analysis. This method did not analyze wettability because the light scattering detection was along the bottom of the cuvette, measuring light scattering after the powder had become wetted and sunk below the surface of the water.

Also from the JMP analysis, the dissolution rate data showed a significant block effect, with a block p-value of 0.0065 . This may be due to many factors in processing, including 
but not limited to, differences in fat free milk supply, differences in the operation of the evaporator or spray dryer, or differences in milk powder storage.

\subsubsection{Reconstituted Particle Size Analysis}

The mean and standard error (S.E.) results for volume mean diameter $(\mathrm{D} 4,3)$ and volume median diameter of the rehydrated particle size distribution are shown in Table 4.6.

Table 4.6. Mean and standard error (S.E.) of volume mean diameter $(\mathrm{D4}, 3)(\mu \mathrm{m})$ mean and standard error (S.E.) of volume median diameter $(\mu \mathrm{m})$ of the rehydrated particle size distribution for each treatment*

\begin{tabular}{|c|ccc|cc|}
\cline { 2 - 6 } \multicolumn{2}{c|}{} & \multicolumn{2}{c|}{$\mathrm{D}(4,3)(\mu \mathrm{m})$} & \multicolumn{2}{c|}{ Median $(\mu \mathrm{m})$} \\
\hline \multicolumn{2}{|c|}{ Treatment } & Mean & S.E & Mean & S.E \\
\hline \multicolumn{2}{|c|}{ Control } & $31.6^{\mathrm{a}}$ & 2.1 & $47.3^{\mathrm{a}}$ & 0.65 \\
\hline \multirow{3}{*}{ SCD } & $5 \mathrm{mM}$ & $0.5^{\mathrm{b}}$ & 1.6 & $0.5^{\mathrm{b}}$ & 1.02 \\
\cline { 2 - 6 } & $10 \mathrm{mM}$ & $0.5^{\mathrm{b}}$ & 1.6 & $0.5^{\mathrm{b}}$ & 1.03 \\
\cline { 2 - 6 } & $15 \mathrm{mM}$ & $0.6^{\mathrm{b}}$ & 1.6 & $0.5^{\mathrm{b}}$ & 1.03 \\
\hline \multirow{3}{*}{ EDTA } & $5 \mathrm{mM}$ & $36.5^{\mathrm{a}}$ & 8.8 & $64.9^{\mathrm{b}}$ & 5.4 \\
\cline { 2 - 6 } & $10 \mathrm{mM}$ & $0.5^{\mathrm{b}}$ & 1.6 & $0.5^{\mathrm{b}}$ & 1.02 \\
\cline { 2 - 6 } & $15 \mathrm{mM}$ & $0.6^{\mathrm{b}}$ & 1.6 & $0.6^{\mathrm{b}}$ & 1.01 \\
\hline
\end{tabular}

*EDTA=Disodium Ethylene Diamine Tetraacetic Acid, SCD=Sodium Citrate Dihydrate ${ }^{a, b}$ Different superscripts denote results that are statistically significantly different from the control $^{\mathrm{a}}$ according to Dunnett procedure with a family wise error rate of $\alpha=0.05$

Many data points were near zero, which complicated the mathematical process of an ANOVA analysis. Thus, the two-way ANOVA was conducted on a $\log _{10}$ transformation of the volume mean diameter and on a $\log _{10}$ transformation of the volume median diameter data.

The JMP analysis of the $\log _{10}$ transformation of the volume mean diameter obtained a treatment $\mathrm{p}$-value of $<0.0001$. This $\mathrm{p}$-value reflected that there is a significant difference in mean volume mean diameter between some of the treatment powders compared to the control. With Dunnett multiple comparisons, all the treatments were compared to the 
control. In Table 4.6 show that all but one (EDTA $5 \mathrm{mM}$ ) of the treated rehydrated samples had a significant difference in mean particle size volume mean diameter of the rehydrated sample as compared to the control. EDTA $5 \mathrm{mM}$ had no statistical significant difference compared to the control (treatment p-value of 0.9872). The 95\% confidence intervals were constructed to analyze the average amount by which treatments would differ from the control mean volume mean diameter. The intervals for all the significantly different treatments showed a decrease in mean volume mean diameter compared to the control mean volume mean diameter.

The JMP analysis of the $\log _{10}$ transformation of the volume median diameter obtained a treatment $p$-value of $<0.0001$. This $p$-value reflected that there is a significant difference in mean volume median diameter between some of the treatment powders compared to the control. With Dunnett multiple comparisons, all the treatments were compared to the control. In Table 4.6 show that all treatments of the treated rehydrated samples had a significant difference in mean particle size volume median diameter of the rehydrated sample as compared to the control. The $95 \%$ confidence intervals were constructed to analyze the average amount by which treatments would differ from the control mean volume median diameter. The intervals for all the treatments, except EDTA $5 \mathrm{mM}$, showed a decrease in mean volume median diameter compared to the control. The interval for EDTA $5 \mathrm{mM}$ is in the range of increasing the control volume median diameter by between $0.15 \mu \mathrm{m}$ and $0.43 \mu \mathrm{m}$. Overall, this particle size data on reconstituted 10\%TS samples may indicate that all treatments except EDTA $5 \mathrm{mM}$ show higher solubility compared to the control. The Volume (\%) vs Particle Diameter distribution curves are shown in Figure 4.5a-b. 


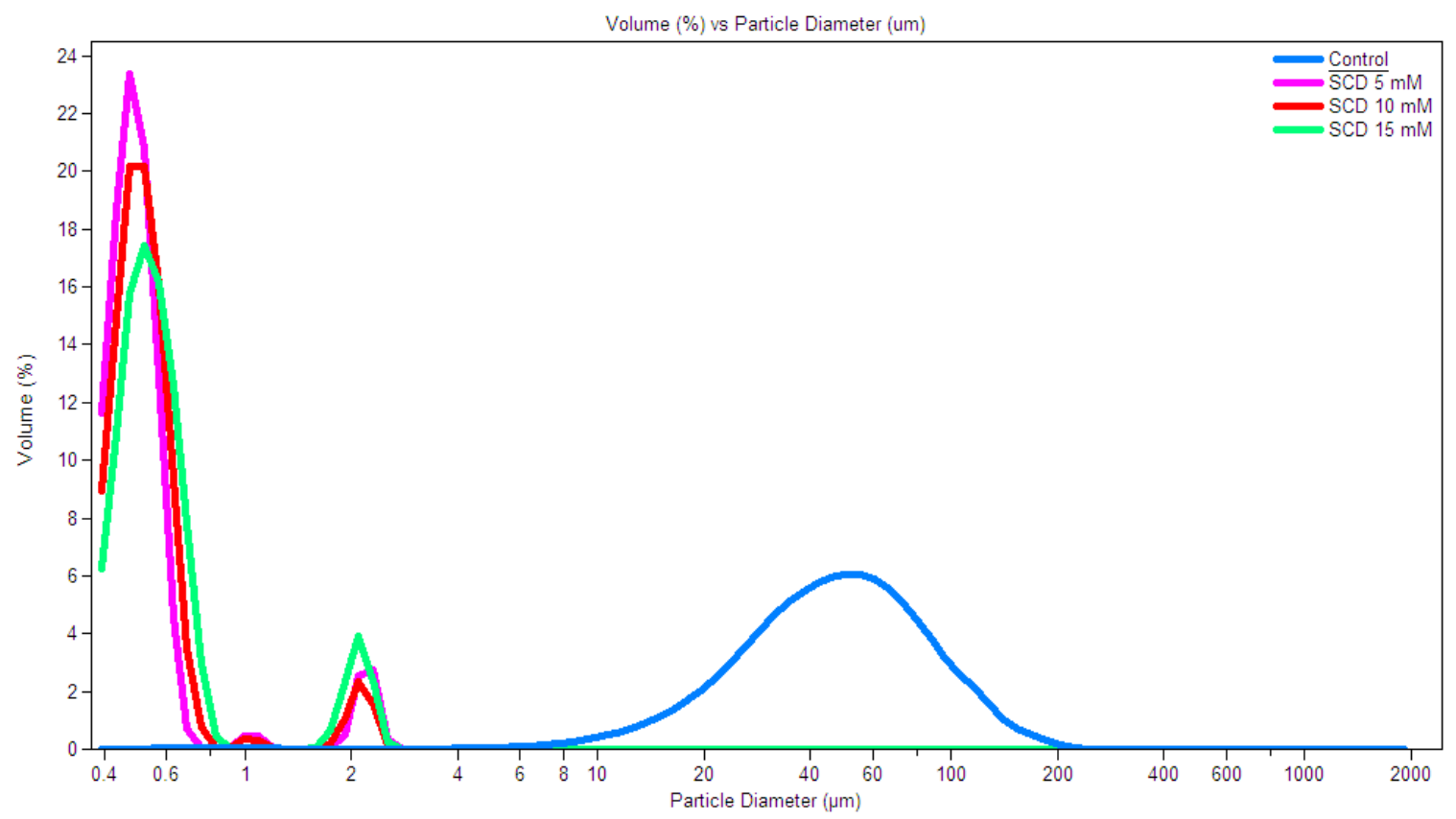

Figure 4.5a. Particle Size Analysis (PSA) for reconstituted samples of Sodium Citrate Dihydrate (SCD) at $5 \mathrm{mM}, 10 \mathrm{mM}$, and $15 \mathrm{mM}$ vs Control

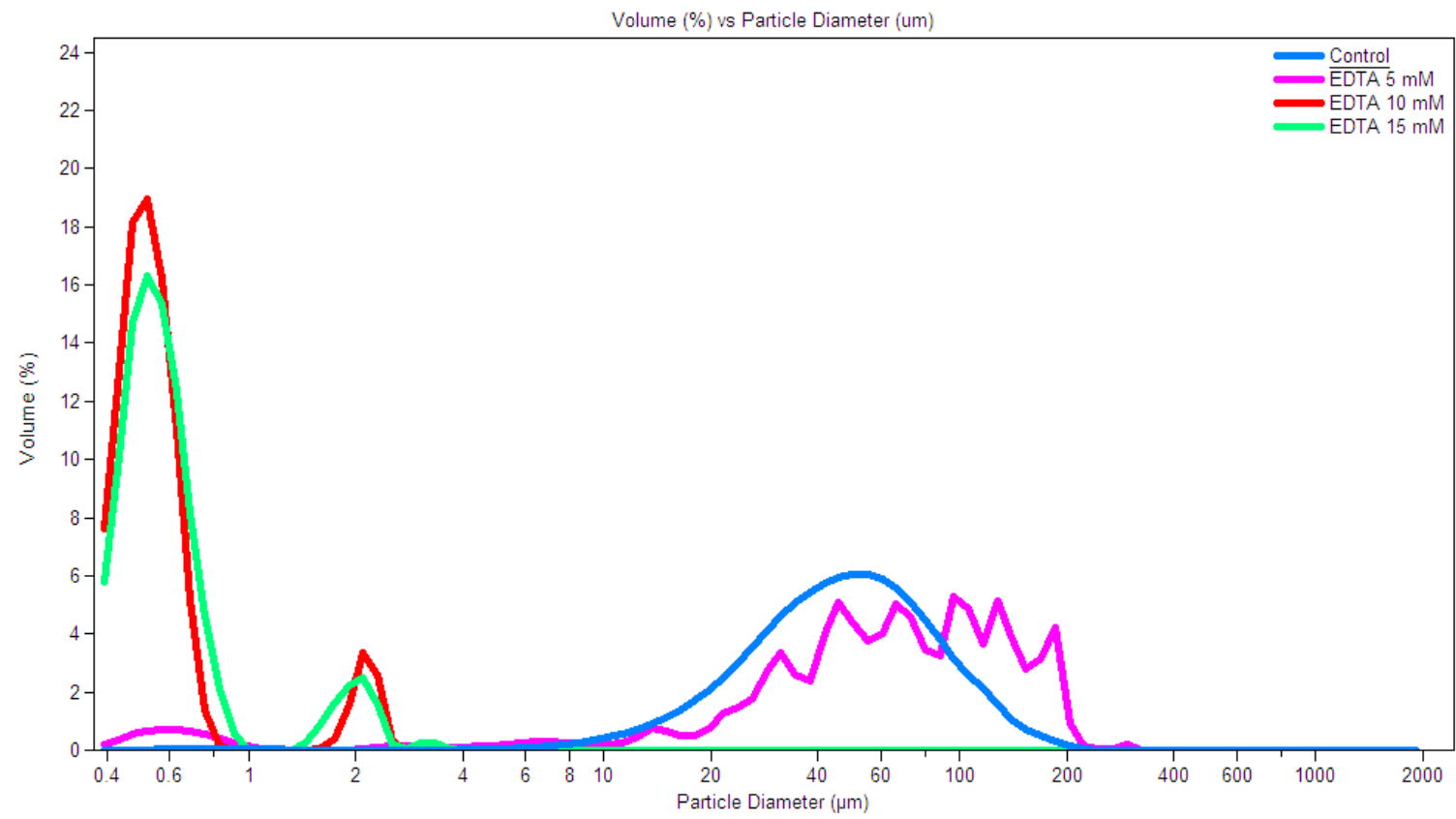

Figure 4.5b. Particle Size Analysis (PSA) for reconstituted samples of Disodium Ethylene Diamine Tetraacetic Acid (EDTA) at 5mM, 10mM, and $15 \mathrm{mM}$ vs Control 
Figure 4.5a show that SCD at all concentrations shifted the Volume (\%) vs Particle Diameter distribution curve to the left compared to the control. Figure $4.5 \mathrm{~b}$ show that EDTA at $15 \mathrm{mM}$ and EDTA at $10 \mathrm{mM}$ shifted the Volume (\%) vs Particle Diameter distribution curve to the left compared to the control. For EDTA $5 \mathrm{mM}$, the Volume (\%) vs Particle Diameter distribution curve did not shift from the control Volume (\%) vs Particle Diameter distribution curve. The behavior of EDTA compared to SCD for the Volume (\%) vs Particle Diameter distribution curve analyses of a reconstituted 10\%TS sample may indicate that EDTA does not chelate as well as SCD. This may be interpreted because the smaller level of EDTA did not disrupt the particle size distribution while the even the smaller level of SCD caused the Volume (\%) vs Particle Diameter distribution curve to shift to the left, compared to the control Volume (\%) vs Particle Diameter distribution curve. However, this behavior is not consistent with the general knowledge that EDTA is a stronger chelator than SCD. Thus, further replication is needed to assess if the particle size distribution behavior for reconstituted $10 \%$ TS samples is true. Crowley et al. (2015) identified major peaks in the Volume (\%) vs Particle Diameter distribution curves in their work, noting that the peak $<1 \mu \mathrm{m}$ was casein and that the peak $>10 \mu \mathrm{m}$ represented primary powder particles. Furthermore, in their work, reconstituted samples with a larger peak $<1 \mu$ m correlated with smaller absolute value contact angles and also a sharper initial drop in contact angle from 0.0 seconds to 2.0 seconds.

Comparing the work of Crowley et al. (2015) to the work in this study, it is clear that the control samples have many primary powder particles while the chelated samples are mostly casein. However, the reconstituted samples with a larger peak $<1 \mu \mathrm{m}$ in this study 
are the SCD at all concentrations, EDTA $15 \mathrm{mM}$, and EDTA $10 \mathrm{mM}$. The contact angle measurements for these treatments are not all significantly different from control, and the treatments that are different from control may be higher or lower with respect to contact angle behavior. Thus, more work is needed to elucidate if the reconstituted particle size distribution behavior can be related with contact angle data.

Also from the JMP analysis, both volume mean diameter and volume median diameter data for a $10 \%$ TS reconstituted sample showed a significant block effect. The block pvalue for volume mean diameter was 0.0035 and the block p-value for volume median diameter was 0.003 . This may be due to many factors in processing, including but not limited to, differences in fat free milk supply, differences in the operation of the evaporator or spray dryer, or differences in milk powder storage.

\subsubsection{Solubility Analysis via Modified Solubility Index}

The mean and standard error (S.E.) results for solubility index (mL) are shown in Table 4.7. The difference between treatment sample mean solubility index minus control sample mean solubility index is also shown in Table 4.7. 
Table 4.7. Mean and standard error (S.E.) for solubility index of each treatment $(\mathrm{mL})$ and difference between treatment mean minus control mean ${ }^{\mathrm{a} *}$

\begin{tabular}{|l|c|c|c|}
\cline { 2 - 3 } \multicolumn{1}{c|}{} & \multicolumn{2}{|c|}{ Solubility index $(\mathrm{mL})$} & $\begin{array}{c}\text { Difference between } \\
\text { treatment mean minus } \\
\text { Treatment }\end{array}$ \\
Control & 2.1 & 0.09 & Sontrol mean \\
\hline SCD $5 \mathrm{mM}$ & 0.5 & 0.06 & $-1.6^{\mathrm{b}}$ \\
\hline SCD $10 \mathrm{mM}$ & 0.2 & 0.01 & $-1.9^{\mathrm{b}}$ \\
\hline SCD $15 \mathrm{mM}$ & 0.05 & 0.04 & $-2.0^{\mathrm{b}}$ \\
\hline EDTA $5 \mathrm{mM}$ & 0.8 & 0.01 & $-1.3^{\mathrm{b}}$ \\
\hline EDTA $10 \mathrm{mM}$ & 0.2 & 0.06 & $-1.9^{\mathrm{b}}$ \\
\hline EDTA $15 \mathrm{mM}$ & 0.05 & 0.04 & $-2.0^{\mathrm{b}}$ \\
\hline
\end{tabular}

*EDTA=Disodium Ethylene Diamine Tetraacetic Acid, SCD=Sodium Citrate Dihydrate ${ }^{\mathrm{a}, \mathrm{b}}$ Different superscripts denote results that are statistically significantly different from the control $^{\mathrm{a}}$ according to Dunnett procedure with a family wise error rate of $\alpha=0.05$ Pooled standard error $=0.06$

Analyzing the data with a two-way ANOVA on JMP obtained a treatment p-value of $<0.0001$. This $\mathrm{p}$-value reflected that there is a significant difference in mean solubility index between some of the treatment powders compared to the control. With Dunnett multiple comparisons, all the treatments were compared to the control. All treatments were significantly different from control for the solubility index. The $95 \%$ confidence intervals were constructed to analyze the average amount by which treatments would differ from the control mean solubility index. All the intervals show a decrease in mean solubility index compared to the control. This may indicate that all treatments show higher solubility compared to the control. Although trends of the solubility index data can be seen with a graphical representation of the data, the solubility index photographs of the individual samples can also show any trends. Figure 4.6(a-d) are photographs of the solubility index centrifuge tubes at the end of analysis, when the sediment was measured, separated by block and chelator type. 


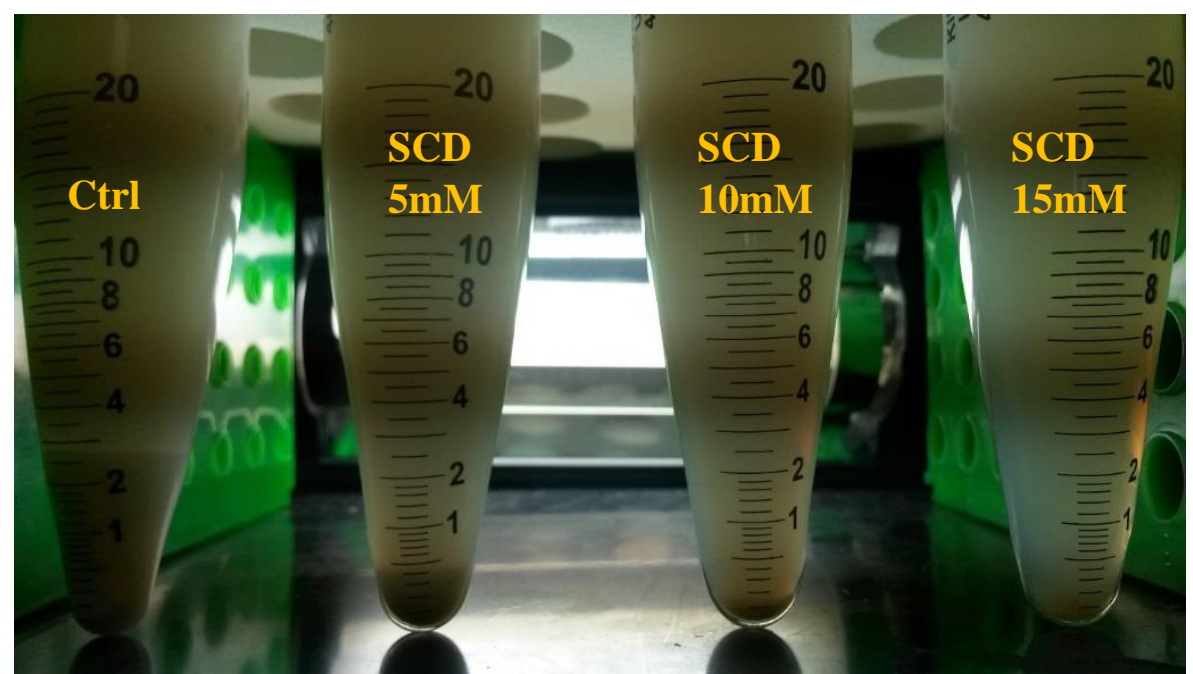

Figure 4.6a. Solubility index for Ctrl vs. SCD, Block 1*

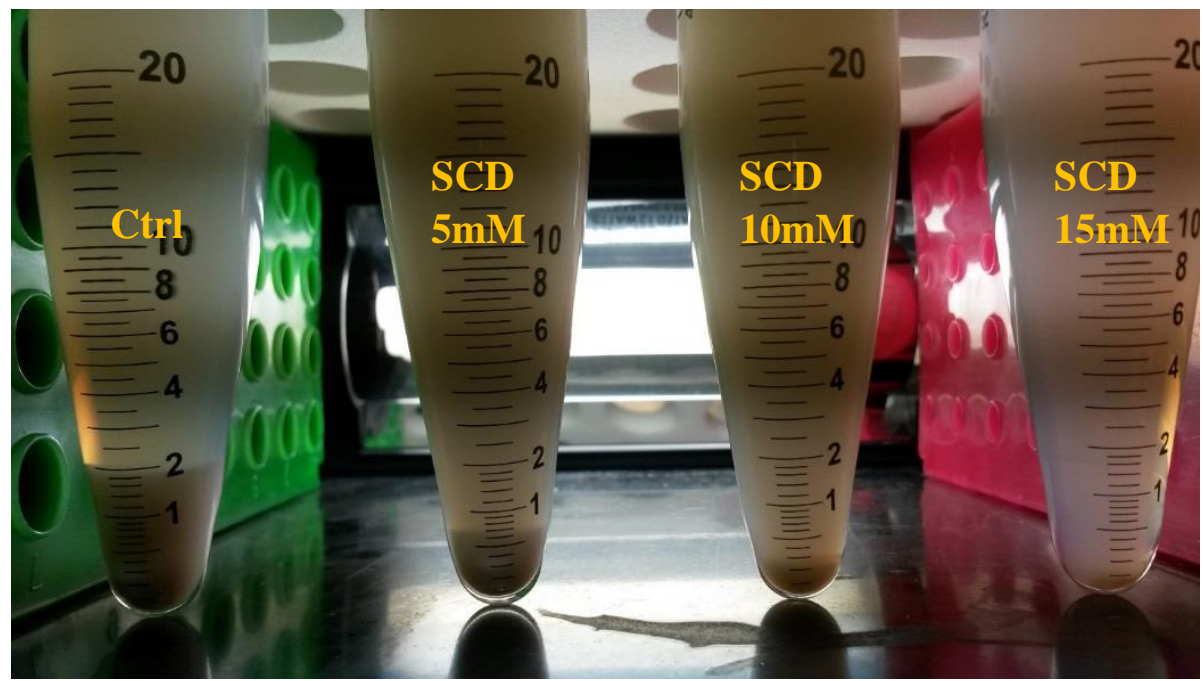

Figure 4.6c. Solubility index for Ctrl vs. SCD, Block 2*

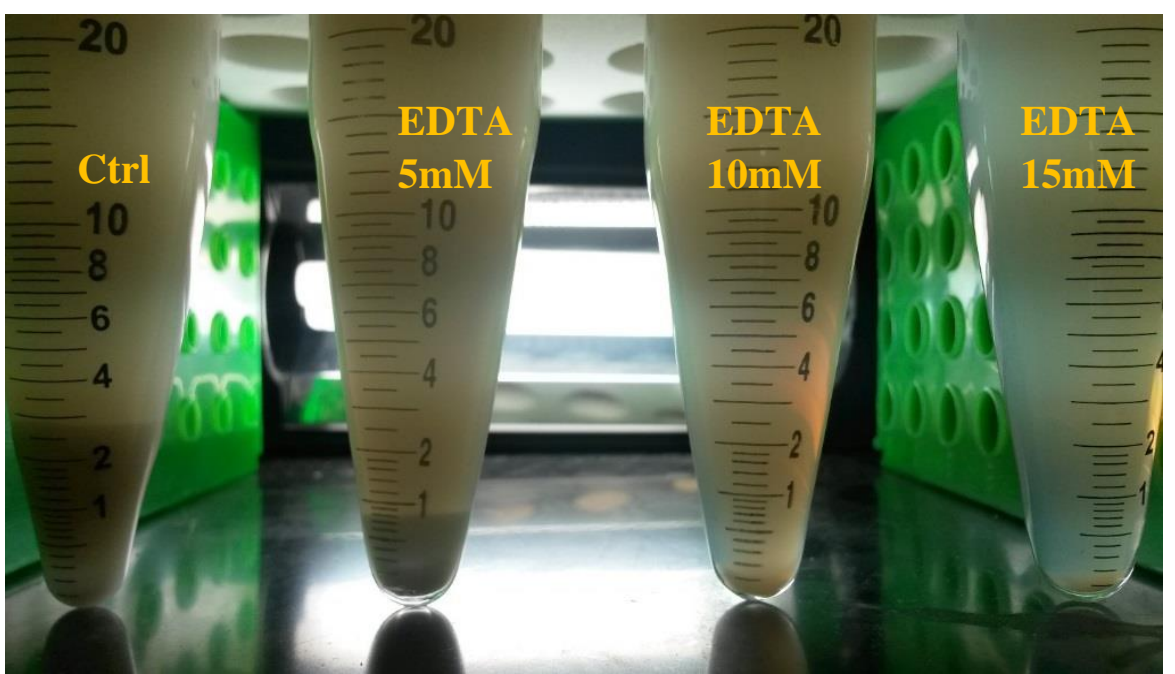

Figure 4.6b. Solubility index for Ctrl vs. EDTA, Block 1*

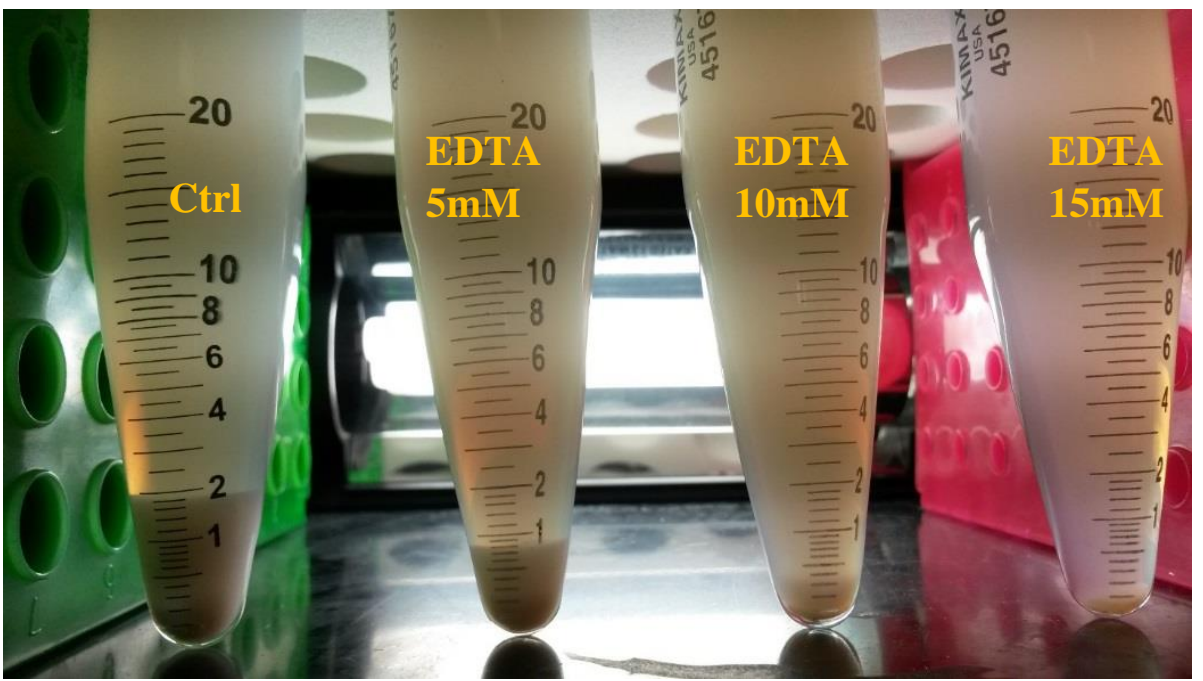

Figure 4.6d. Solubility index for Ctrl vs. EDTA, Block 2*

$*$ Ctrl $=$ Control, SCD = Sodium Citrate Dihydrate, EDTA = Disodium Ethylene Diamine Tetraacetic Acid 
Further discussion of the $95 \%$ confidence intervals was necessary to elaborate on the trend seen in Figures 4.6a-d. The intervals for EDTA 15 mM, EDTA 10 mM, SCD 15 $\mathrm{mM}$, and SCD $10 \mathrm{mM}$ are in the range of reducing the control mean solubility index response by between $2.1 \mathrm{~mL}$ and $1.7 \mathrm{~mL}$. The interval for SCD $5 \mathrm{mM}$ is in the range of reducing the control mean solubility index response by between $1.8 \mathrm{~mL}$ and $1.3 \mathrm{~mL}$. The interval for EDTA $5 \mathrm{mM}$ is in the range of reducing the control mean solubility index response by between $1.6 \mathrm{~mL}$ and $1.0 \mathrm{~mL}$. This may indicate that as the level of concentration of chelator increases, the solubility also increases, regardless of chelator type.

Overall, from Figure 4.6a-d, as the level of concentration increased, regardless of chelator type, the solubility was higher. It is interesting to note that in this solubility index test, the concentration seemed more significant than the chelator type, indicating little to no difference in solubility effect between the chelator types. For example, the concentration at $15 \mathrm{mM}$, regardless of chelator type, achieved a solubility index of $0.05 \mathrm{~mL}$ and the concentration at $10 \mathrm{mM}$, regardless of chelator type, achieved a solubility index of around $0.2 \mathrm{~mL}$. Moreover, powder particle size differences are not reflected in the particle size distribution of a fully solubilized reconstituted sample nor in the solubility index. This may indicate that in this study, the final solubility is more affected by the chemistry of the treatments rather than the physical property of the powder.

The changes to the solubility index could be due to a sequence of events. First, the chelators chelate all the ionic calcium in the serum. The decrease in ionic calcium shifts the protein-mineral balance between the minerals in the casein micelle and the minerals in the serum, which leads to a depletion of colloidal calcium phosphate, and a subsequent 
release of caseins from the initial micelle structure. This behavior influenced by EDTA or SCD dissolves the calcium phosphate bridge so that nanoclusters in the casein micelle do not exist (Dalgleish and Corredig, 2012). Hence, the casein micelle would be disrupted into individual caseins that may create the appearance that the solution as a whole has higher solubility, as seen in the particle size analyses of fully rehydrated reconstituted $10 \%$ TS samples and in the solubility index.

\subsubsection{Calcium and Phosphorous Behavior via Inductively Coupled Plasma Optical Emission Spectrometry (ICP-OES)}

Table 4.8 shows showed the single check for the total calcium and phosphorus levels in the water used during this study.

Table 4.8. Single check of total calcium and phosphorus in the water supply

\begin{tabular}{lcc}
\hline Water supply & Total Ca $(\mathrm{ppm})$ & Total P $(\mathrm{ppm})$ \\
\hline Deionized water (Room 103) & 0.08 & 0.35 \\
Softened water (Pilot plant) & 0.35 & 0.42 \\
\hline
\end{tabular}

The deionized water in the laboratory room 103 was used for reconstitution while the softened water in the pilot plant was used for adjusting \% TS for the concentrate prior to spray drying into powder. Overall, the single check observes that the water supply may not have contributed to the total calcium and phosphorus levels in the samples.

It was important to analyze the percent soluble calcium and phosphorus levels to perceive the chelators chelating calcium. The mean and standard error (S.E.) results for \%soluble $\mathrm{Ca}$ and \%soluble $\mathrm{P}$ are shown in Table 4.9. 
Table 4.9. Mean and standard error (S.E.) of \% soluble Calcium (Ca) and \% soluble Phosphorus (P) for all treatments for ICP-OES*

\begin{tabular}{|l|cc|cc|}
\cline { 2 - 5 } \multicolumn{1}{c|}{} & \multicolumn{2}{c|}{ \%soluble Ca } & \multicolumn{2}{c|}{ \%soluble P } \\
\hline Treatment & Mean & S.E & Mean & S.E \\
SCD $5 \mathrm{mM}$ & $39^{\mathrm{a}}$ & 0.9 & $54^{\mathrm{a}}$ & 1.0 \\
SCD $10 \mathrm{mM}$ & $54^{\mathrm{b}}$ & 1.6 & $64^{\mathrm{b}}$ & 1.6 \\
SCD $15 \mathrm{mM}$ & $72^{\mathrm{b}}$ & 1.7 & $79^{\mathrm{b}}$ & 1.7 \\
EDTA $5 \mathrm{mM}$ & $80^{\mathrm{b}}$ & 0.8 & $83^{\mathrm{b}}$ & 1.1 \\
EDTA $10 \mathrm{mM}$ & $57^{\mathrm{b}}$ & 0.8 & $64^{\mathrm{b}}$ & 0.7 \\
EDTA $15 \mathrm{mM}$ & $81^{\mathrm{b}}$ & 0.7 & $82^{\mathrm{b}}$ & 1.2 \\
\hline
\end{tabular}

*EDTA=Disodium Ethylene Diamine Tetraacetic Acid, SCD=Sodium Citrate Dihydrate ${ }^{a, b}$ Different superscripts denote results that are statistically significantly different from the control $^{\mathrm{a}}$ according to Dunnett procedure with a family wise error rate of $\alpha=0.05$

Pooled standard error for \%soluble $\mathrm{Ca}=1.25$

Pooled standard error for \%soluble $\mathrm{P}=1.25$

Analyzing the \%soluble calcium and the \%soluble phosphorus data separately, each with a two-way ANOVA on JMP obtained a treatment p-value of $<0.0001$ for each analysis. A treatment $\mathrm{p}$-value of $<0.0001$ reflected that there is a significant difference in both mean \%soluble calcium and \%soluble phosphorus between some of the treatment powders compared to the control. With Dunnett multiple comparisons, all the treatments were compared to the control. All treatments were significantly different than the control mean \%soluble calcium and \%soluble phosphorus. Figure 4.7 shows a graphical comparison of each treatment mean \%soluble $\mathrm{Ca}$ and \%soluble $\mathrm{P}$ to the control mean \%soluble $\mathrm{Ca}$ and control mean \%soluble P. 


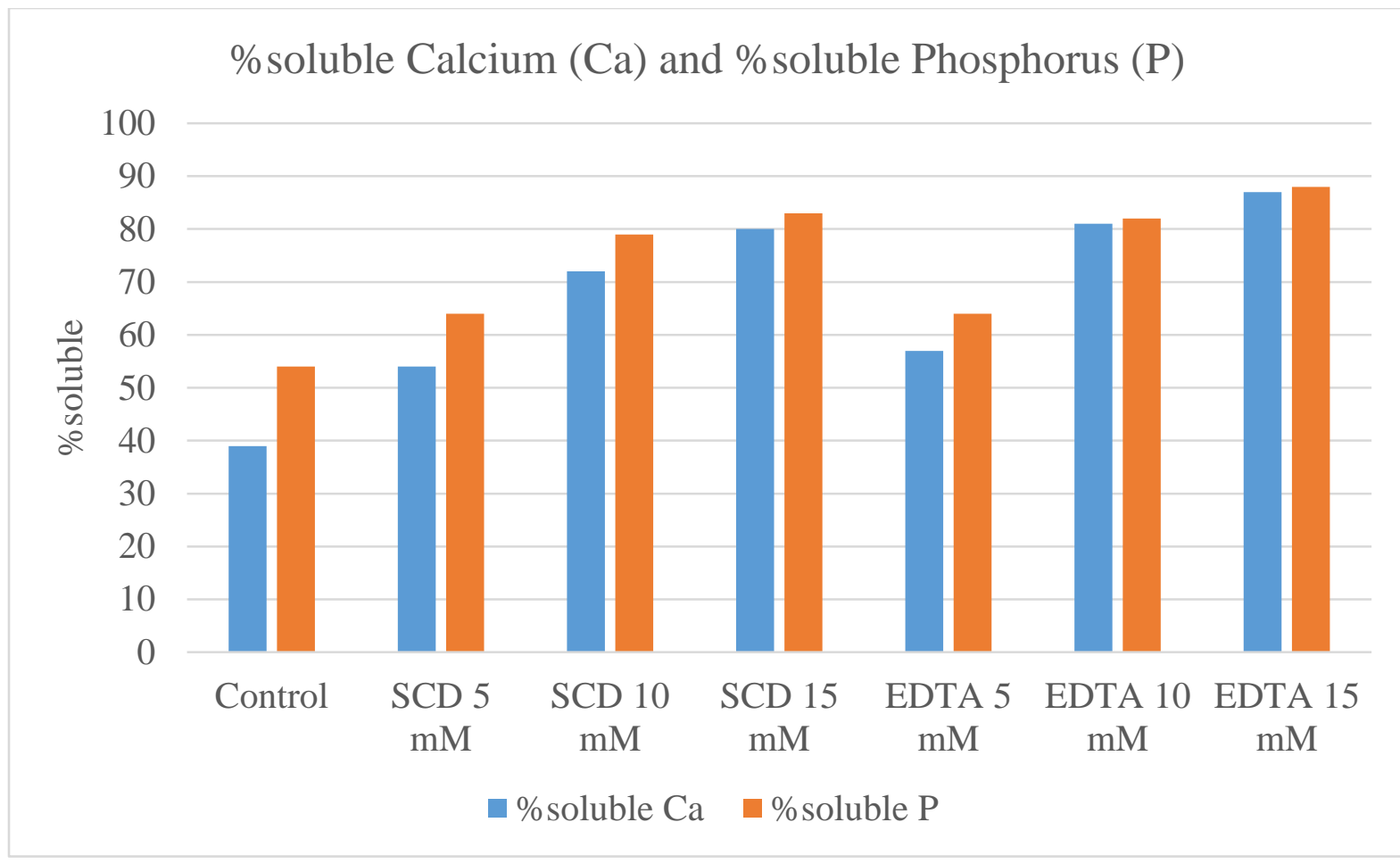

Figure 4.7. Graph of \% soluble Calcium (Ca) and \% soluble Phosphorus (P) for all treatments for ICP-OES*

*EDTA=Disodium Ethylene Diamine Tetraacetic Acid, SCD=Sodium Citrate Dihydrate

Construction of $95 \%$ confidence intervals were necessary to elaborate on the trend seen in Figures $4.6 \mathrm{a}-\mathrm{d}$. The $95 \%$ confidence intervals were constructed to analyze the average amount by which treatments would differ from the control mean \%soluble calcium and \%soluble phosphorus. All the intervals may indicate that as the level of concentration of chelator increases, there is also an increase in \%soluble calcium and \%soluble phosphorus compared to the control mean \%soluble calcium and \%soluble phosphorus. In this study, as the level of concentration increased for each chelator type, the mean \%soluble calcium and the mean \%soluble phosphorus was higher. Moreover, as expected and seen with the work of Anema (2015), the \%soluble calcium and phosphorus were linearly correlated- as calcium had a higher \%soluble percentage, phosphorus also had a 
higher \%soluble percentage. It is important to note the make-up of the \%soluble calcium and \%soluble phosphorus fractions in this study. For example, EDTA has a strong ionbinding capacity so it follows that EDTA $15 \mathrm{mM}$ and EDTA $10 \mathrm{mM}$ would have chelated the ionic calcium in the serum. Subsequently, the level of ionic calcium in the serum decreased as the ionic calcium became chelated and no longer available. Thus, this chelated calcium would still be captured, along with any remaining ionic calcium, in the $\%$ soluble calcium measurement by ICP-OES. Thus, the higher levels of \%soluble calcium and of \%soluble phosphorus may be due to the increase in chelated calcium in the serum as well as a decrease in colloidal calcium in the serum. 


\section{CHAPTER 5: CONCLUSIONS AND LIMITATIONS}

The first major hypothesis of the study was that powder produced from chelated skim milk have higher wettability, sinkability, dispersibility, and solubility than SMP not treated with chelators. The goal of this study was to understand how the addition of EDTA or SCD at concentrations of 5, 10, and $15 \mathrm{mM}$ to skim milk prior to evaporating and spray drying affected all the rehydration properties of SMP during reconstitution to $10 \%$ TS, not just the final solubility as observed by Sikand et al. (2016). Overall, EDTA $15 \mathrm{mM}$ and EDTA $10 \mathrm{mM}$ had significantly lower initial wettability compared to the control as measured by both contact angle and IDF method. This suggests that EDTA 15 $\mathrm{mM}$ and EDTA $10 \mathrm{mM}$ had high surface hydrophobicity. However, EDTA at all levels had significantly higher levels of solubility compared to the control (treatment p-value of $<0.0001)$. Thus, in this study, early stages of rehydration such as wettability cannot be used a predictor for later stages of rehydration such as solubility. This trend is also seen in the work by Mao et al. (2012). Mao et al. (2012) observed that treated MPC80 with $150 \mathrm{mM}$ sodium chloride during diafiltration had the highest solubility of their treatments but also the highest surface hydrophobicity. This may be due to the modified surface properties by the reduced intermolecular disulfide bonds and the associated decrease in mean particle size observed by Mao et al. (2012). However, this study did not analyze the disulfide bond interactions nor was there a decrease in volume mean diameter particle size of the powder for these treatments. Moreover, powder particle size differences are not reflected in the particle size distribution of a fully solubilized reconstituted sample nor in the solubility index. This may indicate that in this study, the final solubility is more affected by the chemistry of the treatments rather than the physical property of the 
powder. It is interesting to note that even though there were large \%composition differences such as 33.3\% protein for SCD $15 \mathrm{mM}$ Block 1 and 36.4\% protein for EDTA $10 \mathrm{mM}$ Block 2, the differences were not reflected in any of the data. Furthermore, this study also found that SCD $15 \mathrm{mM}$, SCD $10 \mathrm{mM}$, and SCD $5 \mathrm{mM}$ did not have a significant effect on wettability as measured by IDF method (treatment p-values of 0.3234 , treatment $p$-value of 0.6376 , and treatment $p$-value of 1.0000 , respectively). However, SCD $15 \mathrm{mM}$, SCD $10 \mathrm{mM}$, and SCD $5 \mathrm{mM}$ also had higher levels of solubility as measured by particle size analysis of reconstituted 10\%TS samples (treatment p-value of $<0.0001$ for all levels) and by solubility index (treatment $p$-value of $<0.0001$ for all levels), compared to the control.

The second major hypothesis was that chelators affect the rehydration properties of SMP by altering the calcium balance between the serum and the casein micelle. Thus, a goal of this study was to provide insight on how the chelators were affecting the SMP system via analyzing \%soluble calcium and \%soluble phosphorus of centrifuged reconstituted $10 \%$ TS samples via ICP-OES. With ICP-OES data, all the treated powders had statistically significant higher levels in \%soluble calcium and \%soluble phosphorus compared to the control. Also seen with the work of Anema (2015), the \% soluble calcium and phosphorus were correlated- as calcium had a higher percentage, phosphorus did as well. Anema (2015) noted that the addition of sodium hexametaphosphate shifted the mineral equilibrium which dissociated the casein micelles. This lead to a shift to the left in particle size distribution of a 9\%TS rehydrated solution compared to the control (as also seen in this study with a $10 \% \mathrm{TS}$ solution) indicating that the chelated samples are mostly casein micelles (Crowley et al., 2015). Furthermore, the increase in \%soluble 
calcium as seen with all the treatments compared to the control is consistent with an increased final solubility for all the treatments compared the control. This is because the initially non-available colloidal calcium was driven out of the micelle to reestablish equilibrium from the EDTA or SCD chelating the ionic calcium in the serum. Thus, the casein micelle would be disrupted into individual caseins that can may create the appearance that the solution as a whole has higher solubility, as seen in this study in the particle size analyses of fully rehydrated reconstituted $10 \% \mathrm{TS}$ samples and in the solubility index. However, this sequence of chelation may have lowered the wettability of the EDTA powders compared to the control, although there was no effect on wettability of the SCD powders compared to the control. This difference between the EDTA and SCD fully rehydrated reconstituted $10 \%$ TS samples may be to the behavior of the chelated calcium.

In general in this study, EDTA treated powders had a lower wettability but a higher solubility compared to the control. SCD treated powders had no difference in wettability but a higher solubility compared to the control. Further work is needed to understand the mechanism in which certain chelators may have lower wettability, sinkability, and dispersibilty, but higher solubility of skim milk powder.

Overall, the findings provide insight on how chelators affect the rehydration properties of skim milk powder, when the chelator is added to liquid skim milk, prior to evaporating and spray drying. The findings in effects on rehydration properties may assist dairy powder manufacturers if deciding to add chelators to affect the end product rehydration properties. 


\section{CHAPTER 6: DIRECTIONS FOR FUTURE RESEARCH}

Additional research into the relationship between the effect of chelator type and concentration on the rehydration properties is needed to advance the understanding of the mechanism in which certain chelators may have lower wettability, sinkability, and dispersibilty, but higher solubility of skim milk powder. Also, future research can involve further method development to quantify each rehydration property of wettability, sinkability, dispersibility, and solubility.

1. As this study measured the physical property of the powder only with particle size, additional research may be helpful in investigating the surface of the spray dried powder particles via electron microscopy to determine changes in conformation and functional properties as a result of the chelator additions (Vega and Roos, 2006).

2. Since this study measured mineral behavior only with ICP-OES, it may be beneficial to develop methods to quantify the changes in protein conformation and hydrophobic interactions that occur as the casein micelle fragments as the calcium-phosphate bridge splits (Anema, 2015).

3. The addition of chelating agents in this investigation was in three levels of concentration. It would be interesting to study the behavior of one chelating agent over six or more levels of concentration to analyze the mineral behavior in terms of soluble (ionized or chelated and ionized) versus colloidal.

4. This study focused on rehydration properties. Thus, it would be useful to determine the effect of the addition of chelators on other functional properties post-reconstitution, such as rheology. For example, do the chelated reconstituted 
samples have similar or different overall functionality as compared to the original milk source?

5. Determine if the chelated skim milk powder has an interaction effect on poorly soluble substances, such as medicine, which utilize skim milk powder as a carrier to achieve a higher level of solubility (Kumar, 2009). 


\section{REFERENCES}

American Dairy Products Institute. 1990. Standards for Grades Including Methods of Analysis Bulletin 916, Revised.

American Dairy Products Institute. 2002. Standards for grades of dry milks, including methods of analysis (Bulletin 916).

American Dairy Products Institute. 2005. Reference Manual for U.S. Milk Powders.

American Dairy Products Institute. 2009. Solubility Index Procedure Standards for Grade of Dry Milks, Including Methods of Analysis.

American Dairy Products Institute. 2014. Dry milks. Skim milk powder. Accessed Feb.20, 2015. https://www.adpi.org/DairyProducts/DryMilks/SkimMilkPowder/tabid/ 359/Default.aspx.

Anema, S. G. 2015. The effect of hexametaphosphate addition during milk powder manufacture on the properties of reconstituted skim milk. International Dairy Journal. 50:58-65.

Association of Official Analytical Chemists (AOAC). 1995a. Sampling of Dried Milk 935.41. Official methods of analysis (16th ed.) AOAC. Gaithersburg, MD.

Association of Official Analytical Chemists (AOAC). 1995b. Sampling of Dried Milk and Its Products 970.28. Official methods of analysis (16th ed.). 970.28. AOAC. Gaithersburg, MD.

Association of Official Analytical Chemists (AOAC). 1995c. Moisture in Dried Milk 927.05. Official methods of analysis (16th ed.). AOAC. Gaithersburg, MD.

Association of Official Analytical Chemists (AOAC). 1995d. Ash of Dried Milk 930.30. Official methods of analysis (16th ed.). AOAC. Gaithersburg, MD.

Association of Official Analytical Chemists (AOAC). 1995e. Fat in Dried Milk 932.05. Official methods of analysis (16th ed.). AOAC. Gaithersburg, MD.

Association of Official Analytical Chemists (AOAC). 1995f. Protein in Dried Milk 930.29. Official methods of analysis (16th ed.). AOAC. Gaithersburg, MD.

Association of Official Analytical Chemists (AOAC). 1995g. Nitrogen (Total) in Milk 991.20. Official methods of analysis (16th ed.). AOAC. Gaithersburg, MD.

Boss, C. B., and K. J. Fredeen. 2004. Concepts, instrumentation and techniques in inductively coupled plasma optical emission spectrometry. Third edition. Perkin Elmer; Shelton, CT. 
Bylund, G. Dairy processing handbook. Tetra Pak Processing Systems AB. 1995.

Canadian Dairy Commission. 2015. Skim milk powder. Accessed June.20, 2015. http://www.milkingredients.ca/index-eng.php?id=192

Caric, M. 1994. Concentrated and dried dairy products. VCH Publishers, New York, USA. p85-90.

Chandan, R. C., A. Kilara, and, N. Shah. 2008. Dairy processing and quality assurance. Pages 319-336 in Dry Milk Products. Wiley-Blackwell.

Code of Federal Regulations, Title 21 (CFR-21). 2015. Sec. 172.120 Calcium disodium EDTA. U.S. Food and Drug Administration. Accessed May.23, 2016.

https://www.accessdata.fda.gov/scripts/cdrh/cfdocs/cfcfr/CFRSearch.cfm?fr=172.120

Codex Alimentarius. 2011. Milk and Milk Products. $2^{\text {nd }}$ edition. FAO and WHO. http://www.fao.org/docrep/015/i2085e/i2085e00.pdf. Accessed May 15, 2015.

Crowley, S. V., B. Desautel, I. Gazi, A. L. Kelly, T. Huppertz, and J. A. O’Mahony. 2015. Rehydration characteristics of milk protein concentrate powders. J. Food Eng. 149(2015)105-113.

Dalgleish, D. G., and M. Corredig. 2012. The structure of the casein micelle of the milk and its changes during processing. Annu. Rev. Food Sci. Technol. 3:449-467.

Dairy Management Inc. 2015. Dairy Market Report - October.

Fang, Y., C. Selomulya, and X. Chen. 2008. On measurement of food powder reconstitution properties. Drying Technol. 26:3-14.

Ferrer, M. A., M. R. Hill, and M. Corredig. 2008. Rheological properties of rennet gels containing milk protein concentrates. J. Dairy Sci. 91:3:959-969.

Flora, S. J. S. and V. Pachauri. 2010. Chelation in metal intoxication. Int J Environ Res Public Health 7(7):2745-2788.

Forney, L., A. Marabi, S. Palzer. 2011. Wetting, disintegration and dissolution of agglomerated water soluble powders. Powder Technology 206:72-78.

Freudig, B., S. Hogekamp, and H. Schubert. 1999. Dispersion of powders in liquids in a stirred vessel. Chemical Engineering and Processing. 38:525-532.

Gaiani, C., S. Banon, J. Scher, P. Schuck, and J. Hardy. 2005. Use of a turbidity sensor to characterize micellar casein powder rehydration: Influence of some technological effects. Journal of Dairy Science. 88(8)2700-2706. 
Gaucheron, F. 2005. The minerals of milk. Reprod. Nutr. Dev. 45:473-483.

Gerstner, G. 2002. Jungbunzlauer. Innovations in Food Technology. 14:26-28. Systems AB.

Horiba Scientific. 2014. A guidebook to particle size analysis. Horiba Instruments, Inc. Irvine, CA.

IUPAC. 1997. Compendium of Chemical Terminology, 2nd ed. (the "Gold Book"). Compiled by A. D. McNaught and A. Wilkinson. Blackwell Scientific Publications, Oxford. XML on-line corrected version: http://goldbook.iupac.org (2006-) created by M. Nic, J. Jirat, B. Kosata; updates compiled by A. Jenkins. ISBN 0-9678550-9-8. doi:10.1351/goldbook.

ISO and IDF. 2012. Determination of the wettability (wetting time) of instant dried milk. ISO/TS 17758:2014|IDF/RM 87:2014. Annex B.

Keogh, K., C. Murray, J. Kelly, B. O'Kennedy. 2004. Effect of the particle size of the spray-dried milk powder on some properties of chocolate. Le Lait. 84:375-384.

Kim, E.H.J., X.D. Chen, and D. Pearce. 2002. Surface chracterization of four industrial spray-dried dairy powders in relation to chemical composition, structure, and wetting property. Colloids and Surfaces B: Biointerfaces. 26:197-212.

Konstance, R. P., and E. D. Strange. 1991. Solubility and viscous properties of casein and caseinates. J Food Sci. 56(2)556-559.

Kumar, K.V., N. Arunkumar, P. R. P. Vermna, and C. Rani. 2009. Preparation and in vitro characterization of Valsartan solid dispersions using skimmed milk powder as carrier. Int. Jour. PharmTech. Res. 1(3):431-437.

Litman, I. I., and U. S. Ashworth. 1957. Insoluble scum-like materials on reconstituted whole milk powders. J Dairy Sci 40(4)403-409.

Mao, X.Y., P.S. Tong, S. Gualco, and S. Vink. 2012. Effect of $\mathrm{NaCl}$ addition during diafiltration on the solubility, hydrophobicity, and disulfide bonds of $80 \%$ milk protein concentrate powder. J. Dairy Sci. 95:3481-3488.

Millqvist-Fureby, A., U. Elofsson, and B. Bergenstahl. 2001. Surface composition of spray-dried milk protein-stabilised emulsions in relation to pre-heat treatment of proteins. Colloids and Surfaces B: Biointerfaces 21:47-58.

Mimouni, A., H.C. Deeth, A.K. Whittaker, M.J. Gidley, B.R. Bhandari. 2009. Rehydration process of milk protein concentrate powder monitored by static light scattering. Food hydrocolloids. 23:1958-1965. 
Odagiri, S. and T. A. Nickerson. 1965. Complexing of calcium by hexametaphosphate, oxalate, citrate, and EDTA in milk. I. Effects of complexing agents on turbidity and rennet coagulation. J Dairy Sci, 47, 1306-1309.

Paracha, G. M. U. 2011. Characterisation of the rehydration behavior of milk protein concentrates in the presence of sugar. MS Thesis. Massey University, Manawatu campus, New Zealand.

Pearce, K. N. 2015. Food Science Section, New Zealand Dairy Research Institute. IIIDairy-C-Milk Powder. III-Dairy-C-Milk Powder 1-5.

Schuck, P., A. Davenel, F. Mariette, V. Briard, S. Mejean, and M. Piot. 2002.

Rehydration of casein powders: effects of added mineral salts and salt addition methods on water transfer. Int Dairy Journal. 12:51-57.

Schuck, P., S. Mejean, A. Dolivet, C. Gaiani, S. Banon, J. Scher, and R. Jeantet. 2007. Water transfer during rehydration of micellar casein powders. EDP Sciences Lait. $87: 425-432$.

Sikand, V., P. S. Tong, S. Roy, L. E. Rodrigues-Saona, and A. Murray. 2011. Solubility of commercial milk protein concentrates and isolates. J. Dairy Sci. 94:6194-6202.

Sikand, V., P. S. Tong, and J. Walker. 2013. Effect of adding salt during the diafiltration step of milk protein concentrate powder manufacture on mineral and soluble protein composition. Dairy Sci. \& Technol. 93:401-413.

Udabage, P., I. R. McKinnon, and M. Augustin. 2000. Mineral and casein equilibria in milk: effects of added salts and calcium-chelating agents. J Dairy Sci 67:361-370.

United States Geological Survey (USGS). 2013. ICP-OES technique description. Accessed Nov.19, 2015. http://minerals.cr.usgs.gov/gips/na/5process.html.

Vega, C., and Y. H. Roos. 2006. Invited review: spray-dried dairy and dairy-like emulsions-compositional considerations. J Dairy Sci 89(2)383-401.

Zeng, A., and P. Jandir. 2015. Accessed July.9, 2015. EDTA. UC Davis Chem Wiki. http://chemwiki.ucdavis.edu/Core/Inorganic_Chemistry/Coordination_Chemistry/Ligan ds/EDTA 


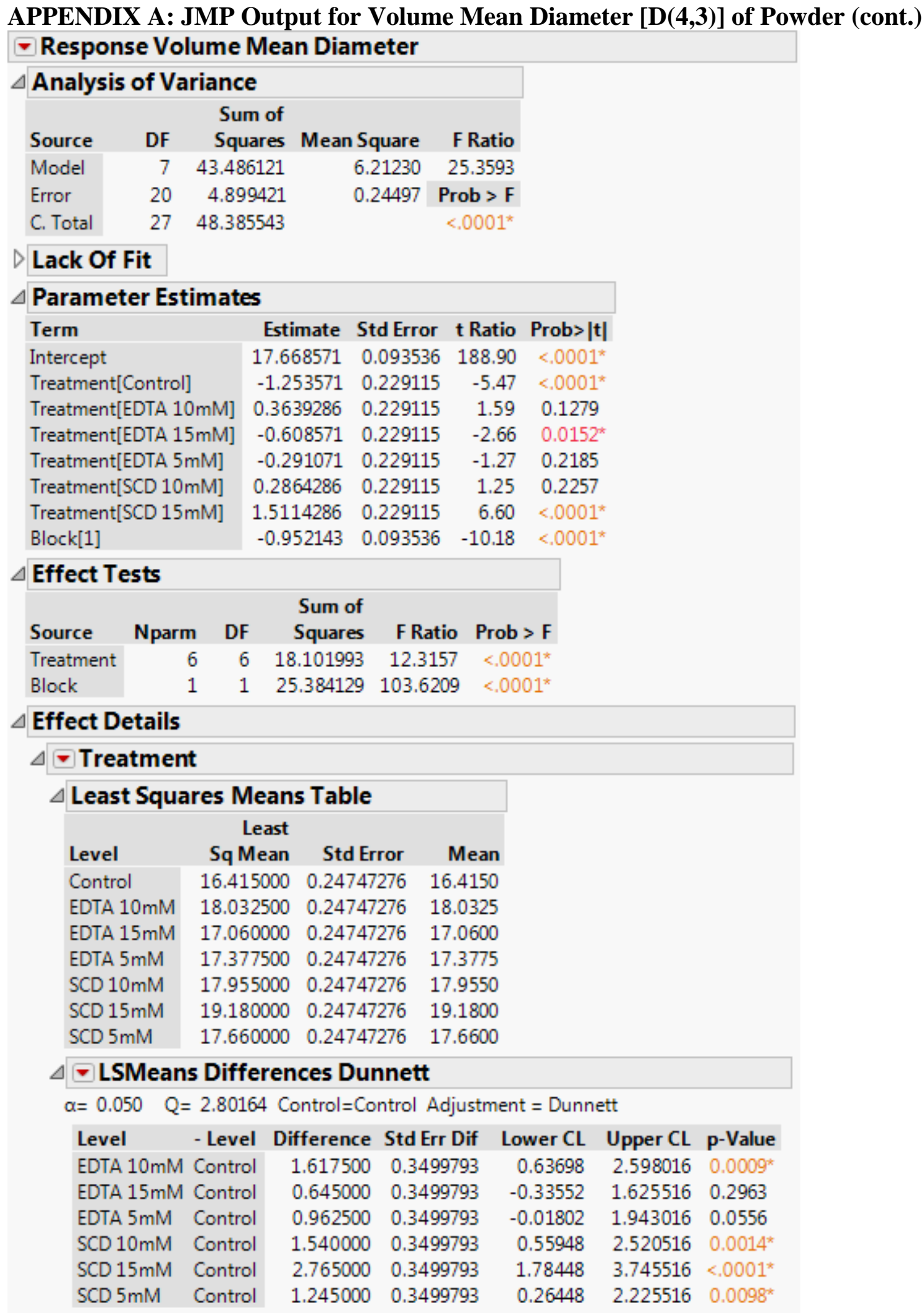


APPENDIX A: JMP Output for Volume Mean Diameter [D(4,3)] of Powder (cont.) - Distributions

\section{Residual Volume Mean Diameter}

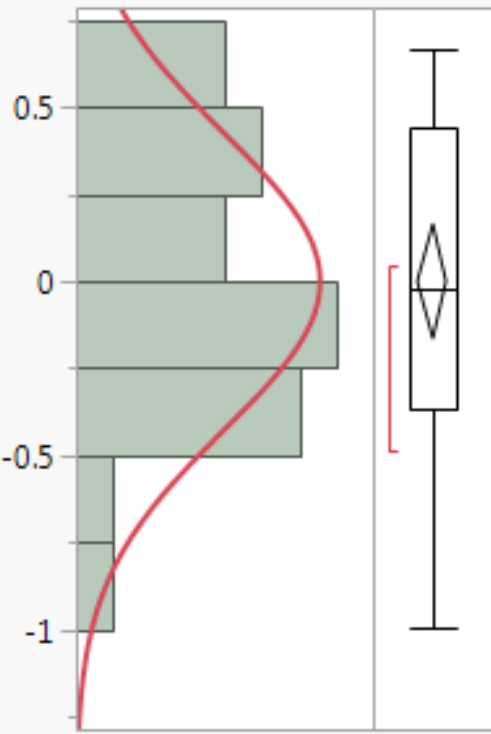

- Normal(-9e-16,0.42598)

$\triangleright$ Quantiles

$\triangle \nabla$ Summary Statistics

Mean $\quad-8.88 \mathrm{e}-16$

Std Dev $\quad 0.4259813$

Std Err Mean $\quad 0.0805029$

Upper $95 \%$ Mean 0.1651783

Lower $95 \%$ Mean -0.165178

$\mathrm{N}$

28

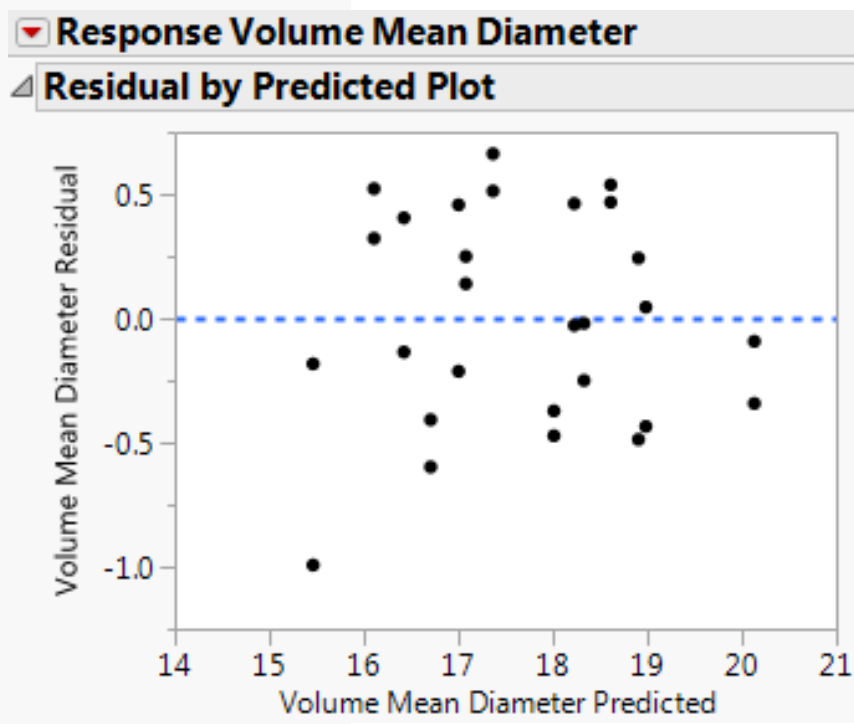

$\triangle$ Fitted Normal

$\triangleright$ Parameter Estimates

\section{$\triangle$ Goodness-of-Fit Test}

Shapiro-Wilk W Test

$\begin{array}{rc}\text { W } & \text { Prob }<W \\ 0.954223 & 0.2525\end{array}$

Note: Ho $=$ The data is from the Normal distribution. Small pvalues reject Ho. 
APPENDIX B: JMP Output for Volume Median Diameter of Powder Volume Median Diameter vs. Treatment

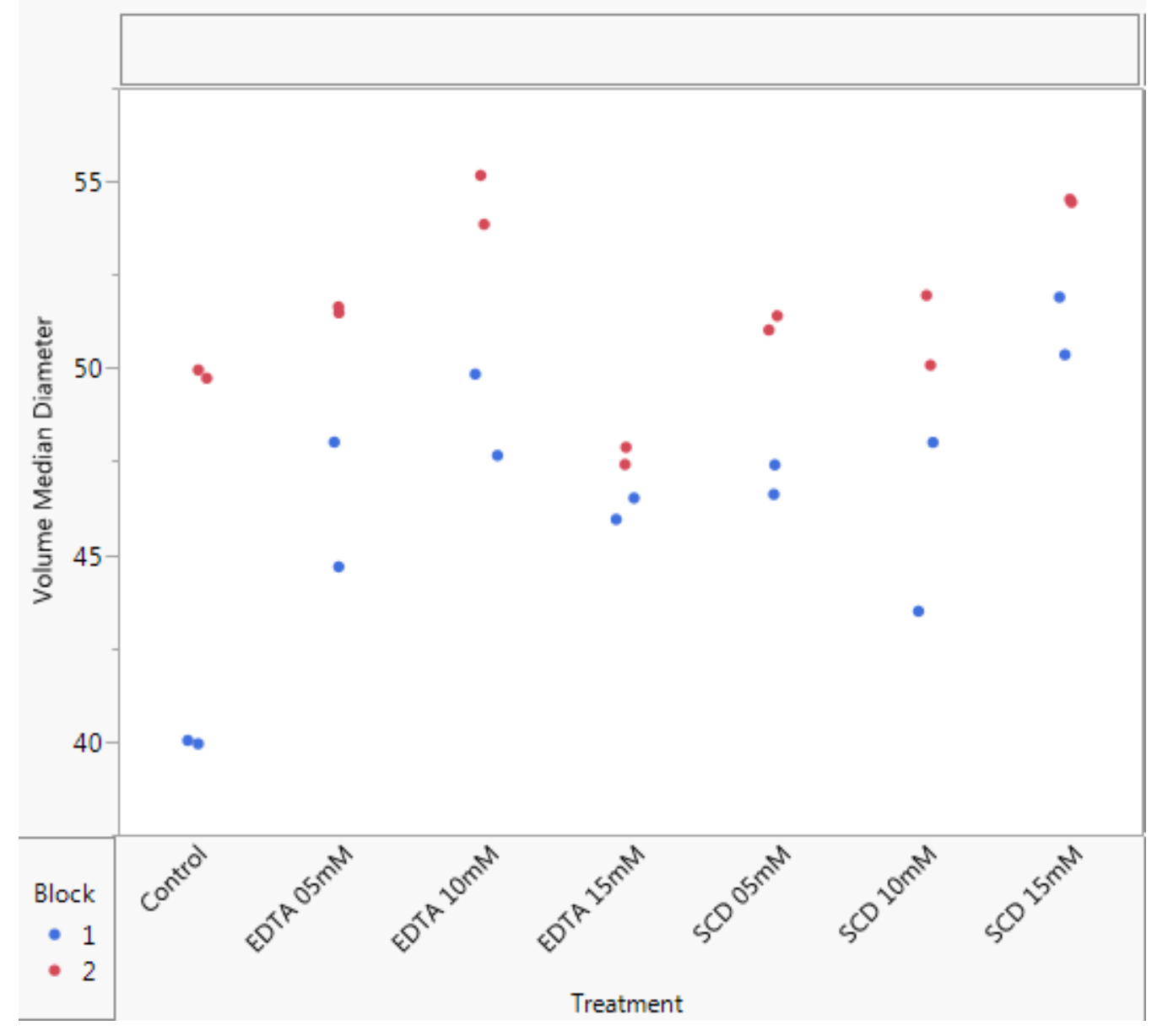

\begin{tabular}{|c|c|c|c|c|c|c|c|}
\hline & \multicolumn{7}{|c|}{ Means and Std Deviations } \\
\hline & Level & Number & Mean & Std Dev & $\begin{array}{r}\text { Std Err } \\
\text { Mean }\end{array}$ & Lower 95\% & Upper 95\% \\
\hline \multirow{9}{*}{ Block 1} & Control & 2 & 49.8400 & 0.15556 & 0.1100 & 48.442 & 51.238 \\
\hline & EDTA $05 \mathrm{mM}$ & 2 & 51.5600 & 0.11314 & 0.0800 & 50.544 & 52.576 \\
\hline & EDTA $10 \mathrm{mM}$ & 2 & 54.5050 & 0.92631 & 0.6550 & 46.182 & 62.828 \\
\hline & EDTA $15 \mathrm{mM}$ & 2 & 47.6500 & 0.32527 & 0.2300 & 44.728 & 50.572 \\
\hline & SCD $05 \mathrm{mM}$ & 3 & 49.6800 & 2.65684 & 1.5339 & 43.080 & 56.280 \\
\hline & $\mathrm{SCD} 10 \mathrm{mM}$ & 2 & 51.0150 & 1.32229 & 0.9350 & 39.135 & 62.895 \\
\hline & $\mathrm{SCD} 15 \mathrm{mM}$ & 2 & 54.4800 & 0.05657 & 0.0400 & 53.972 & 54.988 \\
\hline & \multicolumn{7}{|c|}{ Means and Std Deviations } \\
\hline & Level & Number & Mean & Std Dev & $\begin{array}{r}\text { Std Err } \\
\text { Mean }\end{array}$ & Lower $95 \%$ & Upper $95 \%$ \\
\hline \multirow{7}{*}{ Block 2} & Control & 2 & 39.9850 & 0.06364 & 0.0450 & 39.413 & 40.557 \\
\hline & EDTA $05 \mathrm{mM}$ & 2 & 46.3500 & 2.36174 & 1.6700 & 25.131 & 67.569 \\
\hline & EDTA $10 \mathrm{mM}$ & 2 & 48.7500 & 1.54149 & 1.0900 & 34.900 & 62.600 \\
\hline & EDTA $15 \mathrm{mM}$ & 2 & 46.2350 & 0.40305 & 0.2850 & 42.614 & 49.856 \\
\hline & SCD $05 \mathrm{mM}$ & 2 & 47.0150 & 0.55861 & 0.3950 & 41.996 & 52.034 \\
\hline & $\mathrm{SCD} 10 \mathrm{mM}$ & 2 & 45.7500 & 3.19612 & 2.2600 & 17.034 & 74.466 \\
\hline & $\mathrm{SCD} 15 \mathrm{mM}$ & 2 & 51.1300 & 1.08894 & 0.7700 & 41.346 & 60.914 \\
\hline
\end{tabular}




\section{APPENDIX B: JMP Output for Volume Median Diameter of Powder (cont.)}

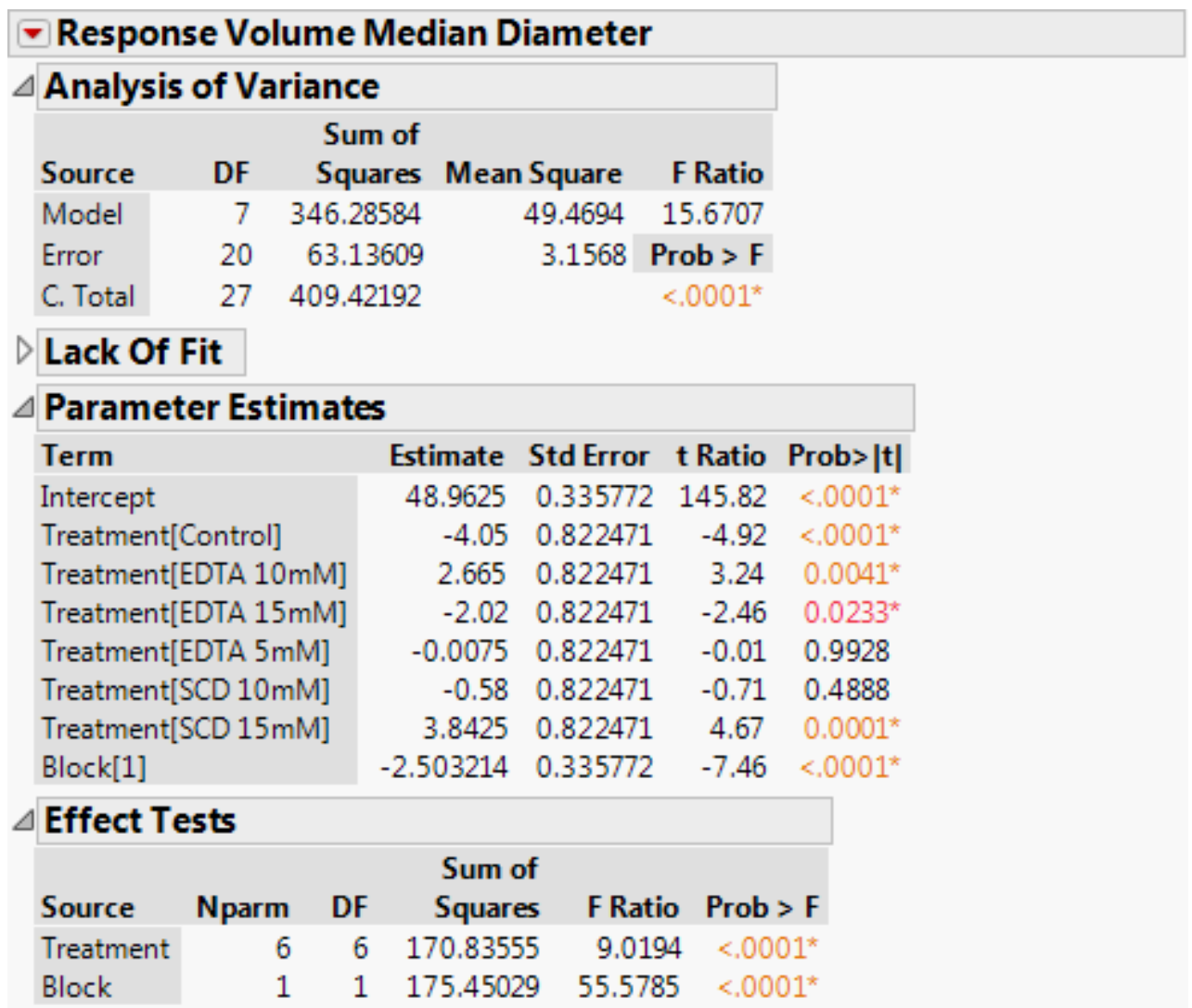

\begin{tabular}{|c|c|c|c|}
\hline \multicolumn{4}{|l|}{$\triangle$ Effect Details } \\
\hline \multicolumn{4}{|c|}{$\Delta \nabla$ Treatment } \\
\hline \multicolumn{4}{|c|}{$\triangle$ Least Squares Means Table } \\
\hline Level & $\begin{array}{r}\text { Least } \\
\text { Sq Mean }\end{array}$ & Std Error & Mean \\
\hline Control & 44.912500 & 0.88836990 & 44.9125 \\
\hline EDTA $10 \mathrm{mM}$ & 51.627500 & 0.88836990 & 51.6275 \\
\hline EDTA $15 \mathrm{mM}$ & 46.942500 & 0.88836990 & 46.9425 \\
\hline EDTA $5 \mathrm{mM}$ & 48.955000 & 0.88836990 & 48.9550 \\
\hline $\mathrm{SCD} 10 \mathrm{mM}$ & 48.382500 & 0.88836990 & 48.3825 \\
\hline SCD $15 \mathrm{mM}$ & 52.805000 & 0.88836990 & 52.8050 \\
\hline SCD $5 \mathrm{mM}$ & 49.112500 & 0.88836990 & 49.1125 \\
\hline
\end{tabular}

$\triangle \nabla$ LSMeans Differences Dunnett

$\alpha=0.050 \quad Q=2.80164$ Control=Control Adjustment $=$ Dunnett

$\begin{array}{llrrrrl}\text { Level } & \text { - Level } & \text { Difference } & \text { Std Err Dif } & \text { Lower CL } & \text { Upper CL } & \text { p-Value } \\ \text { EDTA 10mM Control } & 6.715000 & 1.256345 & 3.19517 & 10.23483 & 0.0002^{*} \\ \text { EDTA 15mM Control } & 2.030000 & 1.256345 & -1.48983 & 5.54983 & 0.4168 \\ \text { EDTA 5mM } & \text { Control } & 4.042500 & 1.256345 & 0.52267 & 7.56233 & 0.0207^{*} \\ \text { SCD 10mM } & \text { Control } & 3.470000 & 1.256345 & -0.04983 & 6.98983 & 0.0543 \\ \text { SCD 15mM } & \text { Control } & 7.892500 & 1.256345 & 4.37267 & 11.41233 & <.0001^{*} \\ \text { SCD 5mM } & \text { Control } & 4.200000 & 1.256345 & 0.68017 & 7.71983 & 0.0157^{*}\end{array}$


APPENDIX B: JMP Output for Volume Median Diameter of Powder (cont.)

\section{- Distributions \\ $\Delta$ Residual Volume Median Diameter}

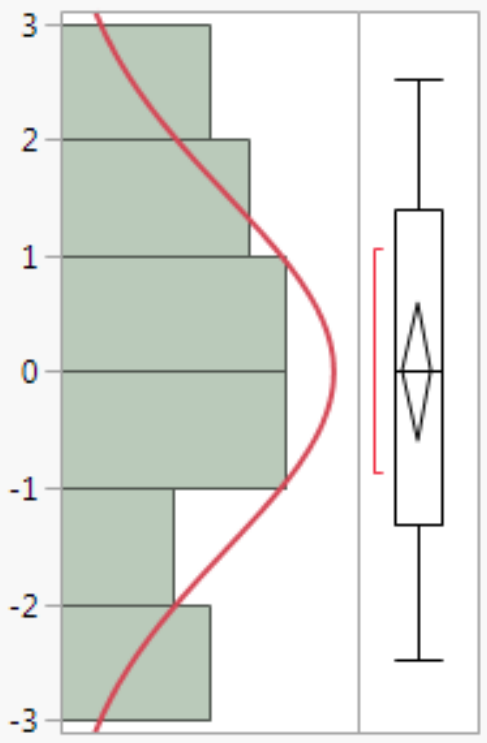

- Normal(1.5e-15,1.52917)

\section{$\triangleright$ Quantiles}

$\triangle \nabla$ Summary Statistics

\section{Mean}

$1.523 \mathrm{e}-15$

Std Dev 1.5291741

Std Err Mean 0.2889867

Upper $95 \%$ Mean 0.5929518

Lower $95 \%$ Mean $\quad-0.592952$

$\mathrm{N}$

\section{$\Delta$ Fitted Normal}

$\triangle$ Parameter Estimates

Type Parameter Estimate Lower 95\% Upper 95\%

Location $\mu$

$\begin{array}{lll}1.523 \mathrm{e}-15 & -0.592952 & 0.5929518\end{array}$

Dispersion $\sigma$

$\begin{array}{lll}1.5291741 & 1.2089951 & 2.0814148\end{array}$

$-2 \log ($ Likelihood $)=102.245315260018$

\section{$\triangle$ Goodness-of-Fit Test}

Shapiro-Wilk W Test

W Prob $<W$

$0.956140 \quad 0.2814$

Note: $\mathrm{Ho}=$ The data is from the Normal distribution. Small pvalues reject $\mathrm{Ho}$. 
APPENDIX C: JMP Output for Contact Angle at 0.5 Seconds

0.5 seconds vs. Treatment

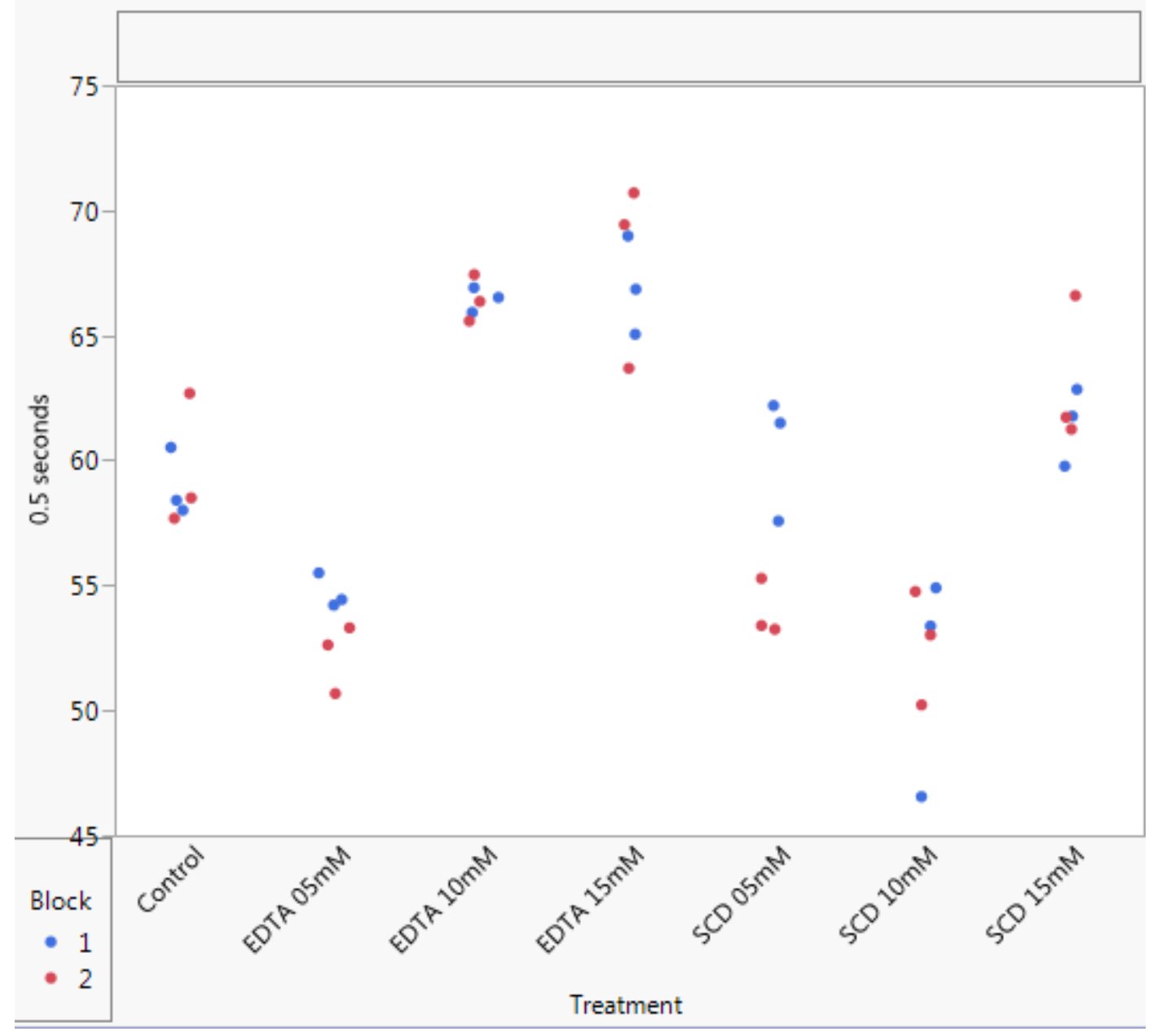

\begin{tabular}{|c|c|c|c|c|c|c|}
\hline \multicolumn{7}{|c|}{ Means and Std Deviations } \\
\hline Level & Number & Mean & Std Dev & $\begin{array}{r}\text { Std Err } \\
\text { Mean }\end{array}$ & Lower $95 \%$ & Upper $95 \%$ \\
\hline Control & 6 & 59.3037 & 2.02594 & 0.8271 & 57.178 & 61.430 \\
\hline EDTA $10 \mathrm{mM}$ & 6 & 66.4542 & 0.75959 & 0.3101 & 65.657 & 67.251 \\
\hline EDTA $15 \mathrm{mM}$ & 6 & 67.4490 & 2.81569 & 1.1495 & 64.494 & 70.404 \\
\hline EDTA $5 \mathrm{mM}$ & 6 & 53.4622 & 1.40681 & 0.5743 & 51.986 & 54.939 \\
\hline $\mathrm{SCD} 10 \mathrm{mM}$ & 6 & 52.1427 & 3.29796 & 1.3464 & 48.682 & 55.604 \\
\hline $\mathrm{SCD} 15 \mathrm{mM}$ & 6 & 62.3268 & 2.48221 & 1.0134 & 59.722 & 64.932 \\
\hline $\mathrm{SCD} 5 \mathrm{mM}$ & 6 & 57.2023 & 3.61470 & 1.4757 & 53.409 & 60.996 \\
\hline
\end{tabular}


APPENDIX C: JMP Output for Contact Angle at 0.5 Seconds (cont.)

Response 0.5 seconds

Effect Summary

Summary of Fit

$\triangle$ Analysis of Variance

\begin{tabular}{|c|c|c|c|c|}
\hline Source & DF & $\begin{array}{l}\text { Sum of } \\
\text { Squares }\end{array}$ & Mean Square & F Ratio \\
\hline Model & 7 & 1294.1652 & 184.881 & 28.1297 \\
\hline Error & 34 & 223.4629 & 6.572 & Prob $>F$ \\
\hline C. Total & 41 & 1517.6281 & & $<.0001^{*}$ \\
\hline
\end{tabular}

\begin{tabular}{|c|c|c|c|c|}
\hline \multicolumn{5}{|l|}{$D$ Lack O } \\
\hline \multicolumn{5}{|l|}{$\triangle$ Parameter Estimates } \\
\hline Term & Estimate & Std Error & t Ratio & Prob $>|t|$ \\
\hline Intercept & 59.762976 & 0.395584 & 151.08 & $<.0001^{*}$ \\
\hline Treatment[Control] & -0.45931 & 0.968979 & -0.47 & 0.6385 \\
\hline Treatment[EDTA $10 \mathrm{mM}$ ] & 6.6911905 & 0.968979 & 6.91 & $<.0001^{\star}$ \\
\hline Treatment[EDTA $15 \mathrm{mM}$ ] & 7.6860238 & 0.968979 & 7.93 & $<.0001^{*}$ \\
\hline Treatment[EDTA $5 \mathrm{mM}$ ] & -6.30081 & 0.968979 & -6.50 & $<.0001^{*}$ \\
\hline Treatment[SCD $10 \mathrm{mM}]$ & -7.62031 & 0.968979 & -7.86 & $<.0001^{*}$ \\
\hline Treatment[SCD 15mM] & 2.5638571 & 0.968979 & 2.65 & $0.0122^{\star}$ \\
\hline Block[1] & 0.3244048 & 0.395584 & 0.82 & 0.4179 \\
\hline
\end{tabular}

\begin{tabular}{lrrrrrr}
\hline Effect Tests & \multicolumn{5}{c}{ Sum of } \\
Source & Nparm & DF & $\begin{array}{r}\text { Squares } \\
\text { F Ratio }\end{array}$ & Prob > F \\
Treatment & 6 & 6 & 1289.7452 & 32.7059 & $<.0001^{*}$ \\
Block & 1 & 1 & 4.4200 & 0.6725 & 0.4179
\end{tabular}

\section{$\triangle$ Effect Details}

$\triangle \nabla$ Treatment

$\triangle$ Least Squares Means Table

$\begin{array}{lrrrr} & \begin{array}{r}\text { Least } \\ \text { Level }\end{array} & \text { Sq Mean } & \text { Std Error } & \text { Mean } \\ \text { Control } & 59.303667 & 1.0466165 & 59.3037 \\ \text { EDTA 10mM } & 66.454167 & 1.0466165 & 66.4542 \\ \text { EDTA 15mM } & 67.449000 & 1.0466165 & 67.4490 \\ \text { EDTA 5mM } & 53.462167 & 1.0466165 & 53.4622 \\ \text { SCD 10mM } & 52.142667 & 1.0466165 & 52.1427 \\ \text { SCD 15mM } & 62.326833 & 1.0466165 & 62.3268 \\ \text { SCD 5mM } & 57.202333 & 1.0466165 & 57.2023\end{array}$

\begin{tabular}{|c|c|c|c|c|c|c|}
\hline \multicolumn{7}{|c|}{$\Delta-$ LSMeans Differences Dunnett } \\
\hline \multicolumn{7}{|c|}{$\alpha=0.050 Q=2.7011$ Control $=$ Control Adjustment $=$ Dunnett } \\
\hline Level & - Level & Difference & Std Err Dif & Lower $\mathrm{CL}$ & Upl & le \\
\hline EDTA 1 & Cont & 0 & & & 11 & \\
\hline EDTA $15 \mathrm{mM}$ & Cont & & & & & \\
\hline EDTA $5 \mathrm{mM}$ & Control & & & -9.8 & & $0.0020^{*}$ \\
\hline $\mathrm{SCD} 10 \mathrm{mM}$ & Control & & & -11. & -3. & $0.0002^{*}$ \\
\hline SCD & Cont & & & & & \\
\hline $\mathrm{SCD} 5 \mathrm{mM}$ & Control & -2.10133 & 1.480139 & -6.0993 & 1.8967 & 0.5333 \\
\hline
\end{tabular}



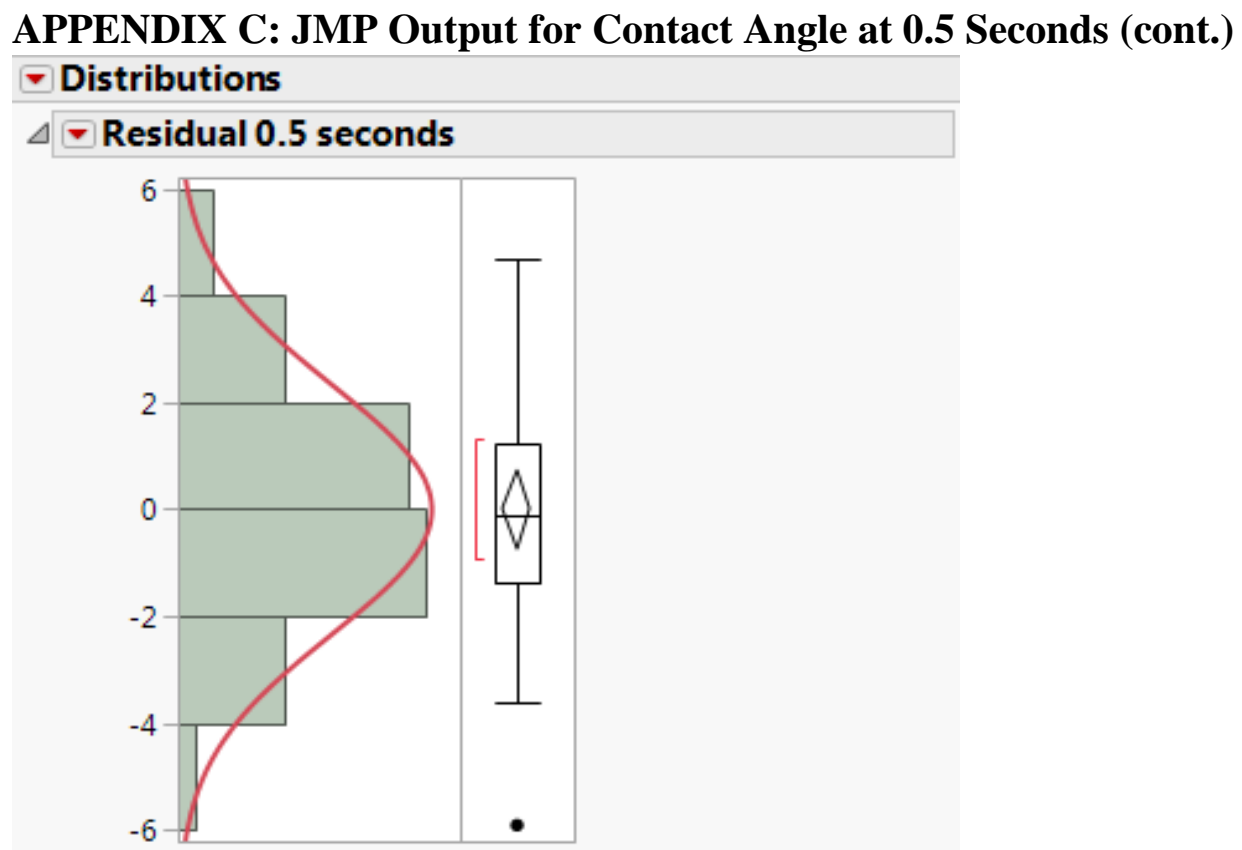

Normal(3.2e-15,2.33459)

\section{$\triangle$ Quantiles}

$100.0 \%$ maximum 4.6682619048

$99.5 \%$

$97.5 \%$

$90.0 \%$

$75.0 \%$

$50.0 \%$

$25.0 \%$

$10.0 \%$

$2.5 \%$

$0.5 \%$

$0.0 \%$

4.6682619048

4.662435119

3.6656380952

quartile 1.2313630952

median -0.103154762

quartile -1.366261905

$-3.268788095$

$-5.739685714$

$-5.911071429$

minimum $\quad-5.911071429$

\section{$\triangle$ Summary Statistics}

Mean

Std Dev

3.214e-15

2.3345907

Std Err Mean

0.3602352

Upper $95 \%$ Mean

Lower $95 \%$ Mean

0.7275097

$-0.72751$
Response 0.5 seconds
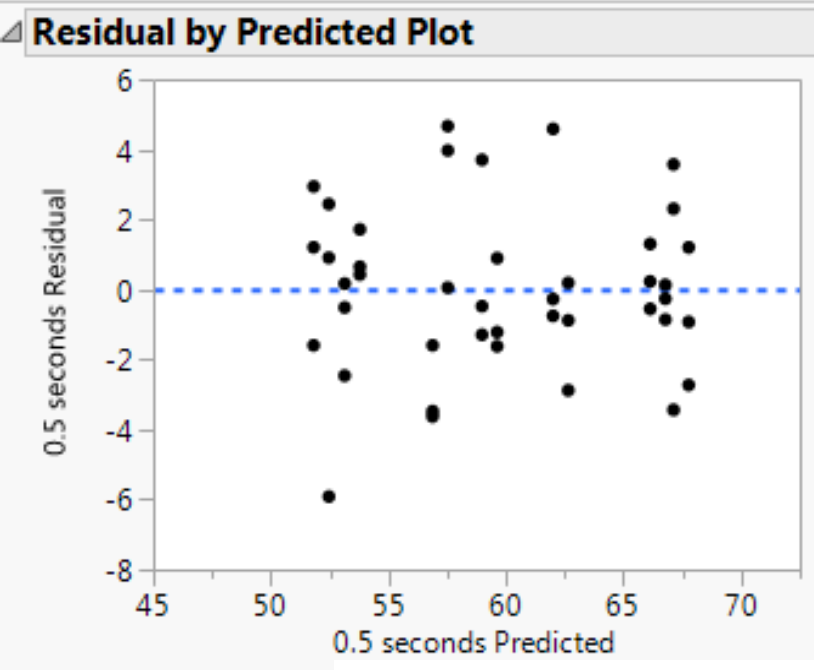
$\mathrm{N}$

$\Delta \nabla$ Fitted Normal

\section{$\triangle$ Parameter Estimates}

Type Parameter Estimate Lower 95\% Upper 95\%

\begin{tabular}{ll|lll} 
Location $\mu$ & $3.214 \mathrm{e}-15$ & -0.72751 & 0.7275097
\end{tabular}

$\begin{array}{llll}\text { Dispersion } \sigma & 2.3345907 & 1.920913 & 2.9769897\end{array}$

$-2 \log ($ Likelihood $)=189.409109773348$

\section{$\triangle$ Goodness-of-Fit Test}

Shapiro-Wilk W Test

W Prob $<$ W

$0.980875 \quad 0.6953$

Note: $\mathrm{Ho}=$ The data is from the Normal distribution. Small pvalues reject $\mathrm{Ho}$. 
APPENDIX D: JMP Output for International Dairy Federation (IDF) Wettability Wettability vs. Treatment

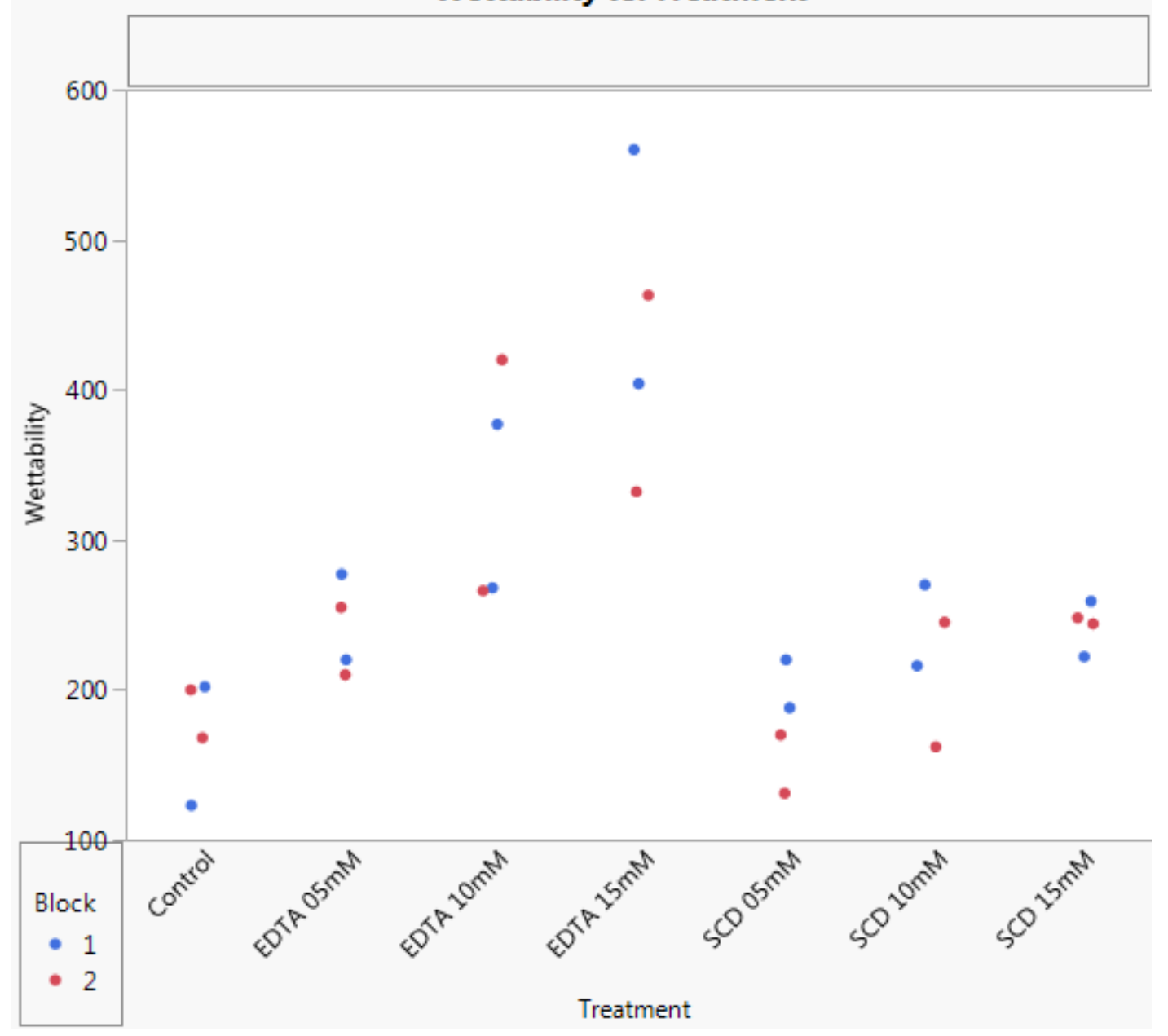

Means and Std Deviations

\begin{tabular}{lrrrrrrr} 
& & \multicolumn{7}{c}{$\begin{array}{c}\text { Std Err } \\
\text { Level }\end{array}$} & Number & Mean & Std Dev & Mean & Lower 95\% & Upper 95\% \\
Control & 4 & 173.250 & 42.5309 & 21.265 & 105.57 & 240.93 \\
EDTA 10mM & 4 & 332.750 & 80.6410 & 40.321 & 204.43 & 461.07 \\
EDTA 15mM & 4 & 439.750 & 90.9192 & 45.460 & 295.08 & 584.42 \\
EDTA 5mM & 4 & 240.500 & 29.7803 & 14.890 & 193.11 & 287.89 \\
SCD 10mM & 4 & 223.250 & 41.8332 & 20.917 & 156.68 & 289.82 \\
SCD 15mM & 4 & 243.250 & 21.5035 & 10.752 & 209.03 & 277.47 \\
SCD 5mM & 4 & 177.250 & 27.9169 & 13.958 & 132.83 & 221.67
\end{tabular}




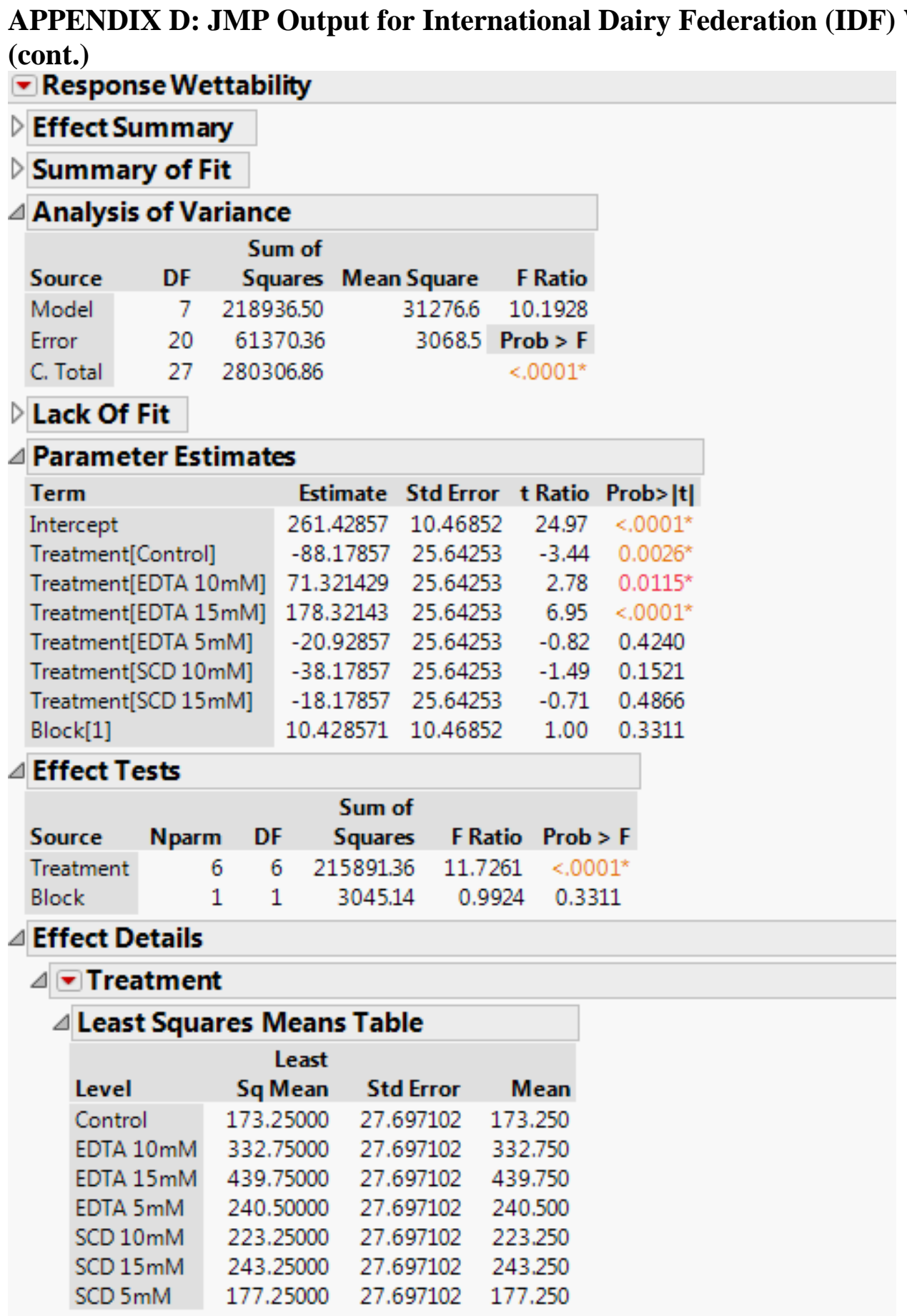

\begin{tabular}{|c|c|c|c|c|c|c|}
\hline \multicolumn{7}{|c|}{ - LSMeans Differences Dunnett } \\
\hline \multicolumn{7}{|c|}{$\alpha=0.050 Q=2.80164$ Control $=$ Control Adjustment $=$ Dunnett } \\
\hline Level & - Level & Difference & Std Err Dif & Lower CL & Upp & p- \\
\hline EDTA $10 \mathrm{mM}$ & Con & 159. & 39 & 1 & 92 & 0.00 \\
\hline EDTA $15 \mathrm{mM}$ & Cont & 26 & & 156 & & $<.0001^{*}$ \\
\hline EDTA $5 \mathrm{mM}$ & Control & 67.25 & & -42.489 & & 0.3 \\
\hline $\mathrm{SCD} 10 \mathrm{mM}$ & Control & 50.0000 & 39. & -59 & 159. & 0.6376 \\
\hline SCD $15 \mathrm{mM}$ & Control & 70.0000 & & -39 & 179.7392 & 0.3234 \\
\hline $\mathrm{SCD} 5 \mathrm{mM}$ & Control & 4.0000 & 39.16962 & -105.739 & 113.7392 & 1.0000 \\
\hline
\end{tabular}


APPENDIX D: JMP Output for International Dairy Federation (IDF) Wettability (cont.)

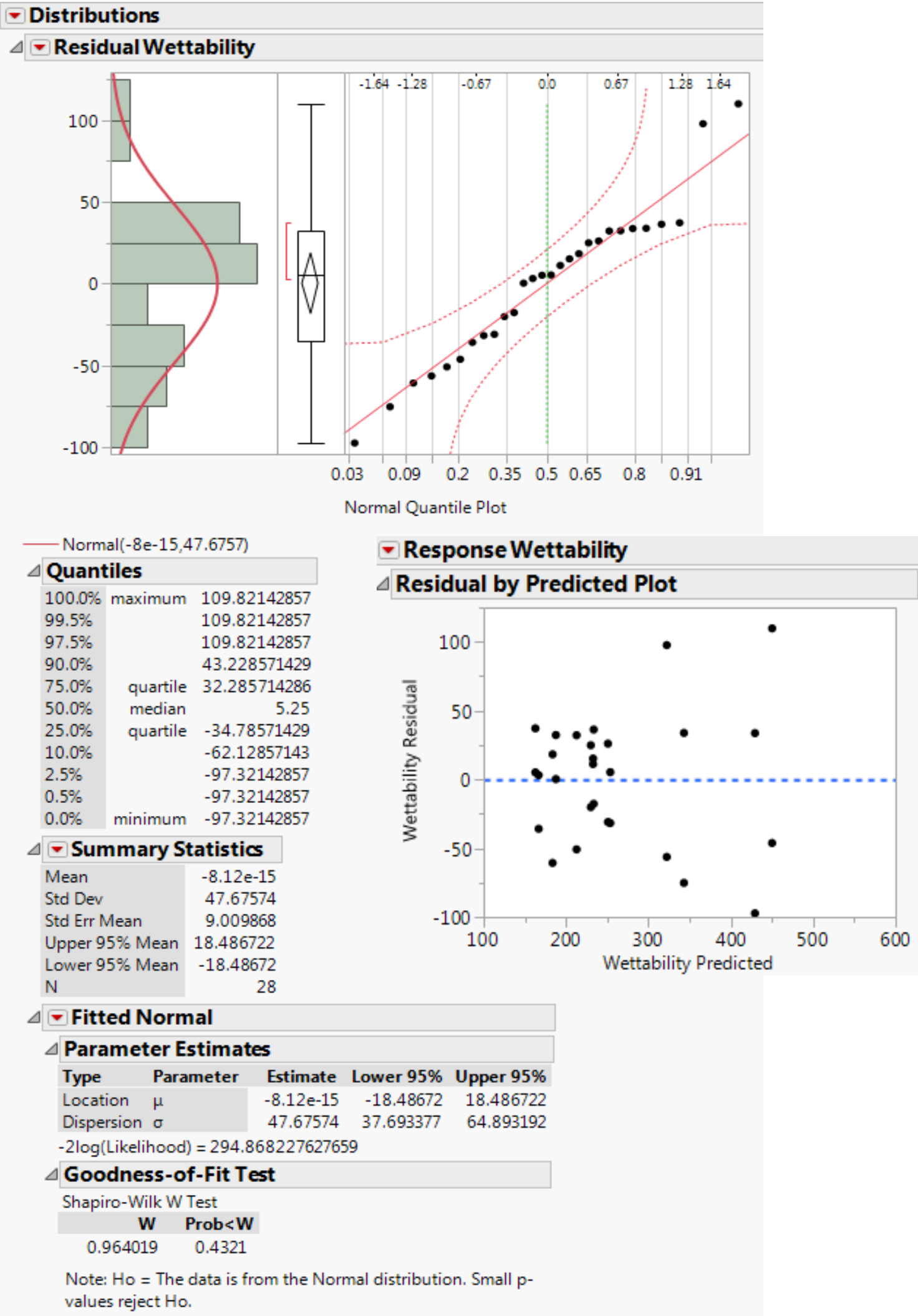


APPENDIX E: JMP Output for Dissolution Rate Dissolution Rate vs. Treatment

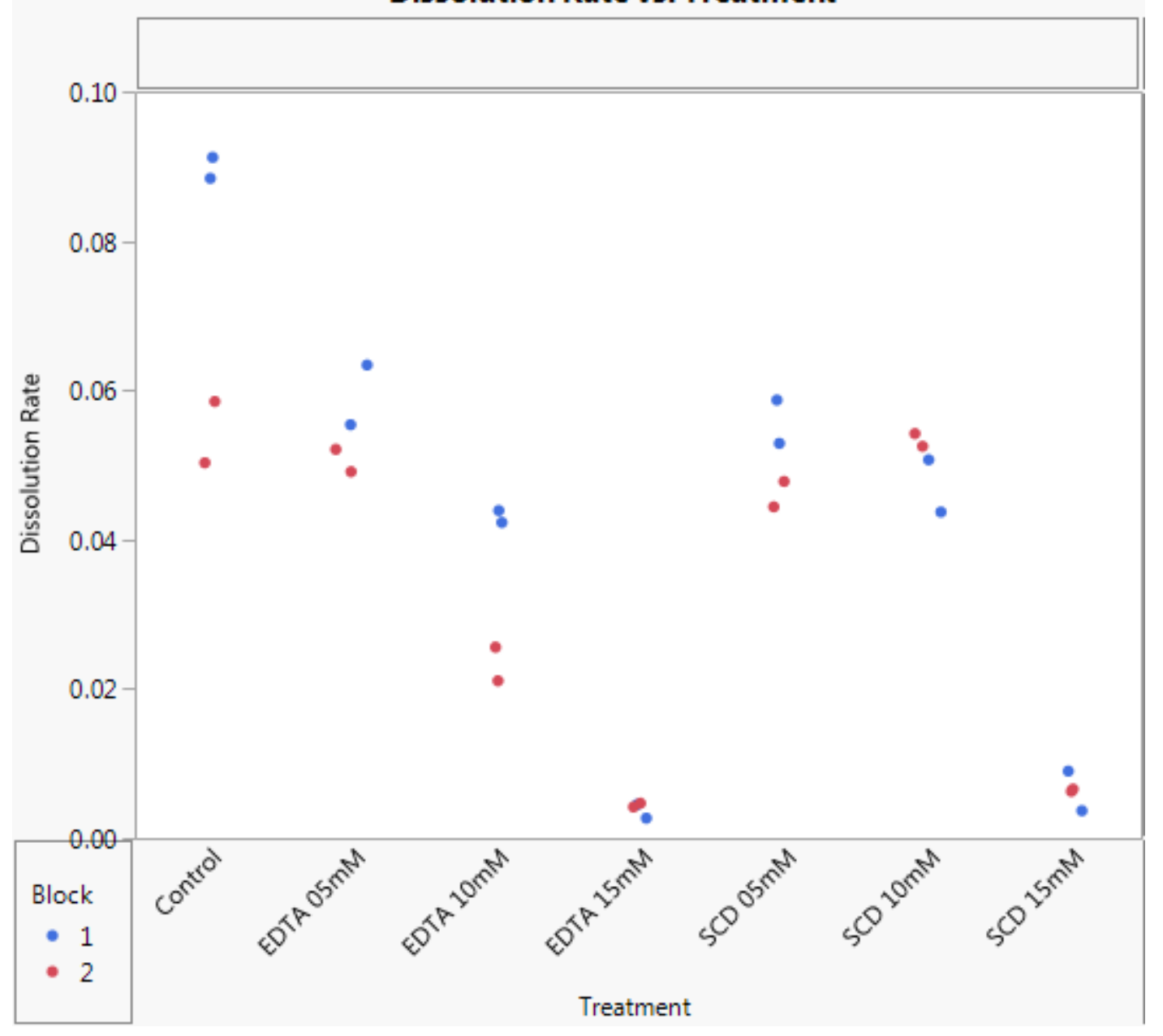

Means and Std Deviations
\begin{tabular}{l|rrrrrr} 
Level & Number & Mean & Std Dev & $\begin{array}{r}\text { Std Err } \\
\text { Mean }\end{array}$ & Lower $95 \%$ & Upper 95\% \\
Control & 4 & 0.072100 & 0.015362 & 0.00768 & 0.0477 & 0.09654 \\
EDTA 10mM & 4 & 0.033225 & 0.006227 & 0.00311 & 0.0233 & 0.04313 \\
EDTA 15mM & 4 & 0.004025 & 0.006028 & 0.00301 & -0.0056 & 0.01362 \\
EDTA 5mM & 4 & 0.055000 & 0.003512 & 0.00176 & 0.0494 & 0.06059 \\
SCD 10 mM & 4 & 0.050275 & 0.009506 & 0.00475 & 0.0351 & 0.06540 \\
SCD 15mM & 4 & 0.006400 & 0.005955 & 0.00298 & -0.0031 & 0.01588 \\
SCD 5mM & 4 & 0.050950 & 0.002747 & 0.00137 & 0.0466 & 0.05532
\end{tabular}




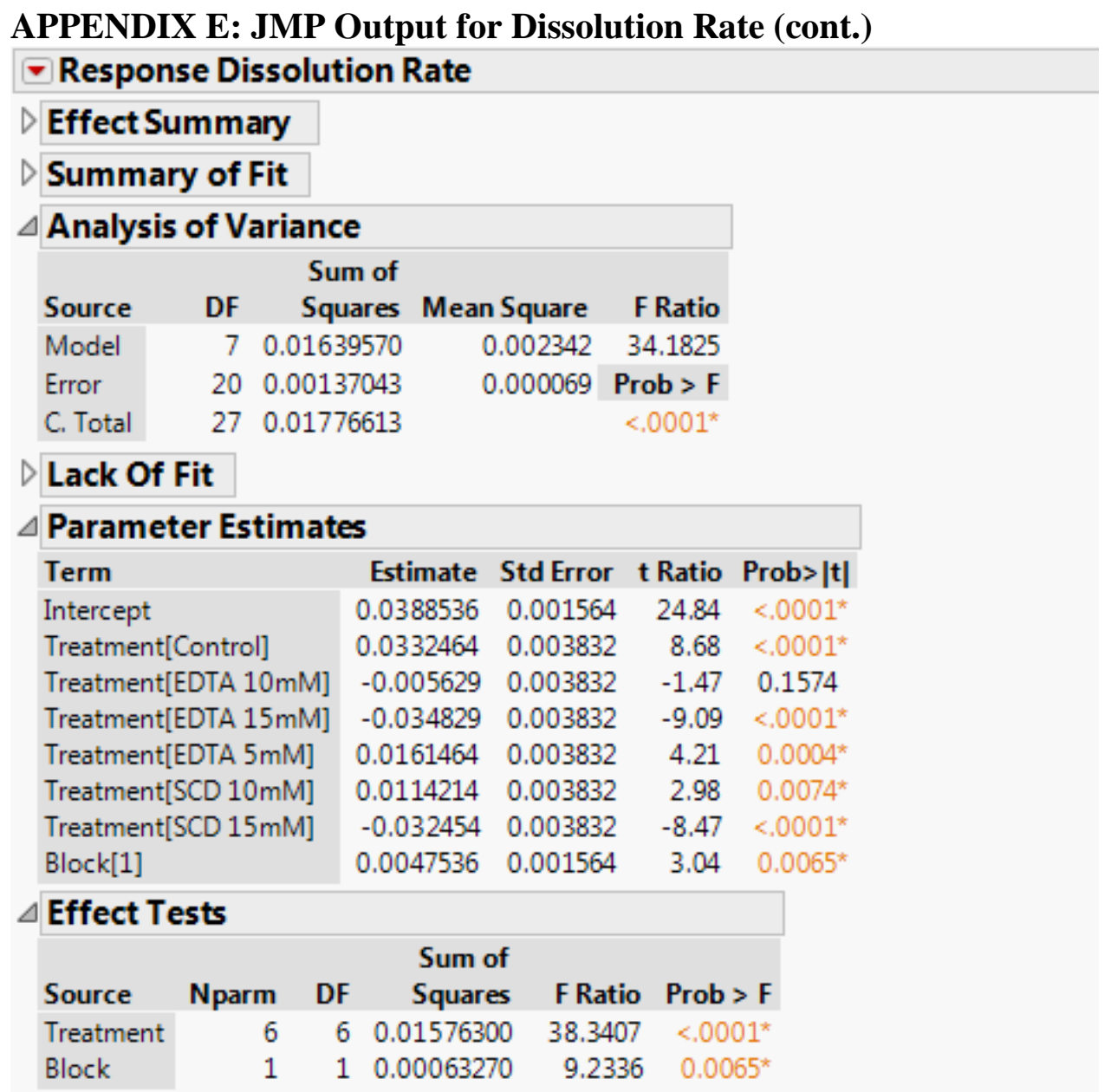

\begin{tabular}{|c|c|c|c|}
\hline \multicolumn{4}{|l|}{$\triangle$ Effect Details } \\
\hline \multicolumn{4}{|l|}{$\Delta-$ Treatment } \\
\hline \multicolumn{4}{|c|}{$\triangle$ Least Squares Means Table } \\
\hline Level & $\begin{array}{r}\text { Least } \\
\text { Sq Mean }\end{array}$ & Std Error & Mean \\
\hline Control & 0.07210000 & 0.00413889 & 0.072100 \\
\hline EDTA $10 \mathrm{mM}$ & 0.03322500 & 0.00413889 & 0.033225 \\
\hline EDTA $15 \mathrm{mM}$ & 0.00402500 & 0.00413889 & 0.004025 \\
\hline EDTA $5 \mathrm{mM}$ & 0.05500000 & 0.00413889 & 0.055000 \\
\hline $\mathrm{SCD} 10 \mathrm{mM}$ & 0.05027500 & 0.00413889 & 0.050275 \\
\hline $\mathrm{SCD} 15 \mathrm{mM}$ & 0.00640000 & 0.00413889 & 0.006400 \\
\hline $\mathrm{SCD} 5 \mathrm{mM}$ & 0.05095000 & 0.00413889 & 0.050950 \\
\hline
\end{tabular}

\begin{tabular}{|c|c|c|c|c|c|c|}
\hline \multicolumn{7}{|c|}{$\checkmark$ LSMeans Differences Dunnett } \\
\hline \multicolumn{7}{|c|}{$\alpha=0.050 Q=2.80164$ Control $=$ Control Adjustment $=$ Dunnett } \\
\hline Level & - Level & Difference & Std Err Dif & Lower CL & $U_{p}$ & \\
\hline EDTA 10 & & & & & & \\
\hline EDTA & & & & & & \\
\hline EDTA & Cont & & & & & \\
\hline$S C D$ & Cont & & & & & \\
\hline$S C D$ & Con & & & & & \\
\hline SCD $5 \mathrm{mM}$ & Control & -0.021150 & 0.0058533 & -0.037549 & -0.004751 & $0.0086^{*}$ \\
\hline
\end{tabular}




\section{APPENDIX E: JMP Output for Dissolution Rate (cont.)}

Distributions

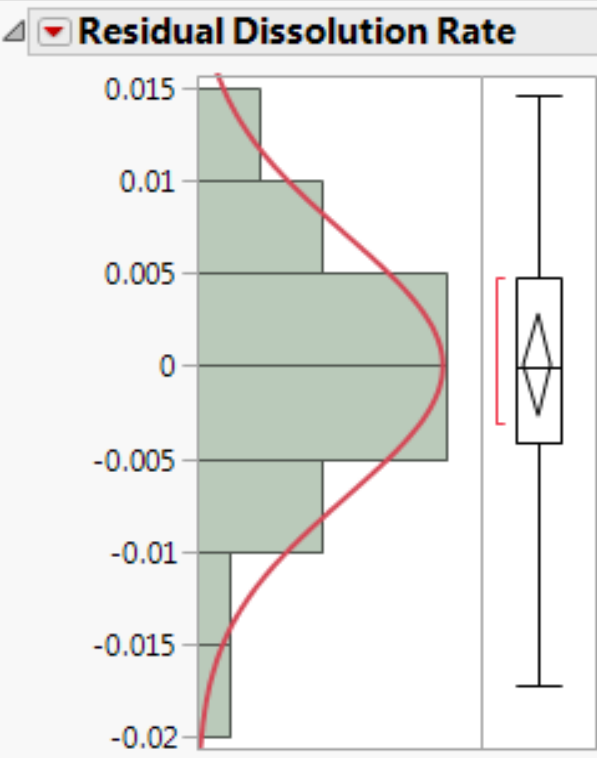

\section{Normal(3e-18,0.00708)}

\section{$\triangle$ Quantiles}

$100.0 \%$ maximum

$99.5 \%$

$97.5 \%$

$90.0 \%$

$75.0 \%$

$50.0 \%$

$25.0 \%$

$10.0 \%$

$2.5 \%$

$0.5 \%$

$0.0 \%$
0.01452875

0.01452875

0.01452875

0.0088195

quartile $\quad 0.004765$

median $\quad-0.00002625$

quartile $\quad-0.00413375$

$-0.0092405$

$-0.01722875$

$-0.01722875$

$-0.01722875$

\section{$\triangle$ - Summary Statistics}

Mean

$2.974 \mathrm{e}-18$

Std Dev

0.0070758

Std Err Mean

0.0013372

Upper 95\% Mean

0.0027437

Lower 95\% Mean

$-0.002744$

N

$\triangle$ Fitted Normal

\section{$\triangle$ Parameter Estimates}

Type Parameter Estimate Lower 95\% Upper 95\%

$\begin{array}{lllll}\text { Location } \mu & 2.974 \mathrm{e}-18 & -0.002744 & 0.0027437\end{array}$

Dispersion $\sigma \quad 0.0070758 \quad 0.0055943 \quad 0.0096312$

$-2 \log ($ Likelihood $)=-198.799430435015$

\section{$\triangle$ Goodness-of-Fit Test}

Shapiro-Wilk W Test

$$
\text { W Prob }<W
$$

$$
0.987526 \quad 0.9778
$$

Note: $\mathrm{Ho}=$ The data is from the Normal distribution. Small pvalues reject $\mathrm{Ho}$. 


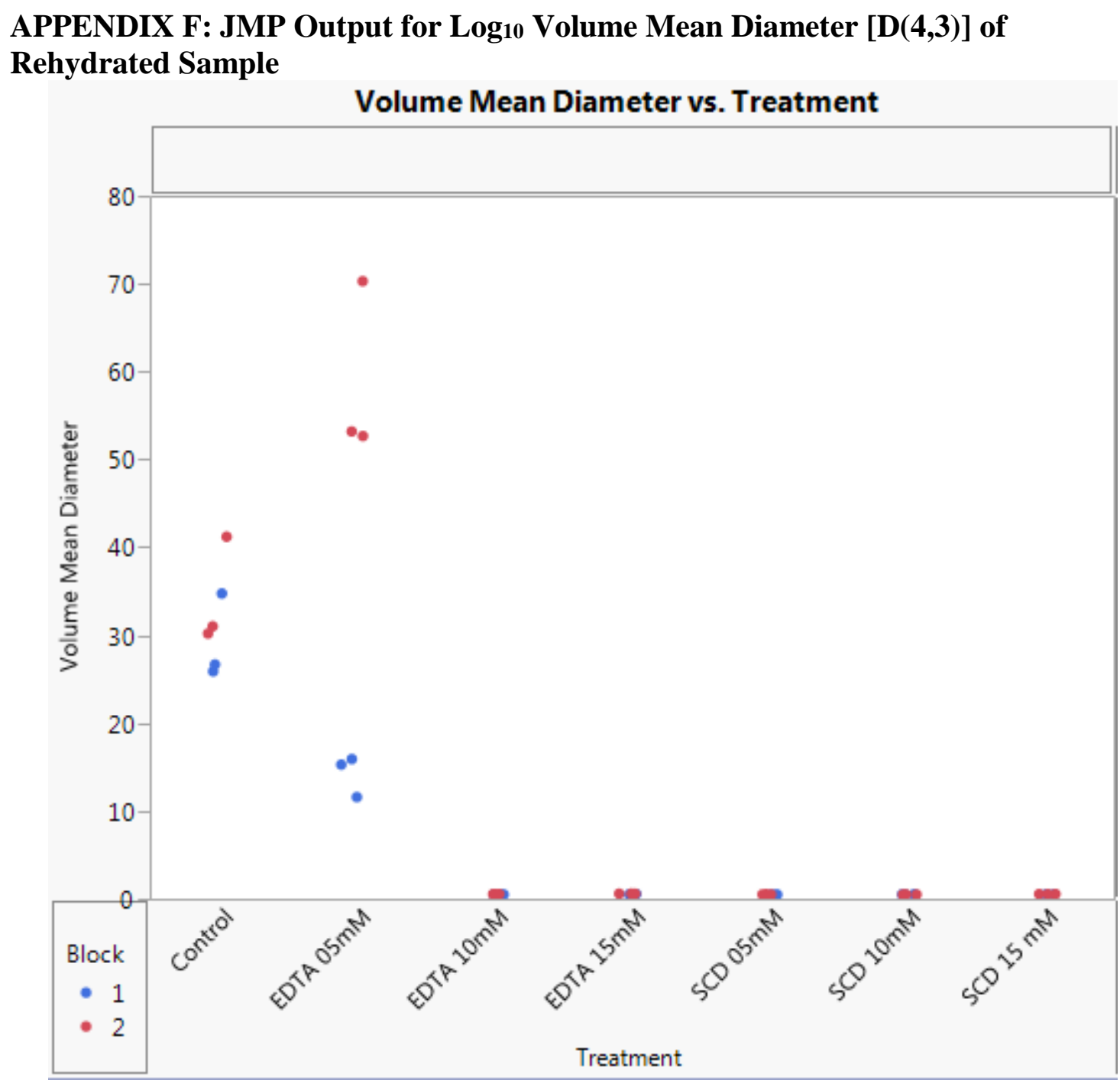

\begin{tabular}{|c|c|c|c|c|c|c|}
\hline \multicolumn{7}{|c|}{ Means and Std Deviations } \\
\hline Level & Number & Mean & Std Dev & $\begin{array}{r}\text { Std Err } \\
\text { Mean }\end{array}$ & Lower $95 \%$ & Upper $95 \%$ \\
\hline Control & 6 & 3.4415 & 0.160909 & 0.06569 & 3.273 & 3.610 \\
\hline EDTA $05 \mathrm{mM}$ & 6 & 3.3562 & 0.646852 & 0.26408 & 2.677 & 4.035 \\
\hline EDTA $10 \mathrm{mM}$ & 6 & -0.6306 & 0.097137 & 0.03966 & -0.733 & -0.529 \\
\hline EDTA $15 \mathrm{mM}$ & 6 & -0.5589 & 0.086148 & 0.03517 & -0.649 & -0.468 \\
\hline $\mathrm{SCD} 05 \mathrm{mM}$ & 6 & -0.6729 & 0.109539 & 0.04472 & -0.788 & -0.558 \\
\hline $\mathrm{SCD} 10 \mathrm{mM}$ & 6 & -0.6518 & 0.160185 & 0.06540 & -0.820 & -0.484 \\
\hline SCD $15 \mathrm{mM}$ & 6 & -0.5838 & 0.131998 & 0.05389 & -0.722 & -0.445 \\
\hline
\end{tabular}




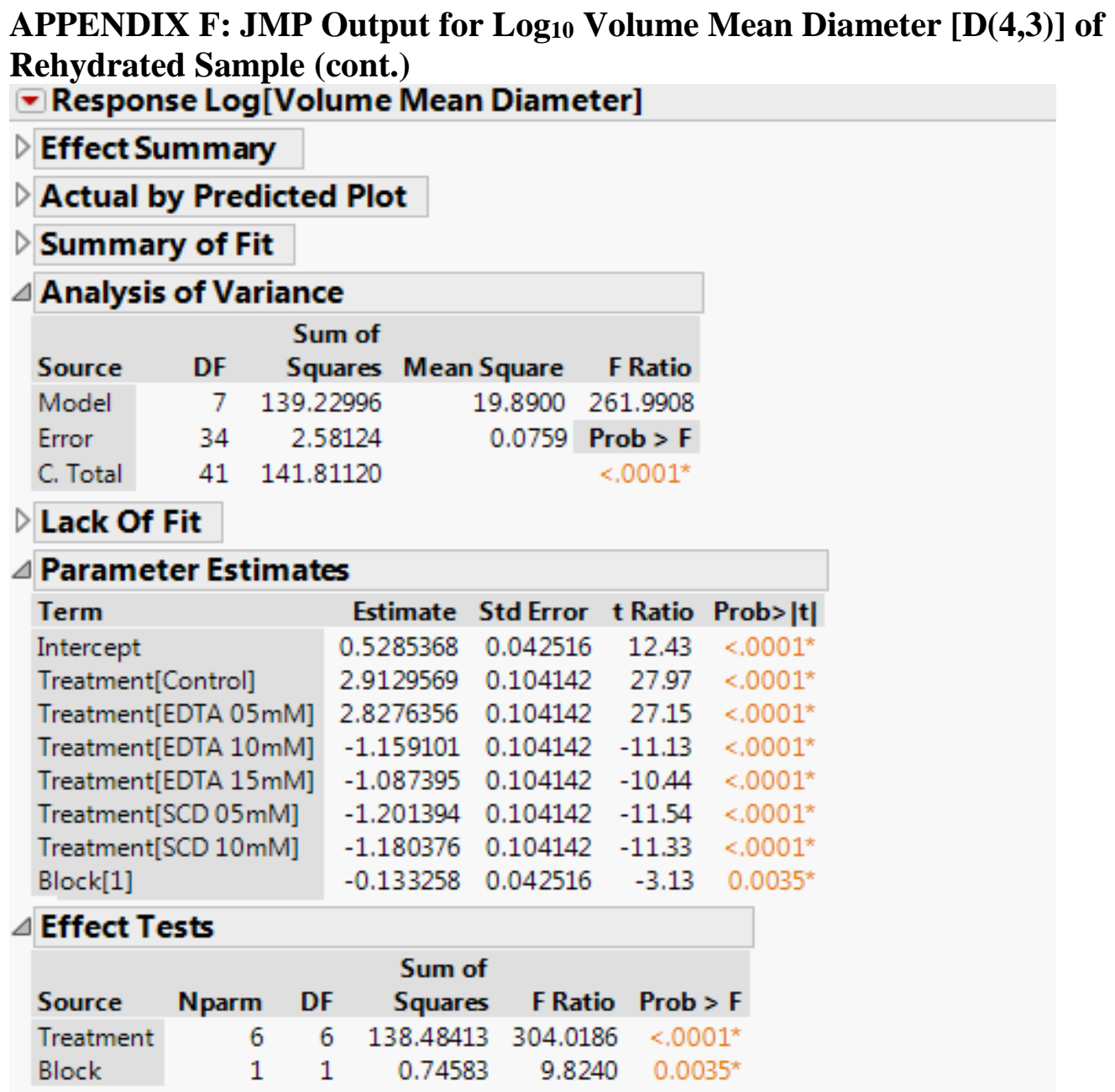

\begin{tabular}{|c|c|c|c|}
\hline \multicolumn{4}{|l|}{$\triangle$ Effect Details } \\
\hline \multicolumn{4}{|c|}{$\Delta \nabla$ Treatment } \\
\hline \multicolumn{4}{|c|}{$\triangle$ Least Squares Means Table } \\
\hline Level & $\begin{array}{r}\text { Least } \\
\text { Sq Mean }\end{array}$ & or & $\mathrm{Me}$ \\
\hline Control & 3.441494 & 0.11248606 & 3.4415 \\
\hline EDTA $05 \mathrm{mM}$ & 3.356172 & 0.11248606 & 3.3562 \\
\hline EDTA $10 \mathrm{mM}$ & -0.630564 & 0.11248606 & -0.6306 \\
\hline EDTA $15 \mathrm{mM}$ & -0.558859 & 0.11248606 & -0.5589 \\
\hline $\mathrm{SCD} 05 \mathrm{mM}$ & -0.672858 & 0.11248606 & -0.6729 \\
\hline $\mathrm{SCD} 10 \mathrm{mM}$ & -0.651839 & 0.11248606 & -0.6518 \\
\hline $\mathrm{SCD} 15 \mathrm{mM}$ & -0.583789 & 0.11248606 & -0.5838 \\
\hline
\end{tabular}

\begin{tabular}{|c|c|c|c|c|c|c|}
\hline \multicolumn{7}{|c|}{$\Delta \nabla$ LSMeans Differences Dunnett } \\
\hline \multicolumn{7}{|c|}{$\alpha=0.050 Q=2.7011$ Control $=$ Control Adjustment $=$ Dunnett } \\
\hline Level & - Level & Difference & Std Err Dif & Lower $\mathrm{CL}$ & Upper CL & p-Value \\
\hline EDTA $05 \mathrm{mM}$ & Control & -0.08532 & 0.1590793 & -0.51501 & 0.34437 & 0.9872 \\
\hline EDTA $10 \mathrm{mM}$ & Control & -4 & 0.15 & 5 & -3.6 & $<.0001^{*}$ \\
\hline EDTA $15 \mathrm{mM}$ & Control & -4.00035 & 0.15 & -4.4 & -3.5 & $<.0001^{*}$ \\
\hline $\mathrm{SCD} 05 \mathrm{mM}$ & Control & -4.11 & 0.15 & -4.5 & -3.6 & $<.0001^{*}$ \\
\hline $\mathrm{SCD} 10 \mathrm{mM}$ & Control & -4.0 & 0.15 & -4.5 & -3.66364 & $<.0001^{*}$ \\
\hline SCD $15 \mathrm{mM}$ & Control & -4.02528 & 0.1590793 & -4.45497 & -3.59559 & $<.0001^{*}$ \\
\hline
\end{tabular}


APPENDIX F: JMP Output for $\log _{10}$ Volume Mean Diameter $[D(4,3)]$ of Rehydrated Sample (cont.)

- Distributions

- Residual Log[Volume Mean Diameter]

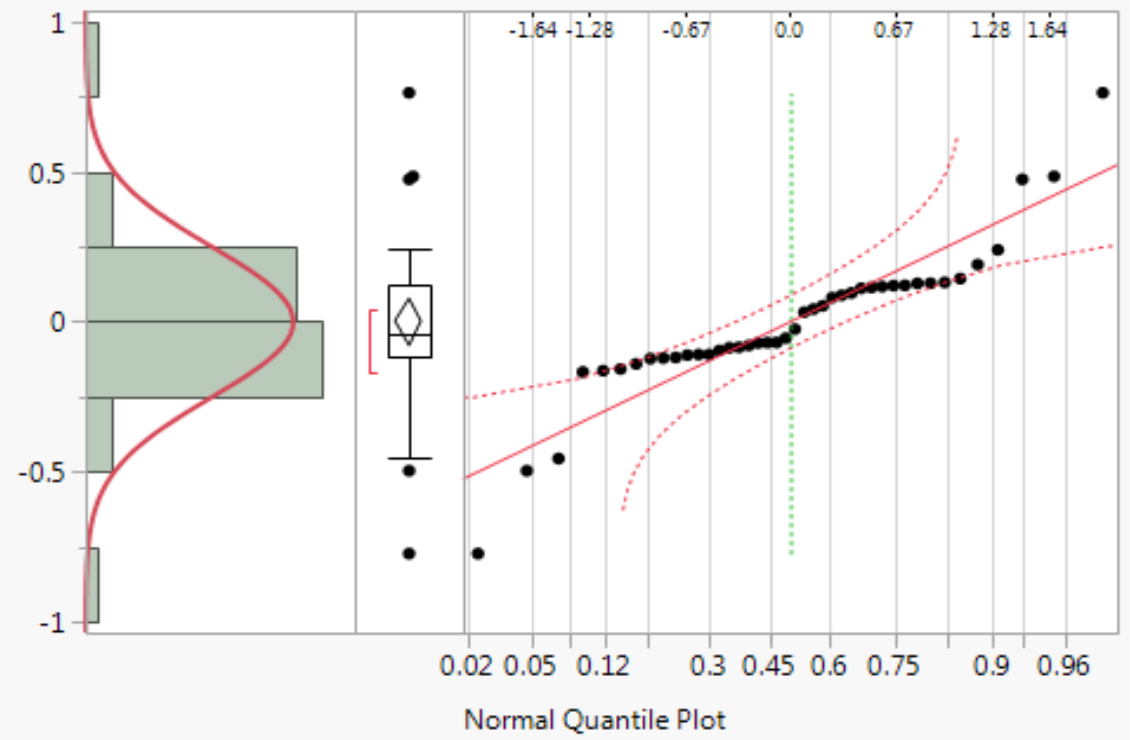

- Normal(-2e-17, 0.25091)

\section{$\triangle$ Quantiles}

$100.0 \%$ maximum

$99.5 \%$

$97.5 \%$

$90.0 \%$

$75.0 \%$

$50.0 \%$

$25.0 \%$

$10.0 \%$

$2.5 \%$

$0.5 \%$

$0.0 \%$

minimum

0.7633410613

0.7633410613

0.7424516525

0.2254294882

quartile 0.1211476499

median -0.038969314

quartile $\quad-0.112647374$

$-0.165628389$

$-0.751194394$

$-0.771908939$

$-0.771908939$

$\Delta \nabla$ Summary Statistics

Mean

Std Dev

Std Err Mean

$-1.72 \mathrm{e}-17$

0.2509123

0.0387166

$\begin{array}{lr}\text { Upper } 95 \% \text { Mean } & 0.0781898 \\ \text { Lower } 95 \% \text { Mean } & -0.07819\end{array}$

$\mathrm{N}$
- Response Log[Volume Mean Diameter]

$\triangle$ Residual by Predicted Plot

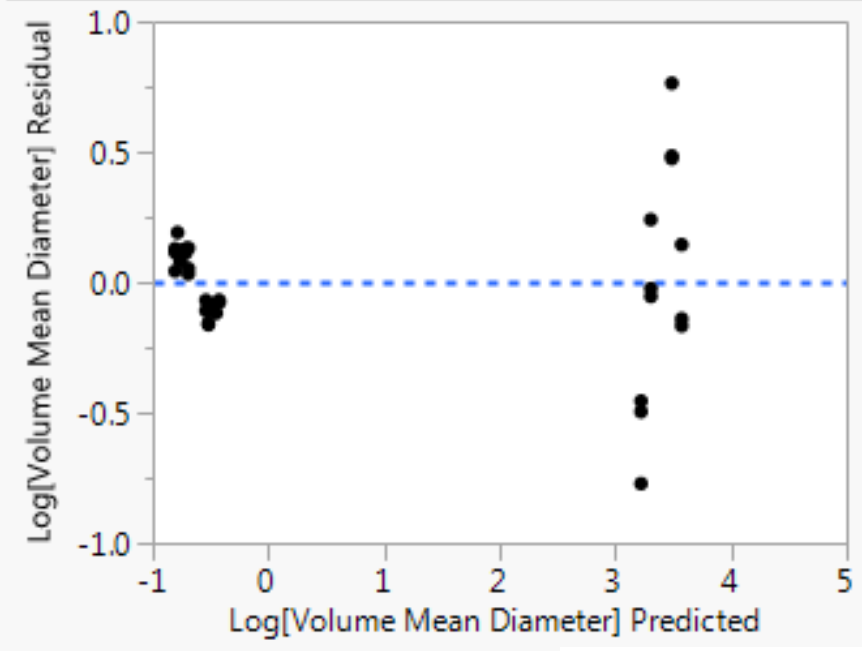

\section{$\Delta-$ Fitted Normal}

\section{$\triangle$ Parameter Estimates}

Type Parameter Estimate Lower 95\% Upper 95\%

\begin{tabular}{ll|lll} 
Location $\mu$ & $-1.72 \mathrm{e}-17$ & -0.07819 & 0.0781898
\end{tabular}

$\begin{array}{llll}\text { Dispersion } \sigma & 0.2509123 & 0.2064519 & 0.3199547\end{array}$

$-2 \log ($ Likelihood $)=2.04806973883304$

\section{$\triangle$ Goodness-of-Fit Test}

Shapiro-Wilk W Test

$$
\begin{array}{rr}
\text { W } & \text { Prob }<W \\
0.898966 & 0.0013^{*}
\end{array}
$$

Note: $\mathrm{Ho}=$ The data is from the Normal distribution. Small $p$ values reject $\mathrm{Ho}$. 
APPENDIX G: JMP Output for $\log _{10}$ Volume Median Diameter of Rehydrated Sample

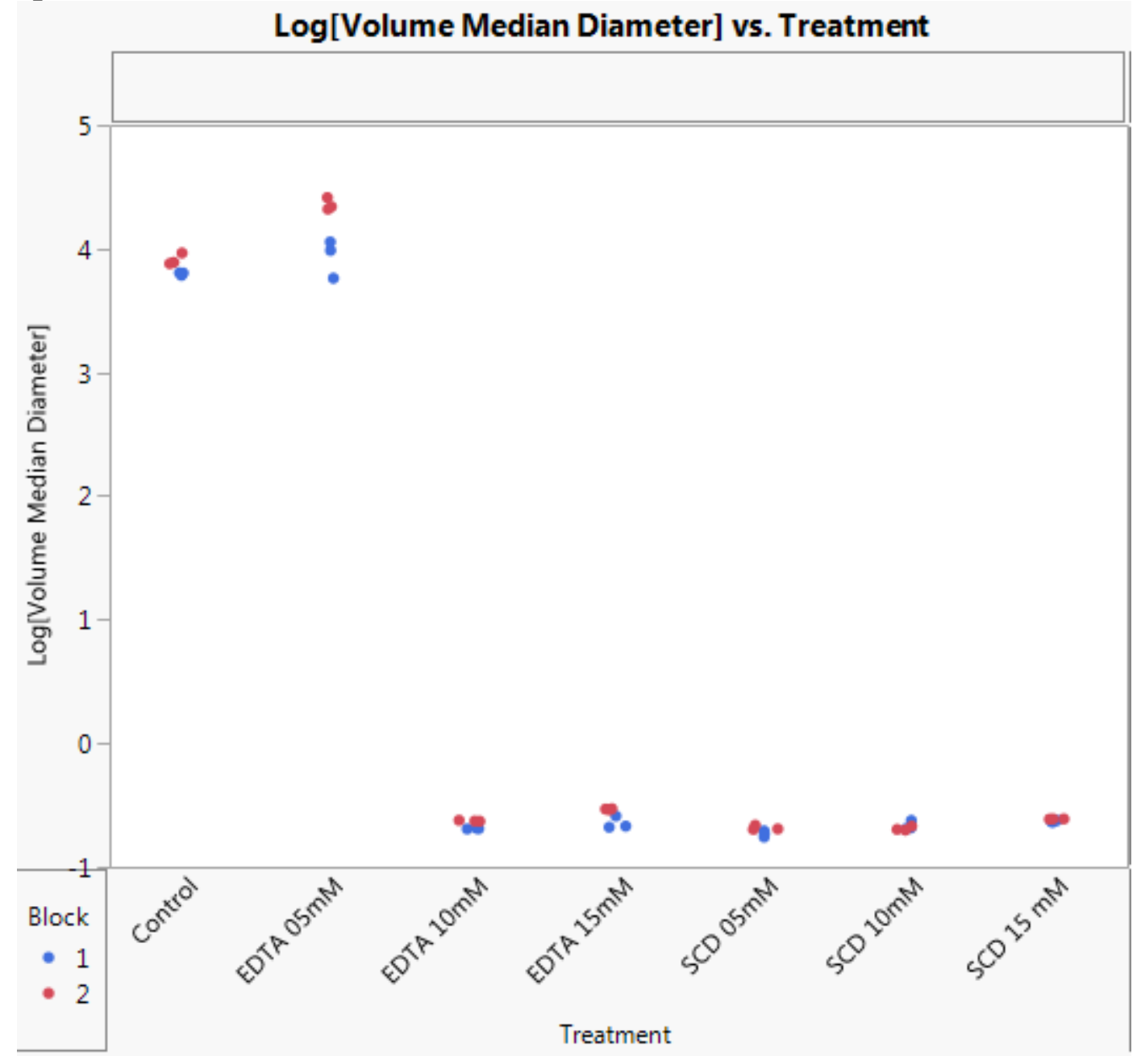

\begin{tabular}{|c|c|c|c|c|c|c|}
\hline \multicolumn{7}{|c|}{ Means and Std Deviations } \\
\hline Level & Number & Mean & Std Dev & $\begin{array}{r}\text { Std Err } \\
\text { Mean }\end{array}$ & Lower 95\% & Upper 95\% \\
\hline Control & 6 & 3.8551 & 0.030564 & 0.01248 & 3.823 & 3.887 \\
\hline EDTA $05 \mathrm{mM}$ & 6 & 4.1466 & 0.200749 & 0.08196 & 3.936 & 4.357 \\
\hline EDTA $10 \mathrm{mM}$ & 6 & -0.6573 & 0.025307 & 0.01033 & -0.684 & -0.631 \\
\hline EDTA $15 \mathrm{mM}$ & 6 & -0.5884 & 0.031886 & 0.01302 & -0.622 & -0.555 \\
\hline $\mathrm{SCD} 05 \mathrm{mM}$ & 6 & -0.7070 & 0.038012 & 0.01552 & -0.747 & -0.667 \\
\hline $\mathrm{SCD} 10 \mathrm{mM}$ & 6 & -0.6773 & 0.076113 & 0.03107 & -0.757 & -0.597 \\
\hline SCD $15 \mathrm{mM}$ & 6 & -0.6209 & 0.048924 & 0.01997 & -0.672 & -0.570 \\
\hline
\end{tabular}




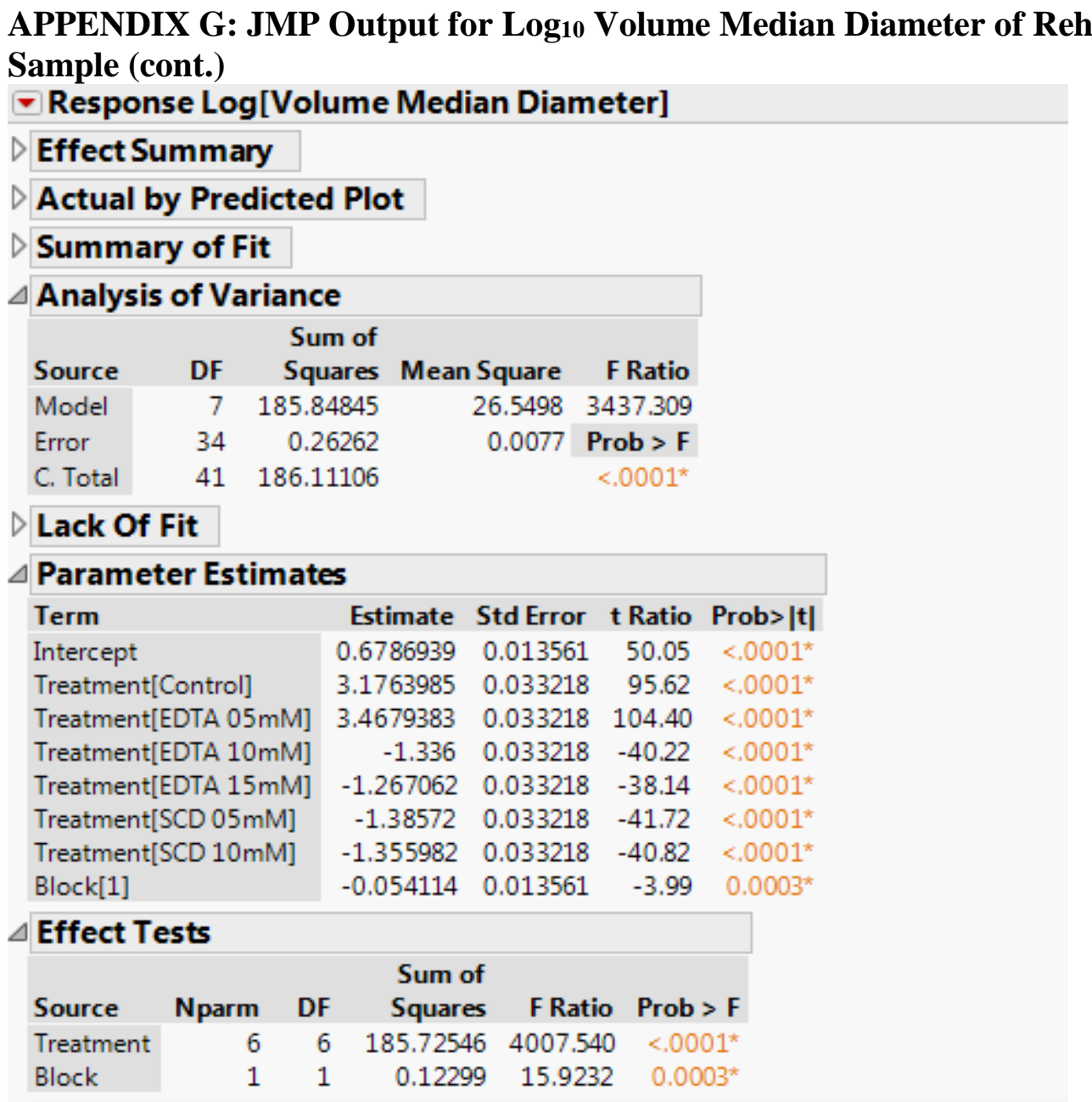

\begin{tabular}{|c|c|c|c|}
\hline \multicolumn{4}{|l|}{$\triangle$ Effect Details } \\
\hline \multicolumn{4}{|l|}{$\Delta \nabla$ Treatment } \\
\hline \multicolumn{4}{|c|}{$\triangle$ Least Squares Means Table } \\
\hline & Least & & \\
\hline Level & Sq Mean & Std Error & Mean \\
\hline Control & 3.855092 & 0.03587943 & 3.8551 \\
\hline EDTA $05 \mathrm{mM}$ & 4.146632 & 0.03587943 & 4.1466 \\
\hline EDTA $10 \mathrm{mM}$ & -0.657306 & 0.03587943 & -0.6573 \\
\hline EDTA $15 \mathrm{mM}$ & -0.588368 & 0.03587943 & -0.5884 \\
\hline $\mathrm{SCD} 05 \mathrm{mM}$ & -0.707026 & 0.03587943 & -0.7070 \\
\hline $\mathrm{SCD} 10 \mathrm{mM}$ & -0.677288 & 0.03587943 & -0.6773 \\
\hline SCD $15 \mathrm{mM}$ & -0.620880 & 0.03587943 & -0.6209 \\
\hline
\end{tabular}

$\triangle$ LSMeans Differences Dunnett

$\alpha=0.050 \quad Q=2.7011$ Control=Control Adjustment $=$ Dunnett

\begin{tabular}{llrrrrr} 
Level & - Level & Difference & Std Err Dif & Lower CL & Upper CL & p-Value \\
\hline EDTA 05mM Control & 0.29154 & 0.0507412 & 0.15448 & 0.42860 & $<.0001^{*}$ \\
EDTA 10mM Control & -4.51240 & 0.0507412 & -4.64945 & -4.37534 & $<.0001^{*}$ \\
EDTA 15mM Control & -4.44346 & 0.0507412 & -4.58052 & -4.30640 & $<.0001^{*}$ \\
SCD 05mM & Control & -4.56212 & 0.0507412 & -4.69918 & -4.42506 & $<.0001^{*}$ \\
SCD 10mM & Control & -4.53238 & 0.0507412 & -4.66944 & -4.39532 & $<.0001^{*}$ \\
SCD 15 mM Control & -4.47597 & 0.0507412 & -4.61303 & -4.33892 & $<.0001^{*}$
\end{tabular}




\section{APPENDIX G: JMP Output for $\log _{10}$ Volume Median Diameter of Rehydrated Sample (cont.)}

- Distributions
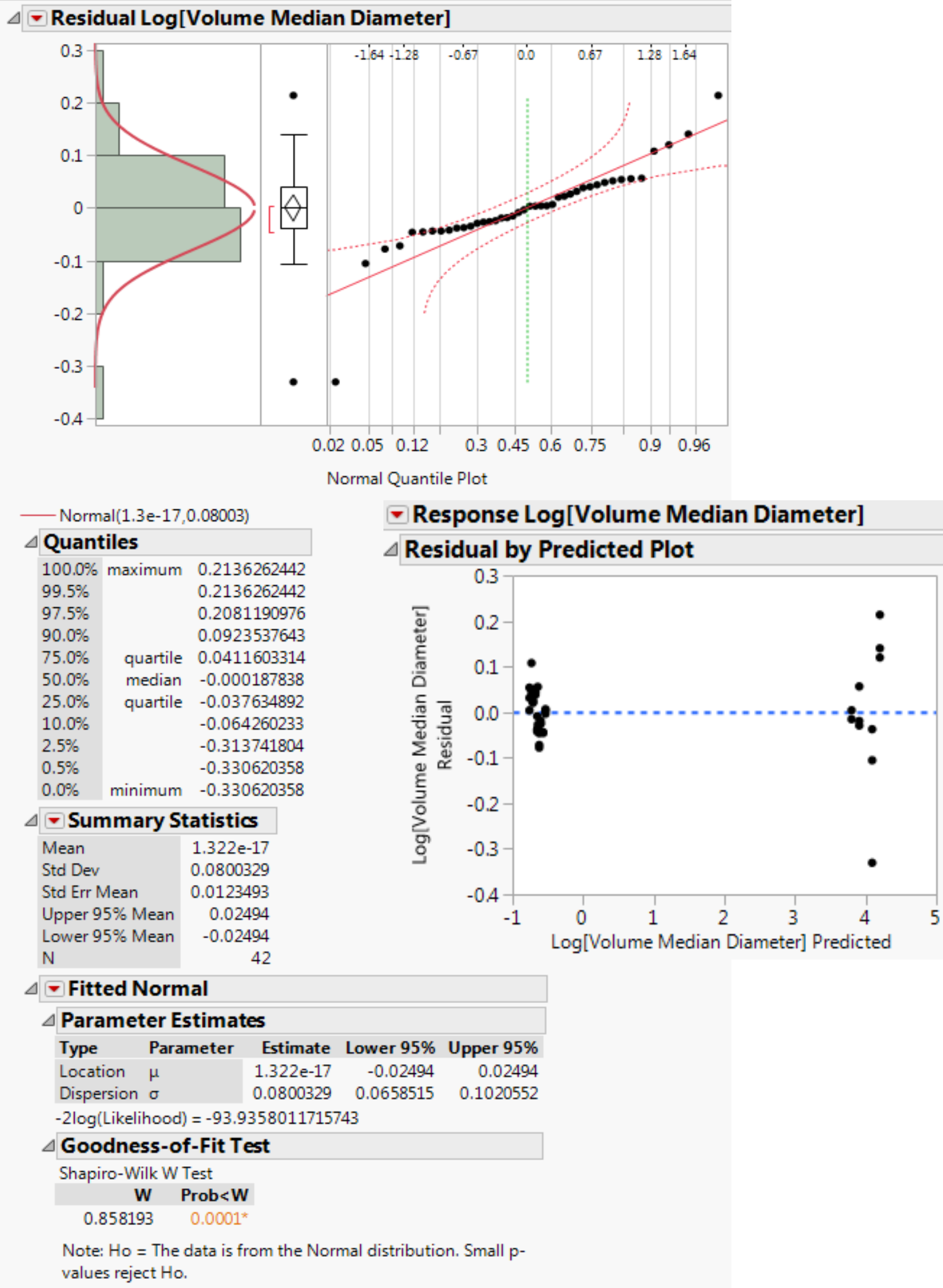
APPENDIX H: JMP Output for Solubility Index

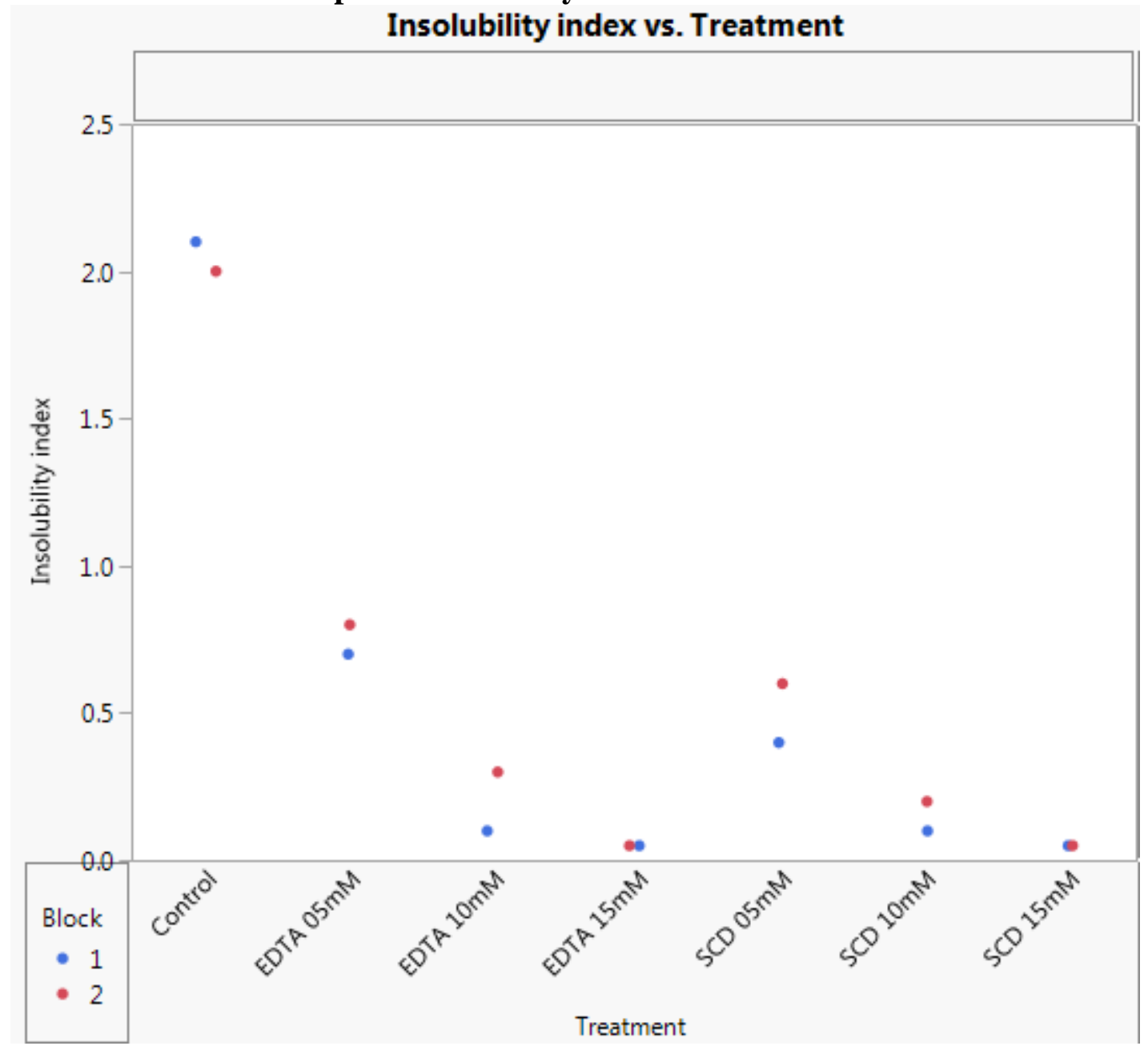

Means and Std Deviations
\begin{tabular}{l|rrrrrr} 
Level & Number & Mean & Std Dev & $\begin{array}{r}\text { Std Err } \\
\text { Mean }\end{array}$ & Lower $95 \%$ & Upper $95 \%$ \\
Control & 2 & 2.05000 & 0.121218 & 0.08571 & 0.9609 & 3.1391 \\
EDTA $10 \mathrm{mM}$ & 2 & 0.20000 & 0.090914 & 0.06429 & -0.6168 & 1.0168 \\
EDTA $15 \mathrm{mM}$ & 2 & 0.05000 & 0.050508 & 0.03571 & -0.4038 & 0.5038 \\
EDTA $5 \mathrm{mM}$ & 2 & 0.75000 & 0.020203 & 0.01429 & 0.5685 & 0.9315 \\
SCD 10 mM & 2 & 0.15000 & 0.020203 & 0.01429 & -0.0315 & 0.3315 \\
SCD 15mM & 2 & 0.05000 & 0.050508 & 0.03571 & -0.4038 & 0.5038 \\
SCD 5 mM & 2 & 0.50000 & 0.090914 & 0.06429 & -0.3168 & 1.3168
\end{tabular}




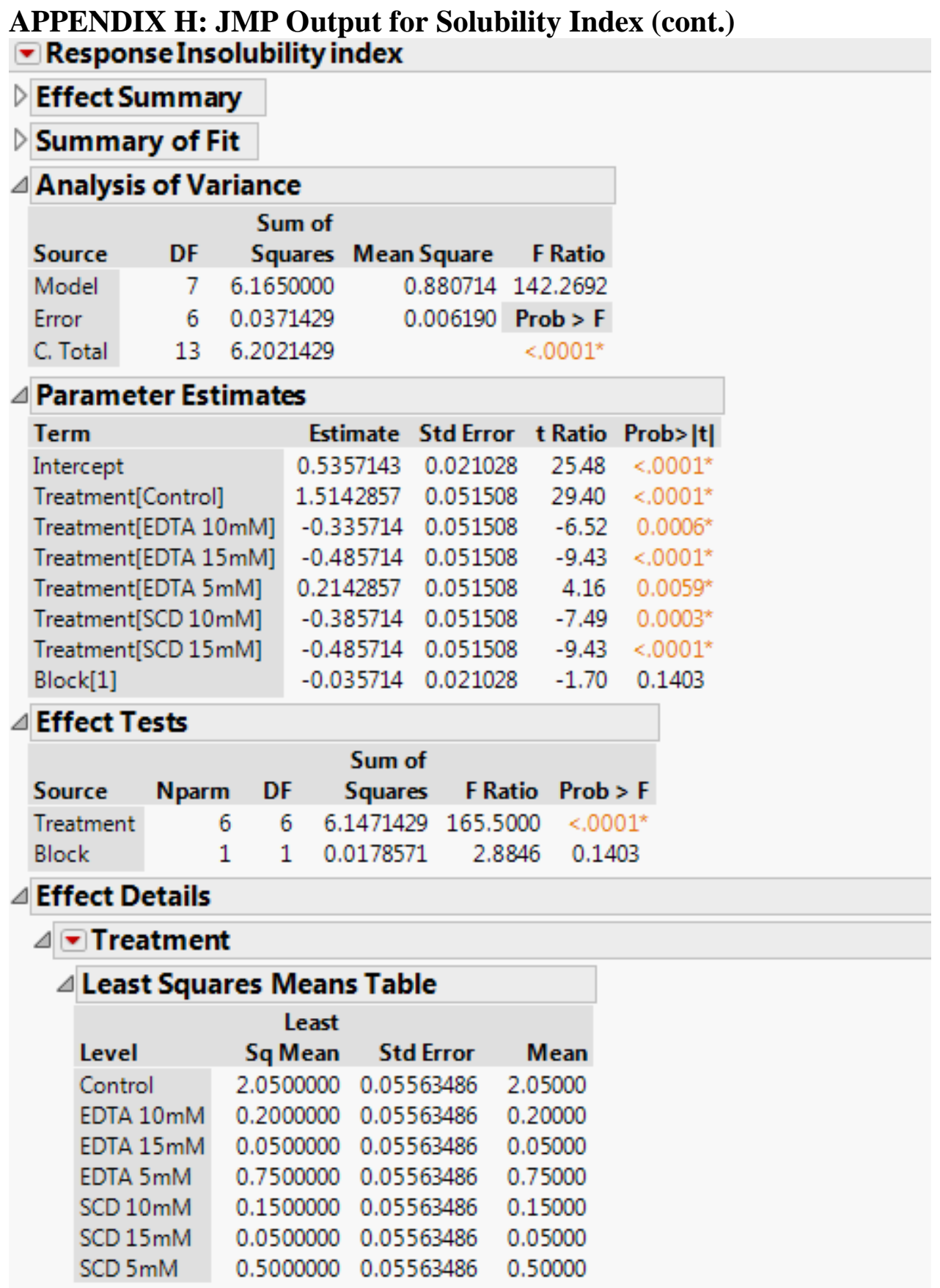

\section{$\triangle$ LSMeans Differences Dunnett}

$\alpha=0.050 Q=3.48878$ Control=Control Adjustment $=$ Dunnett

$\begin{array}{lcrrrrr}\text { Level } & \text { - Level } & \text { Difference } & \text { Std Err Dif } & \text { Lower CL } & \text { Upper CL } & \text { p-Value } \\ \text { EDTA 10mM Control } & -1.85000 & 0.0786796 & -2.12450 & -1.57550 & <.0001^{*} \\ \text { EDTA 15mM Control } & -2.00000 & 0.0786796 & -2.27450 & -1.72550 & <.0001^{*} \\ \text { EDTA 5mM } & \text { Control } & -1.30000 & 0.0786796 & -1.57450 & -1.02550 & <.0001^{*} \\ \text { SCD 10mM } & \text { Control } & -1.90000 & 0.0786796 & -2.17450 & -1.62550 & <.0001^{*} \\ \text { SCD 15mM } & \text { Control } & -2.00000 & 0.0786796 & -2.27450 & -1.72550 & <.0001^{*} \\ \text { SCD 5mM } & \text { Control } & -1.55000 & 0.0786796 & -1.82450 & -1.27550 & <.0001^{*}\end{array}$




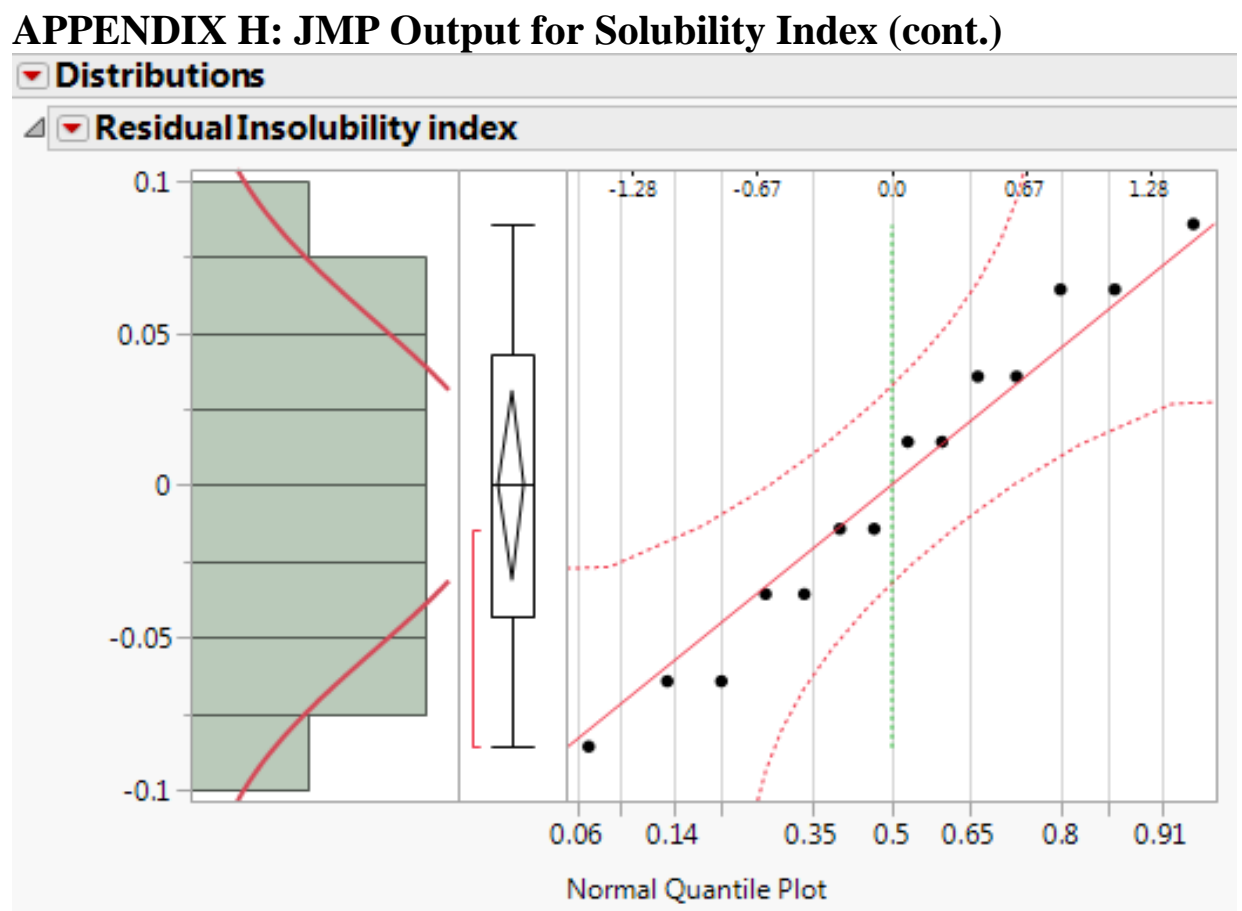

\begin{tabular}{|c|c|c|}
\hline \multicolumn{3}{|c|}{$\triangle$ Quantiles } \\
\hline $100.0 \%$ & maximum & 0.0857142857 \\
\hline $99.5 \%$ & & 0.0857142857 \\
\hline $97.5 \%$ & & 0.0857142857 \\
\hline $90.0 \%$ & & 0.075 \\
\hline $75.0 \%$ & quartile & 0.0428571429 \\
\hline $50.0 \%$ & median & $-6.93889 e-18$ \\
\hline $25.0 \%$ & quartile & -0.042857143 \\
\hline $10.0 \%$ & & -0.075 \\
\hline $2.5 \%$ & & -0.085714286 \\
\hline $0.5 \%$ & & -0.085714286 \\
\hline $0.0 \%$ & minimum & -0.085714286 \\
\hline
\end{tabular}

\section{$\triangle$ - Summary Statistics}

\begin{tabular}{l|r} 
Mean & $5.65 e-17$ \\
Std Dev & 0.0534522 \\
Std Err Mean & 0.0142857 \\
Upper 95\% Mean & 0.0308624 \\
Lower 95\% Mean & -0.030862 \\
$\mathrm{~N}$ & 14
\end{tabular}

\section{- Response Insolubility index}

$\triangle$ Residual by Predicted Plot

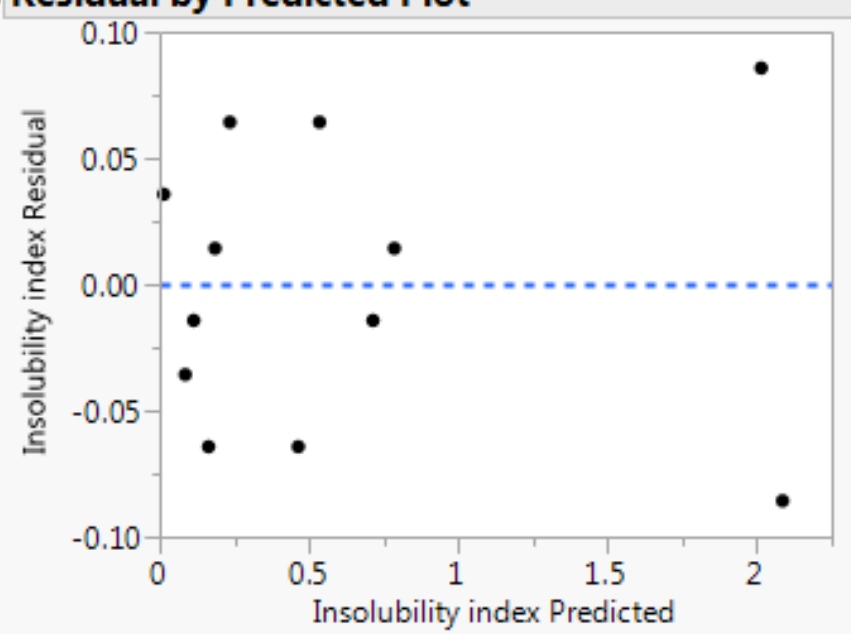

$\triangle$ Fitted Normal

\section{$\triangle$ Parameter Estimates}

Type Parameter Estimate Lower 95\% Upper 95\%

\begin{tabular}{ll|lll} 
Location $\mu$ & $5.65 \mathrm{e}-17$ & -0.030862 & 0.0308624
\end{tabular}

$\begin{array}{llll}\text { Dispersion } \sigma & 0.0534522 & 0.0387504 & 0.0861138\end{array}$

$-2 \log$ (Likelihood) $=-43.2807852330376$

\section{$\triangle$ Goodness-of-Fit Test}

Shapiro-Wilk W Test

$$
\text { W Prob }<\text { W }
$$

$0.959480 \quad 0.7145$

Note: $\mathrm{Ho}=$ The data is from the Normal distribution. Small pvalues reject $\mathrm{Ho}$. 


\section{APPENDIX I: JMP Output for Percent Soluble Calcium (Ca)}

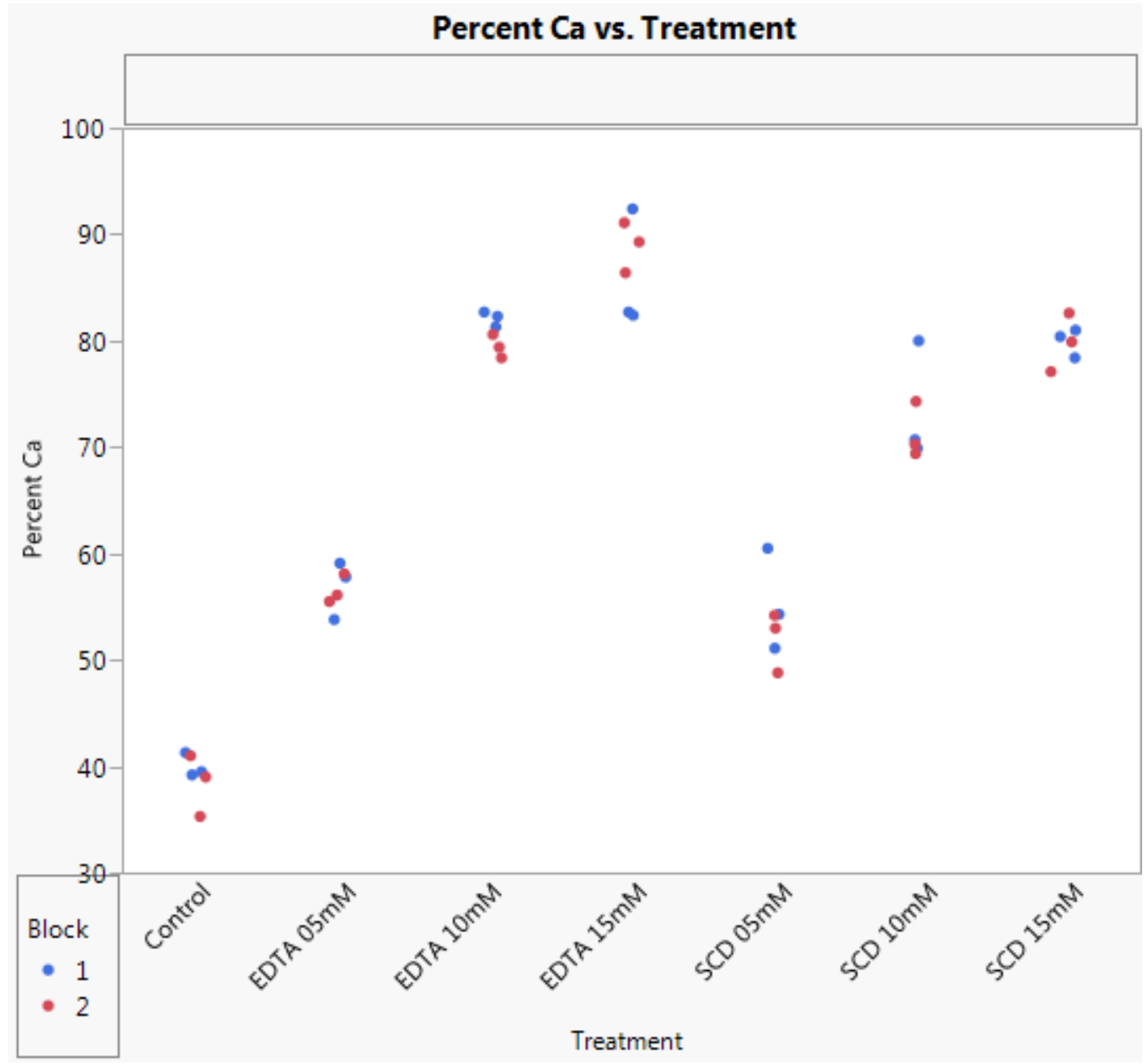

\begin{tabular}{|c|c|c|c|c|c|c|}
\hline \multicolumn{7}{|c|}{ Means and Std Deviations } \\
\hline Level & Number & Mean & Std Dev & $\begin{array}{l}\text { Std Err } \\
\text { Mean }\end{array}$ & Lower $95 \%$ & Upper $95 \%$ \\
\hline Control & 6 & 39.2167 & 2.14422 & 0.8754 & 36.966 & 41.467 \\
\hline EDTA $10 \mathrm{mM}$ & 6 & 80.7833 & 1.66543 & 0.6799 & 79.036 & 82.531 \\
\hline EDTA $15 \mathrm{mM}$ & 6 & 87.3833 & 4.25178 & 1.7358 & 82.921 & 91.84 \\
\hline EDTA $5 \mathrm{mM}$ & 6 & 56.7333 & 1.95619 & 0.7986 & 54.680 & 58.78 \\
\hline $\mathrm{SCD} 10 \mathrm{mM}$ & 6 & 72.4333 & 4.09667 & 1.6725 & 68.134 & 76.733 \\
\hline SCD $15 \mathrm{mM}$ & 6 & 79.9000 & 1.94113 & 0.7925 & 77.863 & 81.937 \\
\hline $\mathrm{SCD} 5 \mathrm{mM}$ & 6 & 53.6500 & 3.95209 & 1.6134 & 49.503 & 57.797 \\
\hline
\end{tabular}




\section{APPENDIX I: JMP Output for Percent Soluble Calcium (Ca) (cont.)}

\section{Response Percent Ca}

Effect Summary

Summary of Fit

$\triangle$ Analysis of Variance

\begin{tabular}{lrrrrr|} 
& & Sum of & & \\
Source & DF & Squares & Mean Square & F Ratio \\
\hline Model & 7 & 11151.056 & 1593.01 & 171.0064 \\
Error & 34 & 316.727 & 9.32 & Prob $>$ F \\
C. Total & 41 & 11467.783 & & $<.0001^{*}$
\end{tabular}

\section{$\triangleright$ Lack Of Fit}

\section{$\triangle$ Parameter Estimates}

Term

Intercept

Treatment[Control]

Treatment[EDTA $10 \mathrm{mM}$ ]

Treatment[EDTA $15 \mathrm{mM}$ ]

Treatment[EDTA $5 \mathrm{mM}$ ]

Treatment $[S C D 10 \mathrm{mM}]$

Treatment $[\mathrm{SCD} 15 \mathrm{mM}]$

Block[1]
Estimate Std Error t Ratio Prob $>|\mathbf{t}|$

$67.157143 \quad 0.470954 \quad 142.60<.0001^{*}$

$-27.940481 .153596 \quad-24.22<.0001^{*}$

$\begin{array}{llll}13.62619 & 1.153596 & 11.81<.0001^{*}\end{array}$

$20.226191 .153596 \quad 17.53<.0001^{*}$

$\begin{array}{llll}-10.42381 & 1.153596 & -9.04 & <.0001^{*}\end{array}$

$\begin{array}{rrrr}5.2761905 & 1.153596 & 4.57 & <.0001^{*}\end{array}$

$12.742857 \quad 1.153596 \quad 11.05<.0001^{*}$

$\begin{array}{llll}0.5 & 0.470954 & 1.06 & 0.2959\end{array}$

\begin{tabular}{lrrrrrr|}
\hline Effect Tests & \multicolumn{1}{c}{ Sum of } \\
Source & Nparm & DF & $\begin{array}{r}\text { Square } \\
\text { F Ratio }\end{array}$ & Prob > F \\
Treatment & 6 & 6 & 11140.556 & 199.3196 & $<.0001^{*}$ \\
Block & 1 & 1 & 10.500 & 1.1272 & 0.2959
\end{tabular}

\begin{tabular}{|c|c|c|c|}
\hline \multicolumn{4}{|l|}{$\triangle$ Effect Details } \\
\hline \multicolumn{4}{|c|}{$\Delta-$ Treatment } \\
\hline \multicolumn{4}{|c|}{$\triangle$ Least Squares Means Table } \\
\hline Level & $\begin{array}{r}\text { Least } \\
\text { Sq Mean }\end{array}$ & Std Error & Mean \\
\hline Control & 39.216667 & 1.2460264 & 39.2167 \\
\hline EDTA $10 \mathrm{mM}$ & 80.783333 & 1.2460264 & 80.7833 \\
\hline EDTA $15 \mathrm{mM}$ & 87.383333 & 1.2460264 & 87.3833 \\
\hline EDTA $5 \mathrm{mM}$ & 56.733333 & 1.2460264 & 56.7333 \\
\hline $\mathrm{SCD} 10 \mathrm{mM}$ & 72.433333 & 1.2460264 & 72.4333 \\
\hline $\mathrm{SCD} 15 \mathrm{mM}$ & 79.900000 & 1.2460264 & 79.9000 \\
\hline SCD $5 \mathrm{mM}$ & 53.650000 & 1.2460264 & 53.6500 \\
\hline
\end{tabular}

$\triangle$ LSMeans Differences Dunnett

$\alpha=0.050 Q=2.7011$ Control=Control Adjustment $=$ Dunnett

Level - Level Difference Std Err Dif Lower CL Upper CL p-Value

EDTA $10 \mathrm{mM}$ Control $\quad 41.56667 \quad 1.762147 \quad 36.80693 \quad 46.32640<.0001^{*}$

EDTA $15 \mathrm{mM}$ Control $\quad 48.16667 \quad 1.762147 \quad 43.40693 \quad 52.92640<.0001^{*}$

$\begin{array}{lllllll}\text { EDTA } 5 \mathrm{mM} & \text { Control } & 17.51667 & 1.762147 & 12.75693 & 22.27640 & <.0001^{*}\end{array}$

$\begin{array}{lllllll}\text { SCD } 10 \mathrm{mM} & \text { Control } & 33.21667 & 1.762147 & 28.45693 & 37.97640 & <.0001^{*}\end{array}$

SCD $15 \mathrm{mM}$ Control $40.68333 \quad 1.762147 \quad 35.92360 \quad 45.44307<.0001^{*}$

SCD 5mM Control $14.43333 \quad 1.762147 \quad 9.67360 \quad 19.19307 \quad<.0001^{*}$ 


\section{APPENDIX I: JMP Output for Percent Soluble Calcium (Ca) (cont.)}

\section{Distributions}

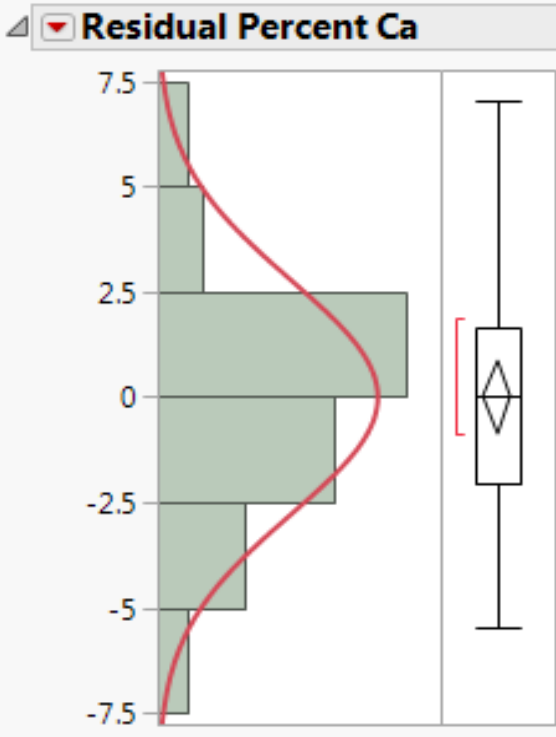

- Normal(3.4e-16,2.7794)

\begin{tabular}{|c|c|c|}
\hline \multicolumn{3}{|c|}{$\triangle$ Quantiles } \\
\hline $100.0 \%$ & maximum & 7.06666666667 \\
\hline $99.5 \%$ & & 7.06666666667 \\
\hline $97.5 \%$ & & 7.0129166667 \\
\hline $90.0 \%$ & & 3.9116666667 \\
\hline $75.0 \%$ & quartile & 1.6541666667 \\
\hline $50.0 \%$ & median & 0.0083333333 \\
\hline $25.0 \%$ & quartile & -2.058333333 \\
\hline $10.0 \%$ & & -3.428333333 \\
\hline $2.5 \%$ & & -5.460833333 \\
\hline $0.5 \%$ & & -5.483333333 \\
\hline $0.0 \%$ & minimum & -5.483333333 \\
\hline
\end{tabular}

\section{$\triangle$ - Summary Statistics}

\begin{tabular}{l|r}
\hline Mean & $3.384 e-16$ \\
Std Dev & 2.7793957 \\
Std Err Mean & 0.4288701 \\
\hline Upper 95\% Mean & 0.8661207 \\
Lower 95\% Mean & -0.866121 \\
$\mathrm{~N}$ & 42
\end{tabular}

\section{Response Percent Ca} $\triangle$ Residual by Predicted Plot

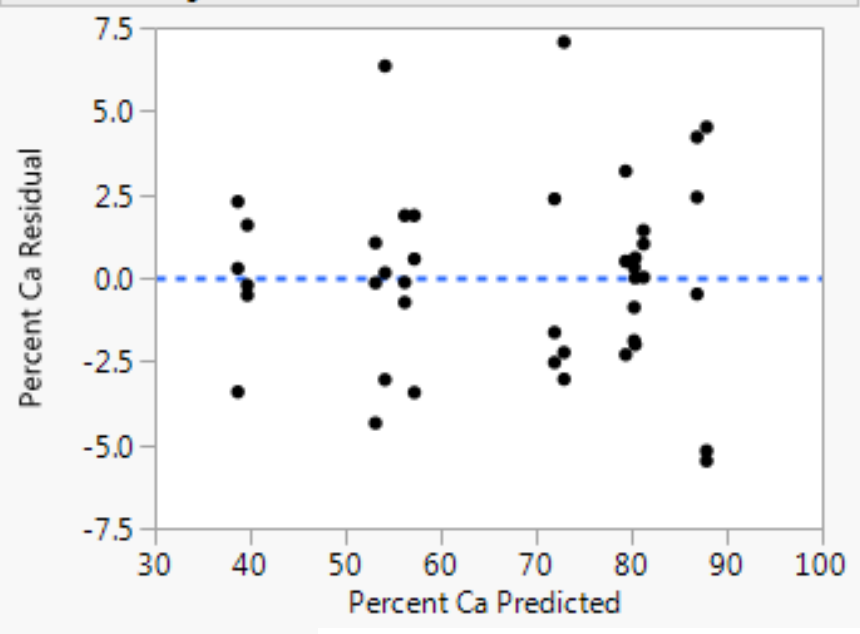

\section{$\Delta-$ Fitted Normal}

\section{$\triangle$ Parameter Estimates}

Type Parameter Estimate Lower 95\% Upper 95\%

\begin{tabular}{ll|lll} 
Location $\mu$ & $3.384 e-16$ & -0.866121 & 0.8661207
\end{tabular}

$\begin{array}{llll}\text { Dispersion } \sigma & 2.7793957 & 2.2869008 & 3.5441898\end{array}$

$-2 \log ($ Likelihood $)=204.05845435745$

\section{$\triangle$ Goodness-of-Fit Test}

Shapiro-Wilk W Test

W Prob $<$ W

$$
0.979189 \quad 0.6303
$$

Note: $\mathrm{Ho}=$ The data is from the Normal distribution. Small pvalues reject $\mathrm{Ho}$. 


\section{APPENDIX J: JMP Output for Percent Soluble Phosphorus (P)}

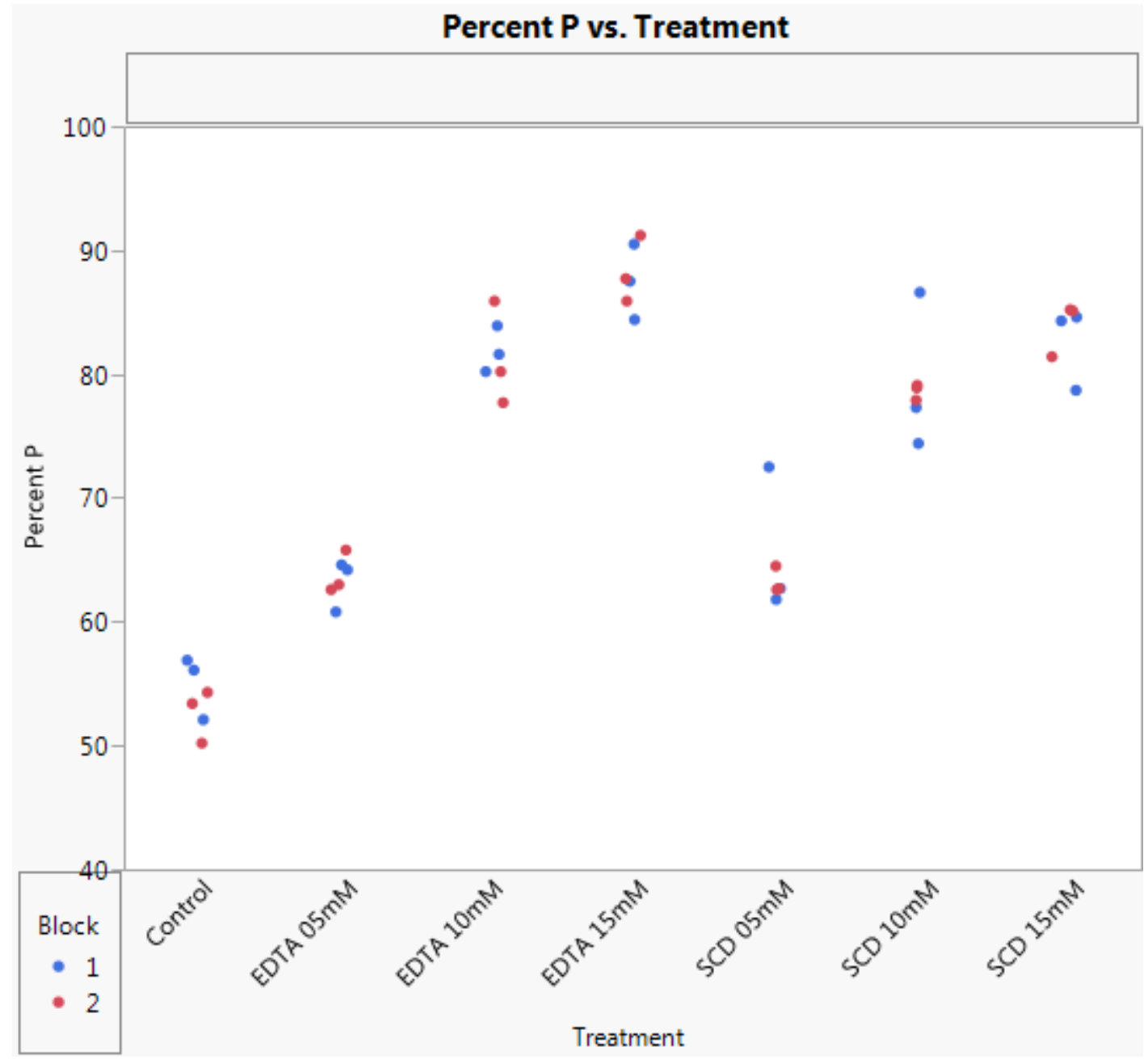

Means and Std Deviations
\begin{tabular}{l|rrrrrrr} 
Level & Number & Mean & Std Dev & $\begin{array}{r}\text { Std Err } \\
\text { Mean }\end{array}$ & Lower $95 \%$ & Upper $95 \%$ \\
Control & 6 & 53.8333 & 2.36455 & 0.9653 & 51.352 & 56.315 \\
EDTA 10 mM & 6 & 81.5833 & 2.90982 & 1.1879 & 78.530 & 84.637 \\
EDTA 15mM & 6 & 87.8667 & 2.67020 & 1.0901 & 85.064 & 90.669 \\
EDTA 5mM & 6 & 63.5000 & 1.82205 & 0.7438 & 61.588 & 65.412 \\
SCD 10 mM & 6 & 79.0333 & 4.05494 & 1.6554 & 74.778 & 83.289 \\
SCD 15mM & 6 & 83.2167 & 2.70801 & 1.1055 & 80.375 & 86.059 \\
SCD 5mM & 6 & 64.4667 & 3.95412 & 1.6143 & 60.317 & 68.616
\end{tabular}




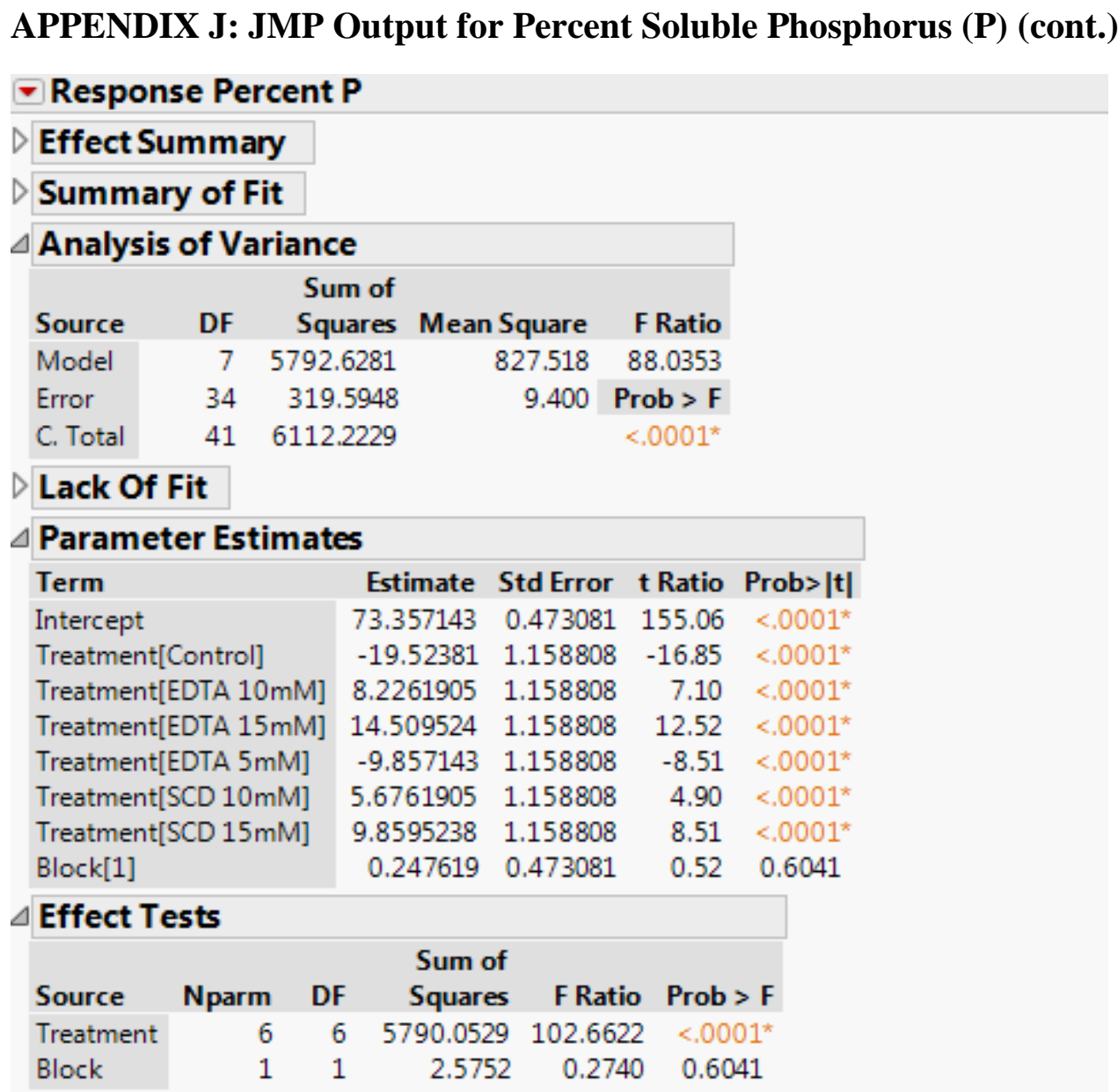

\begin{tabular}{|c|c|c|c|}
\hline$\triangle$ Effect Details & & & \\
\hline$\Delta \nabla$ Treatme & & & \\
\hline$\Delta$ Least Squ & res Mean & Table & \\
\hline Level & $\begin{array}{r}\text { Least } \\
\text { Sq Mean }\end{array}$ & Std Error & Mean \\
\hline Control & 53.833333 & 1.2516553 & 53.8333 \\
\hline EDTA $10 \mathrm{mM}$ & 81.583333 & 1.2516553 & 81.5833 \\
\hline EDTA $15 \mathrm{mM}$ & 87.866667 & 1.2516553 & 87.8667 \\
\hline EDTA $5 \mathrm{mM}$ & 63.500000 & 1.2516553 & 63.5000 \\
\hline $\mathrm{SCD} 10 \mathrm{mM}$ & 79.033333 & 1.2516553 & 79.0333 \\
\hline $\mathrm{SCD} 15 \mathrm{mM}$ & 83.216667 & 1.2516553 & 83.2167 \\
\hline $\operatorname{SCD} 5 \mathrm{mM}$ & 64.466667 & 1.2516553 & 64.4667 \\
\hline
\end{tabular}

\begin{tabular}{|c|c|c|c|c|c|c|}
\hline \multicolumn{7}{|c|}{ LSMeans Differences Dunnett } \\
\hline \multicolumn{7}{|c|}{$\alpha=0.050 Q=2.7011$ Control=Control Adjustment $=$ Dunnett } \\
\hline Level & - Level & Difference & Std Err Dif & Lower CL & Upper CL & p-Value \\
\hline EDTA $10 \mathrm{mM}$ & Control & 27.75000 & 1.770108 & 22.96876 & 32.53124 & $<.0001^{*}$ \\
\hline EDTA $15 \mathrm{mM}$ & Control & 34.03333 & 1.770108 & 29.25210 & 38.81457 & $<.0001^{*}$ \\
\hline EDTA $5 \mathrm{mM}$ & Control & 9.66667 & 1.770108 & 4.88543 & 14.44790 & $<.0001^{*}$ \\
\hline $\mathrm{SCD} 10 \mathrm{mM}$ & Control & 25.20000 & 1.770108 & 20.41876 & 29.98124 & $<.0001^{*}$ \\
\hline $\mathrm{SCD} 15 \mathrm{mM}$ & Control & 29.38333 & 1.770108 & 24.60210 & 34.16457 & $<.0001^{*}$ \\
\hline $\mathrm{SCD} 5 \mathrm{mM}$ & Control & 10.63333 & 1.770108 & 5.85210 & 15.41457 & $<.0001^{*}$ \\
\hline
\end{tabular}




\section{APPENDIX J: JMP Output for Percent Soluble Phosphorus (P) (cont.) Distributions \\ Residual Percent P}

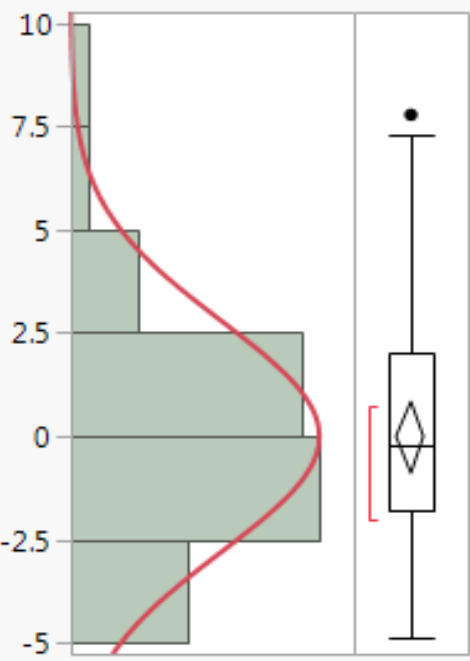

Normal(-2e-15,2.79195)

\section{$\triangle$ Quantiles}

$100.0 \%$ maximum 7.785714285

$99.5 \%$

$97.5 \%$

$90.0 \%$

$75.0 \%$

$50.0 \%$

$25.0 \%$

$10.0 \%$

$2.5 \%$

$0.5 \%$

$0.0 \%$
7.7857142857

7.7507142857

3.3523809524

quartile 2.031547619

median -0.208333333

quartile $\quad-1.78452381$

$-3.560714286$

$-4.872202381$

$-4.880952381$

minimum -4.880952381

\section{$\triangle$ - Summary Statistics}

Mean

Std Dev

Std Err Mean

Upper 95\% Mean

Lower 95\% Mean

N
$-2.37 e-15$

2.7919517

0.4308075

0.8700334

$-0.870033$
Response Percent $\mathbf{P}$

$\triangle$ Residual by Predicted Plot

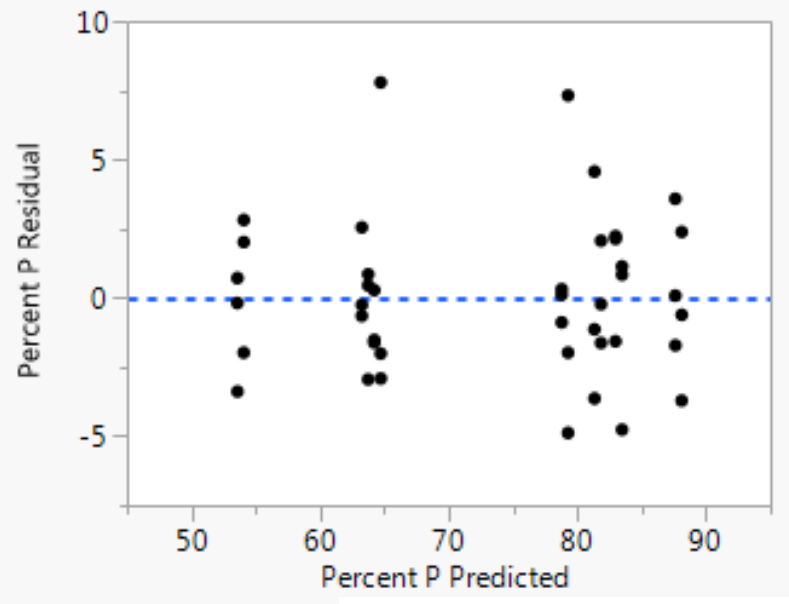

\section{$\Delta-$ Fitted Normal}

\section{$\triangle$ Parameter Estimates}

Type Parameter Estimate Lower 95\% Upper 95\%

\begin{tabular}{ll|lll} 
Location $\mu$ & $-2.37 \mathrm{e}-15$ & -0.870033 & 0.8700334
\end{tabular}

$\begin{array}{llll}\text { Dispersion } \sigma & 2.7919517 & 2.2972319 & 3.5602007\end{array}$

$-2 \log ($ Likelihood $)=204.437070604989$

\section{$\triangle$ Goodness-of-Fit Test}

Shapiro-Wilk W Test

$$
\begin{array}{rc}
\text { W } & \text { Prob }<\text { W } \\
0.956946 & 0.1147
\end{array}
$$

Note: $\mathrm{Ho}=$ The data is from the Normal distribution. Small pvalues reject $\mathrm{Ho}$. 